Dritter Beratungsgegenstand:

\title{
Dynamische Grundrechtsdogmatik von Ehe und Familie?
}

1. Referat von Professorin Dr. Monika Böhm, Marburg

Inhalt

Seite

I. Einleitung .................... . . 212

II. Ehe und Familie im Wandel. . . . . . . . . . . . . . . . . . 213

III. Entwicklungsoffenheit des Grundgesetzes . . . . . . . . . . . 215

1. Ehe und Familie in der deutschen Verfassungsentwicklung 215

a. Entwicklungslinien vor Verabschiedung des Grundgesetzes ................... . . 215

b. Vorstellung bei Schaffung des Grundgesetzes . . . . . . 216

2. Statische oder dynamische Verfassungsauslegung? . . . . . 219

a. Grundstrukturen der Grundrechtsdogmatik . . . . . . . 219

b. Dynamisierungsfaktoren . . . . . . . . . . . 221

IV. Grundrechtsdogmatik von Ehe und Familie im Wandel. . . . 222

1. Grundlinien ......................... 222

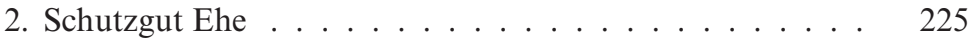

3. Schutzgut Familie . . . . . . . . . . . . . . . 227

4. Gleichheitsrechte . . . . . . . . . . . . . . . . 229

5. Wahlfreiheit ................... 233

a. Eingriffsabwehr und Fördergebot . . . . . . . . 233

b. Verfassungsrechtliche Vorgaben für finanzielle staatliche Leistungen . . . . . . . . . . . . . . . . . . . . . . . . . . . . . . . 234

6. Zwischenfazit. . . . . . . . . . . . . . 238

V. Externe Dynamisierungsfaktoren. . . . . . . . . . 239

1. Rechtsvergleich . . . . . . . . . . . . . . 239

2. Recht der Europäischen Union . . . . . . . . . . . . 242

3. Europäische Menschenrechtskonvention . . . . . . . . 245

VI. Schlussfolgerungen ................. . 249 


\section{Einleitung}

Grundrechtsdogmatik befasst sich mit der Definition von Schutzgütern und Eingriffen, mit Grundrechtsfunktionen und Grundrechtskonkurrenzen. ${ }^{1}$ Sie systematisiert und gibt Handlungsanleitungen für die Praxis vor. Maßgebliche Akteure bei ihrer Entwicklung sind Wissenschaft und Rechtsprechung, aber auch der Gesetzgeber und die Verwaltung.

Legt man dieses Verständnis zugrunde, können jedenfalls neuere Entwicklungen der Dogmatik von Ehe und Familie nur als dynamisch bezeichnet werden. In seiner Entscheidung zur Sukzessivadoption hat das Bundesverfassungsgericht im Februar dieses Jahres gleichgeschlechtliche Lebenspartnerschaften mit Kindern als Familie in den Schutzbereich von Art. 6 Abs. $1 \mathrm{GG}$ einbezogen. ${ }^{2} \mathrm{Ihr}$ Ausschluss vom Ehegattensplitting wurde im Mai als Verstoß gegen den Gleichheitssatz gewertet. ${ }^{3} 1957$ dagegen urteilte das Gericht: Männliche Homosexualität ,,verstößt eindeutig gegen das Sittengesetz" ${ }^{4}$ Ihre Strafbarkeit verstieß folglich nicht gegen das Grundgesetz. ${ }^{5}$ Erst 1994 hob der Gesetzgeber $§ 175$ StGB vollständig auf. ${ }^{6}$

Nicht ganz so lange dauerte es, bis die sog. nichtehelichen Lebensgemeinschaften mit Kindern ${ }^{7}$ als Einheit dem Schutzbereich des Art. 6 Abs. 1 GG unterstellt wurden. ${ }^{8}$ Noch in den 1980er Jahren jedoch galten

${ }^{1}$ S. etwa M. Jestaedt Die Verfassung hinter der Verfassung, 2009, 31. Zum Begriff vgl. auch die einzelnen Beiträge in: Kirchhof/Magen/Schneider (Hrsg.) Was weiß Dogmatik?, 2012, jeweils mwN; H. D. Jarass AöR 120 (1995), 345 ff. Den dogmatischen Grundsätzen wird normativer Gehalt zuerkannt. Vgl. dazu A. Voßkuhle ebd., 111 ff. $\mathrm{mwN}$.

${ }^{2}$ Einem eingetragenen Lebenspartner muss nun die Adoption eines angenommenen Kindes seines Partners ermöglicht werden. BVerfG, Urt. v. 19.02.2013, 1 BvL 1/11 und 1 BvR 3247/09, NJW 2013, 847 ff. Möglich war zuvor schon die sog. Stiefkindadoption, also die Adoption eines eigenen Kindes des Lebenspartners.

3 BVerfG, Beschl. v. 07.05.2013, 2 BvR 909/06 u.a., NJW 2013, 2257 ff. Die Entscheidung wurde umgesetzt durch das Gesetz zur Änderung des Einkommensteuergesetzes v. 15.07.2013 (BGB1. I 2397), in Kraft seit 19.07.2013.

${ }^{4}$ BVerfGE 6, 389 (434), die frühere Strafbarkeit spricht auch das BVerfG im Urt. v. 19.02.2013, 1 BvL 1/11 und 1 BvR 3247/09, Rn. 56, NJW 2013, 847 (849) an, ohne allerdings die frühere Entscheidung ausdrücklich zu nennen.

${ }^{5}$ BVerfGE 6, 389 (432 ff.).

${ }^{6}$ Durch das 29. Gesetz zur Änderung des Strafgesetzbuches v. 21.05.1994 (BGB1. I 1168).

${ }^{7}$ S. dazu die rechtsvergleichenden Beiträge in: Scherpe/ Yasari (Hrsg.) Die Rechtsstellung nichtehelicher Lebensgemeinschaften, 2005.

${ }^{8}$ Im Übrigen unterfallen nichteheliche Lebensgemeinschaften zwar nicht dem Schutz des Art. 6 Abs. 1 GG, dafür aber immerhin dem des Art. 2 Abs. 1 GG, M. Kotzur in: K. Stern/F. Becker (Hrsg.) Grundrechte - Kommentar, Köln 2010, Art. 6 Rn. 29. 
unverheiratet zusammenlebende Eltern mit Kind als zwei Familien, verbunden durch das gemeinsame Kind als "Scharnier“. 9

Wie im Einzelnen nachgezeichnet wird, handelt es sich bei diesen Beispielen nicht um Ausnahmen. Gewandelt haben sich nicht nur die gesellschaftlichen Rahmenbedingungen, die Einstellungen und die Lebenswirklichkeit von Ehe und Familie. Gewandelt hat sich auch die Dogmatik des Grundrechts aus Art. 6 Abs. 1 GG. ${ }^{10}$ Das Grundgerüst ist zwar weitgehend gleich geblieben. In seinem Rahmen aber hat eine dynamische Entwicklung stattgefunden, externe Faktoren haben dabei eine wichtige Rolle gespielt.

Nachfolgend wird zunächst kurz auf die soziale Entwicklung eingegangen (II.). Im Anschluss daran wird das Dynamisierungspotential des Grundgesetzes herausgearbeitet (III.) und aufgezeigt, wie es sich bei der Grundrechtsdogmatik von Ehe und Familie verwirklicht hat (IV.). Von außen eingewirkt haben rechtsvergleichende Impulse sowie das Recht der Europäischen Union (EU) und der Europäischen Menschenrechtskonvention (EMRK) (V.). Am Ende steht ein kurzes Fazit (VI.).

\section{Ehe und Familie im Wandel}

Lange Zeit wurde die Ehe als grundsätzlich lebenslange Verbindung von Mann und Frau, die Familie als ihre quasi natürliche Folge angesehen. ${ }^{11}$ Vorherrschend war eine klare Rollenverteilung.

\footnotetext{
9 Die nichteheliche Mutter wie der nichteheliche Vater, die mit ihrem Kind zusammen leben, bildeten mithin jeweils eine Familie, s. BVerfGE 24, 119 (135); 45, 104 (123); 56, 363 (382). Vgl. W. Zeidler Handbuch des Verfassungsrechts der Bundesrepublik Deutschland, Band 1, 1983, 555 (584). Als „seltsames Ergebnis“ sah dies schon T. Maunz in: ders./G. Dürig (Hrsg.) GG, Band 1, 6. Aufl. 1983, Art. 6 Rn. 16a an. Vgl. nunmehr BVerfGE 106, 166 (176); 108, 82 (112); BVerfG im Urt. v. 19.02.2013, 1 BvL $1 / 11$ und $1 \mathrm{BvR} 3247 / 09$, NJW 2013, $847 \mathrm{ff}$.

10 R. Wahl FS Frank, 2008, 31 (32).

${ }^{11}$ Schon das germanische Recht kannte verschiedene Formen des Zusammenlebens, die allerdings vor allem als soziale Lebensformen angesehen wurden und rechtlich nur zum Teil eingebunden waren. Erst durch den Einfluss der christlichen Kirchen entwickelte sich ein Verständnis der Ehe als eine - grundsätzlich unauflösbare - Verbindung von Mann und Frau. Die Familie wurde lange Zeit als eher weite Haus- und Erwerbsgemeinschaft angesehen, zu der nicht nur Eheleute und Kinder, sondern auch Verwandte und Bedienstete gerechnet wurden. S. etwa F. Brosius-Gersdorf in: H. Dreier (Hrsg.) GG, Band 1, 2013, Art. 6 Rn. 1 ff. mwN. Zu den Erscheinungsformen der Familie in der Geschichte vgl. V. Schmid Die Familie in Art. 6 des Grundgesetzes, 1989, insbes. 120 ff.; zum Ganzen D. Schwab Wertewandel und Familienrecht, 1993; zu den Veränderungen der gesellschaftlichen Verhältnisse und Vorstellungen, die Art. 6 GG zugrunde liegen, s.a. M. Burgi in: K. H. Friauf/W. Höfling (Hrsg.) Berliner Kommentar
} 
Tatsächlich nahm die Zahl der Eheschließungen in den vergangenen Jahrzehnten ab. ${ }^{12}$ Bei den Scheidungen ist der Trend steigend. ${ }^{13}$ Mit einem Anteil von $71 \%$ ist die Ehe mit Kindern noch immer die meistgelebte Familienform. $9 \%$ der Familien leben ohne Trauschein zusammen und weitere $20 \%$ sind alleinerziehend. ${ }^{14}$ Der Anteil gleichgeschlechtlicher Lebensgemeinschaften mit minderjährigen Kindern liegt seit ca. 15 Jahren unverändert bei $0,05 \% .15$

In den meisten Familien ist zwar noch immer der Mann der Haupternährer, Anzahl und Alter der Kinder wirken sich kaum auf seine Berufstätigkeit aus. ${ }^{16}$ Gleichwohl ist seine Rolle innerhalb der Familie facettenreicher geworden. Nach Angaben des Bundesfamilienministeriums nehmen mittlerweile fast $30 \%$ der Väter Elterngeld in Anspruch und bleiben durchschnittlich etwas länger als drei Monate zu Hause. ${ }^{17}$

zum GG, Band 1, 4. Erg.-Lfg. 2002, Art. 6 Rn. 13 ff. Außerdem K. Stern Staatsrecht, Band IV/1, 2006, 330 ff., insbes. 340 ff. Zum Wandel der Produktions- und Konsumgemeinschaft zur bloßen Konsumgemeinschaft J. Gernhuber/D. Coester-Waltjen Familienrecht, 6. Auf1. 2010, §1 Rn. 8.

12 Aktuell ist allerdings wieder ein leichter Anstieg zu verzeichnen, s. https://wwwgenesis.destatis.de/genesis/online/link/tabelleErgebnis/12611-0001 (zuletzt abgerufen am 17.09.2013).

${ }^{13}$ Die Scheidungszahlen unterliegen jedoch starken Schwankungen. Aber seit 1981 liegen sie kontinuierlich über 100.000 und seit Mitte der 90er Jahren über 175.000, s. https://www-genesis.destatis.de/genesis/online;jsessionid=

96F486FE4515E3F4F2C00BEFA2C7B238.tomcat_GO_1_2?operation=previous\& levelindex $=2 \&$ levelid $=1378126750942 \&$ step $=2$ (zuletzt abgerufen am 17.09.2013).

${ }_{14}$ Bundesministerium für Familie, Senioren, Frauen und Jugend Familienreport 2012. Leistungen, Wirkungen, Trend, 2012, 14. Noch 1996 lebten 81,4 \% der Familien mit Kind(ern) in einer Ehe, lediglich 4,8\% lebten in einer nichtehelichen Lebensgemeinschaft und 13,8\% alleinerziehend. In den vergangenen Jahren stieg die Zahl der nichtehelichen Lebensgemeinschaften und Alleinerziehenden kontinuierlich, s. https://www. destatis.de/DE/ZahlenFakten/GesellschaftStaat/Bevoelkerung/HaushalteFamilien/Tabel len/Familienformen.html (zuletzt abgerufen am 17.09.2013). Patchwork- oder Stieffamilien machen 10-14\% der Familien mit Kind(ern) aus; drei Viertel von ihnen sind verheiratet, ebd., 20. 2011 lag die Geburtenrate bei 1,36 Kindern je Frau im Alter von 15 bis 49 Jahren, ebd., 23. Der Anteil kinderloser Ehen betrug 2011 41,9\%, Bundeszentrale für politische Bildung Paare ohne Kinder und Familien, 2012, http://www.bpb.de/ nachschlagen/zahlen-und-fakten/soziale-situation-in-deutschland/61575/paare-und-

familien (zuletzt abgerufen am 17.09.2013). Oft entscheiden sich Ehepaare aber nicht freiwillig gegen Kinder, M. Rupp ZfF 2005, 21 ff.

${ }^{15}$ In Zahlen ausgedrückt sind dies 4.000, Bundesministerium für Familie, Senioren, Frauen und Jugend Politischer Bericht zur Gesamtevaluation der ehe- und familienbezogene Leistungen, 2013, 2.

${ }_{16}$ Bundesministerium für Familie, Senioren, Frauen und Jugend Familienreport 2012 (Fn. 14), 71.

${ }_{17}$ S. http://www.bmfsfj.de/BMFSFJ/familie,did=200170.html (zuletzt abgerufen am 17.09.2013). Zum Wandel der Vaterrolle s.a. Bundesministerium für Familie, Senioren, 
Die Erwerbstätigkeit von Frauen ist in den letzten 50 Jahren kontinuierlich von 47,2 \% im Jahr 1960 auf $65 \%$ im Jahr 2009 gestiegen. ${ }^{18}$ Davon arbeiten $35 \%$ in Vollzeit. ${ }^{19}$ Bei Müttern nahm die Teilzeitbeschäftigung in den vergangenen 20 Jahren jedoch zu. ${ }^{20}$ Viele Frauen würden gern auch in der Familienphase mehr berufstätig sein. ${ }^{21}$

\section{Entwicklungsoffenheit des Grundgesetzes}

\section{Ehe und Familie in der deutschen Verfassungsentwicklung \\ a. Entwicklungslinien vor Verabschiedung des Grundgesetzes}

In der Verfassungsentwicklung tauchen Regelungen zum Schutz von Ehe und Familie erst spät auf, nämlich im Jahre 1919 in Art. 119 der Weimarer Reichsverfassung (WRV). ${ }^{22}$ Zuvor hatte es lediglich Regelungen zur Säkularisierung der Ehe durch Einführung der obligatorischen Zivilehe gegeben, etwa in der Paulskirchenverfassung von 1849 und in der Preußi-

Frauen und Jugend (Hrsg.) Facetten der Vaterschaft. Perspektiven einer innovativen Väterpolitik, 2006. S. außerdem Väter gGmbH Trendstudie „Moderne Väter“. Wie die neue Vätergeneration Familie, Gesellschaft und Wirtschaft verändert, 2012, insbes. $20 \mathrm{ff}$., die Studie ist abrufbar unter http://vaeter-ggmbh.de/wp-content/uploads/2012/ 12/Trendstudie_Vaeter_gGmbH_Download.pdf (zuletzt abgerufen am 17.09.2013).

18 Bundeszentrale für politische Bildung Erwerbstätigkeit, 2010, www.bpb.de/system/ files/pdf/O4NQPA.pdf_ (zuletzt abgerufen am 17.09.2013). Die Berufstätigkeit von Müttern mit minderjährigen Kindern lag 2010 indes lediglich bei $60 \%$, Bundesministerium für Familie, Senioren, Frauen und Jugend, Familienreport 2012 (Fn. 14), 71. Zum Einfluss der Familienform auf die Erwerbstätigkeit von Müttern s. Bundesministerium für Familien, Senioren, Frauen und Jugend Ausgeübte Erwerbstätigkeit von Müttern. Erwerbstätigkeit, Erwerbsumfang und Erwerbsvolumen 2010, 2012, 32 ff.

19 Bundeszentrale für politische Bildung, Erwerbstätigkeit, (Fn. 18).

20 Während die Teilzeitquote von Müttern 1996 bei nur $51 \%$ lag, stieg sie auf $70 \%$ im Jahre 2010 an, Bundesministerium für Familie, Senioren, Frauen und Jugend Gesamtevaluation der ehe- und familienbezogene Leistungen (Fn. 15), 71.

${ }^{21}$ Bundesministerium für Arbeit und Soziales Lebenslagen in Deutschland. Der Vierte Armuts- und Reichtumsbericht der Bundesregierung, 2013, XXVIII. Die Vereinbarkeit von Kindererziehung und Arbeit ist gerade für Alleinerziehende eine große Herausforderung. Viele von ihnen sind auf staatliche Förderung angewiesen, ebd., XXIX ff., $126 \mathrm{ff}$.

${ }^{22}$ Zur Entstehungsgeschichte des Art. 119 WRV A. Wieruszowski in: H. C. Nipperdey, Die Grundrechte und Grundpflichten der Reichsverfassung, Band 2, 1930, Art. 119 WRV, 72 (72 f.); siehe außerdem Art. 120 Abs. 1 WRV: „Die Erziehung des Nachwuchses zur leiblichen, seelischen und gesellschaftlichen Tüchtigkeit ist oberste Pflicht und natürliches Recht der Eltern, über deren Betätigung die staatliche Gemeinschaft wacht.“ sowie Art. 121 Abs. 1 WRV: „Den unehelichen Kindern sind durch die Gesetzgebung die gleichen Bedingungen für ihre leibliche, seelische und gesellschaftliche Entwicklung zu schaffen wie den ehelichen Kindern." Dazu nur Schmid Die Familie in Art. 6 des Grundgesetzes (Fn. 11), 244 ff. 
schen Verfassung von $1850 .{ }^{23}$ Die Weimarer Reichsverfassung enthielt zumindest einen Programmsatz zum Schutz von Ehe und Familie. ${ }^{24}$ Als Ehe wurde dabei ausdrücklich die Verbindung von Mann und Frau, wörtlich „,der beiden Geschlechter“, bezeichnet. Sie wurde als Grundlage der Familie hervorgehoben und sollte der Erhaltung und Vermehrung der Nation dienen. ${ }^{25}$

\section{b. Vorstellung bei Schaffung des Grundgesetzes}

Bei den Verhandlungen zum Grundgesetz kamen Regelungen zu Ehe und Familie spät zur Sprache. ${ }^{26}$ Verabschiedet wurde im Hauptausschuss schließlich eine Fassung, in der in Anknüpfung an die Weimarer Reichsverfassung die Ehe ausdrücklich als fortdauernde Lebensgemeinschaft von Mann und Frau und die mit ihr gegebene Familie unter den besonderen Schutz der Verfassung gestellt wurden. Mit der Norm sollte über einen bloßen Programmsatz hinaus unmittelbar geltendes Recht geschaffen werden. ${ }^{27}$

23 Vgl. G. Robbers in: H. v. Mangoldt/F. Klein/Ch. Starck (Hrsg.) GG, Band 1, 6. Aufl. 2010, Art. 6 Rn. 2; Brosius-Gersdorf in: Dreier (Fn. 11), Art. 6 Rn. 1; Kotzur in: Stern/Becker (Fn. 8), Art. 6 Rn. 4; J. Ipsen HStR VII, 2009, § 154 Rn. 1; Burgi in: Friauf/Höfling (Fn. 11), Art. 6 Rn. 5.

24 Zur Qualifizierung als Programmsatz G. Anschütz Die Verfassung des Deutschen Reiches, 14. Aufl. 1933, Art. 119 WRV, 559 (560), welcher Art. 119 WRV insoweit als bloßes „Zukunftsrecht“ bezeichnet; Wieruszowski in: Nipperdey (Fn. 22), Art. 119 WRV, 72 ff.; vgl. auch P. Badura in: Maunz/Dürig, GG, 68. Erg-Lfg. 2013, Art. 6 Rn. 15; Ipsen HStR (Fn. 23), § 154 Rn. 1; Schmid Die Familie in Art. 6 des Grundgesetzes, (Fn. 11), 260 f.; Kotzur in: Stern/Becker (Fn. 8), Art. 6 Rn. 4; Burgi in: Friauf/Höfling (Fn. 11), Art. 6 Rn. 6. Anders E. R. Huber Deutsche Verfassungsgeschichte seit 1789, Band 4, 1989, $107 \mathrm{f}$.

25 Der vollständige Art. 119 WRV lautet:

„(1) Die Ehe steht als Grundlage des Familienlebens und der Erhaltung und Vermehrung der Nation unter dem besonderen Schutz der Verfassung. Sie beruht auf der Gleichberechtigung der beiden Geschlechter.

(2) Die Reinerhaltung, Gesundung und soziale Förderung der Familie ist Aufgabe des Staats und der Gemeinden. Kinderreiche Familien haben Anspruch auf ausgleichende Fürsorge.

(3) Die Mutterschaft hat Anspruch auf den Schutz und die Fürsorge des Staats.“

Im Schutz von Ehe und Familie wurde eine Entscheidung gegen die Gleichstellung von ehelichem und nichtehelichem Zusammenleben gesehen. Anderseits sah Art. 121 WRV die prinzipielle Gleichstellung unehelicher Kinder vor, dazu C. Gusy Die Weimarer Reichsverfassung, 1997, 300.

${ }_{26}$ Erst in der 24. Sitzung des Grundsatzausschusses wurde die Frage erörtert, ob und in welcher Form Grundsätze über ihren Schutz aufzunehmen seien. Zur Entstehungsgeschichte s. Jahrbuch des öffentlichen Rechts der Gegenwart (JöR), Band 1, 1951, 92 ff.

27 Der Herrenchiemseer Konvent sah entsprechende Bestimmungen noch nicht vor. JöR (Fn. 26), 92 ff.; Ungenauigkeiten in der dortigen Darstellung bezüglich über pro- 
Im Wesentlichen aus Gründen der sprachlichen Vereinfachung ${ }^{28}$ verkürzte der allgemeine Redaktionsausschuss auf:

„Ehe und Familie stehen unter dem besonderen Schutze der staatlichen Ordnung."

In der letztlich verabschiedeten Fassung wurden Gegengeschlechtlichkeit und die enge Verbindung von Ehe und Familie nicht erwähnt. Auch wenn die Väter und Mütter des Grundgesetzes an ein traditionelles Bild von Ehe und Familie anknüpften: Der Wortlaut eröffnet Auslegungspotentiale. Auch Dynamisierungsfaktoren, die später eine wichtige Rolle spielen sollten, scheinen in den Verhandlungen schon auf: Die Gleichberechtigung der Frau ${ }^{29}$ und die Orientierung an internationalen Regelwerken und damit perspektivisch auch an der EMRK. ${ }^{30}$

Die Verfassungen der Bundesländer enthalten teilweise weitergehende Bestimmungen, ${ }^{31}$ etwa zum Schutz kinderreicher Familien, ${ }^{32}$ Alleinerzie-

grammatische hinausgehende Wirkungen weist BVerfGE 6, 55 (73 ff.) nach; zur Entstehungsgeschichte s.a. D. Pirson in: Bonner Kommentar GG, 77. Erg.-Lfg. 1996, Art. 6 Rn. 2a f.

${ }_{28}$ Zur Begründung wurde dabei darauf abgestellt, dass durch den Schutz der staatlichen Ordnung zugleich die genannten Rechte unter Schutz gestellt würden. Ebenso sei der Hinweis auf die rechtmäßige Form der fortdauernden Lebensgemeinschaft überflüssig, wenn die Ehe als solche geschützt werde. Siehe JöR (Fn. 26), 97 f.

${ }_{29}$ Obwohl die Bedeutung der Gleichberechtigung der Frau allgemein bejaht wurde, konnte die Forderung einer ausdrücklichen Regelung zur Gleichstellung der Geschlechter im Familienrecht nicht realisiert werden. Zur Debatte zur Forderung der Abgeordnete Nadig (SPD), s. JöR (Fn. 26), 93 f. Verabschiedet wurde aber auf Vorschlag von Elisabeth Selbert und nach einer für die damalige Zeit außergewöhnlichen außerparlamentarischen Initiative Art. 3 Abs. 2 GG, siehe B. Böttger Das Recht auf Gleichheit und Differenz, 1990, 191 ff. Zur Person s. etwa Selbert Internationales Biographisches Archiv 31/2011 vom 2. August 2011 und R. Ley NJW 1986, 2301. Art. 3 Abs. 2 GG wurde zudem ergänzt durch Art. 117 GG, wonach Art. 3 Abs. 2 GG entgegenstehendes Recht spätestens zum 31. März 1953 außer Kraft treten sollte. Vgl. dazu nur JöR (Fn. 26), 67 ff. und 827 ff.; gleichwohl wurde etwa dem Vater noch 1957 mit Änderung des $\S 1628$ BGB a.F. der Stichentscheid bei der Ausübung des Sorgerechts zuerkannt. Begründet wurde dies mit einem Verweis auf natürliche und christliche Ordnungsbegriffe, BT-Drs. 1/3802, 74. 1959 erklärte das BVerfG die Regelung dann für verfassungswidrig, BVerfGE 10, 59 ff. Hierzu R. Frank FamRZ 2004, 841 (841).

30 In den Verhandlungen wurde ausdrücklich auf die im Entwurf vorliegende Menschenrechtskonvention der Vereinten Nationen verwiesen, s. JÖR (Fn. 26), 93 Fn. 2, die im Dezember 1948 verkündet wurde und heute meist als Allgemeine Erklärung der Menschenrechte bezeichnet wird. Die EMRK wurde im November 1950 unterzeichnet.

31 Überblick bei Brosius-Gersdorf in: Dreier (Fn. 11), Art. 6 Rn. 36 ff.

32 Zum einen Art. 125 Abs. 3 BayVerf., wonach kinderreiche Familien einen Anspruch auf angemessene Fürsorge haben, insbes. auf gesunde Wohnungen. Dieser 
hender ${ }^{33}$ und von nichtehelichen Lebensgemeinschaften. ${ }^{34}$ Auf die Auslegung des Grundgesetzes hat sich dies jedoch nicht ausgewirkt.

kollidiert mit keiner Grundgesetzbestimmung und gilt daher weiter; vgl. H. A. Wolff in: J. F. Lindner/M. Möst1/H. A. Wolff (Hrsg.) Verfassung des Freistaats Bayern, 2009, Art. 125 Rn. 4. Unterschiedliche Auffassungen werden jedoch zu dessen Normcharakter vertreten; z.T. wird unter engen Voraussetzungen ein subjektiver Anspruch aus der Norm hergeleitet, so ebd., Art. 125 Rn. 13. Dagegen wird jedoch insbes. vom BayVerfGH vertreten, die Norm erteile dem Staat lediglich den Auftrag, bei seinen Maßnahmen den Bedarf kinderreicher Familien zu bedenken, so BayVerfGH, BayVBl 2005, 140 f.; das VG Augsburg spricht insoweit von einem der Norm allein zu entnehmenden Programmsatz, VG Augsburg, Urt. v. 31.05.2005, Au 3 K 05.94, Rn. 21. So auch H. Nawiasky/C. Leusser Die Verfassung des Freistaates Bayern, 1948, 206. Ähnlich T. Meder Die Verfassung des Freistaates Bayern, 4. Aufl. 1992, Art. 125 Rn. 3: „Richtlinie“. Ferner formuliert auch Art. 5 Abs. 1 S. 3 NRW Verf. einen Fürsorgeanspruch kinderreicher Familien. Der Normcharakter wird ebenso unterschiedlich beurteilt. Teilweise wird wiederum ein Programmsatz angenommen; so bspw. H. Peters DVB1. 1950, 449 (450) und H.-J. Fleck in: G. Geller/K. Kleinrahm/H.-J. Fleck (Hrsg.) Verfassung des Landes Nordrhein-Westfalen, 2. Aufl. 1963, Art. 5 Rn. 3. Demgegenüber messen M. Kamp in: A. Heusch/K. Schönenbroicher (Hrsg.) Landesverfassung NordrheinWestfalen, 2010, Art. 5 Rn. 8 sowie R. Müller-Terpitz in: W. Löwer/P. J. Tettinger (Hrsg.) Verfassung des Landes Nordrhein-Westfalen, Art. 5 Rn. 27, Art. 5 Abs. 1 S. 3 NRW Verf. (auch) Grundrechtscharakter zu.

${ }^{33}$ So Art. 12 Abs. 7 S. 2 Berliner Verf., nach dem alleinerziehende Frauen und Männer einen Anspruch auf besonderen Schutz im Arbeitsverhältnis haben. Diesem wird ein Grundrecht im Sinne eines Diskriminierungsverbotes sowie ein an den Gesetzgeber gerichteter objektiv-rechtlicher Auftrag entnommen wird, s. K.-J. Stöhr in: G. Pfennig/ M. J. Neumann (Hrsg.) Verfassung von Berlin, 3. Aufl. 2000, Art. 12 Rn. 35 f. sowie H.-J. Driehaus in: ders., Verfassung von Berlin, 2. Aufl. 2005, Art. 12 Rn. 16. Ähnlich Art. 26 Abs. 1 S. 2 und Art. 48 Abs. 4 Brandenburgische Verf. Dazu S. J. Iwers in: H. Lieber/S. J. Iwers/M. Ernst (Hrsg.) Verfassung des Landes Brandenburg, 2012, Art. 26, 230. Ebenso wird nach Art. 23 Abs. 2 Rheinland-Pfälzische Verf. Alleinerziehenden besondere Fürsorge zuteil. Dazu M. Jutzi in: Ch. Grimm/P. Caesar (Hrsg.) Verfassung für Rheinland-Pfalz, 2001, Art. 23 Rn. 11 ff.

${ }^{34}$ So Art. 26 Abs. 2 Brandenburgische Verf. wonach auch andere, auf Dauer angelegte Lebensgemeinschaften als schutzbedürftig anerkannt werden. Art. 26 Abs. 2 Brandenburgische Verf. billigt diesen einen besonderen Schutz vor Diskriminierungen zu und strebt(e) ausweislich seiner Entstehungsgeschichte keine Gleichstellung der nichtehelichen Lebensgemeinschaft mit Ehe und Familie an, so Iwers in: Lieber/Iwers/Ernst (Fn. 33), Art. 26, 231. Ebenso gibt die Verfassung Berlins anderen auf Dauer angelegten Lebensgemeinschaften Anspruch auf Schutz vor Diskriminierung, s. Art. 12 Abs. 2 Berliner Verf. Dazu Stöhr in: Pfennig/Neumann (Fn. 33), Art. 12 Rn. 10 ff. Die Bestimmungen stehen mit Art. 6 Abs. 1 GG im Einklang. Zur Verfassungskonformität von Art. 26 Abs. 2 Brandenburgische Verf. auch schon U. Sacksofsky NVwZ 1993, 235 (237). 


\section{Statische oder dynamische Verfassungsauslegung? \\ a. Grundstrukturen der Grundrechtsdogmatik}

$\mathrm{Ob}$ und wie wandlungsfähig das Grundgesetz ist und wo Grenzen der Auslegung bestehen, sind Grundsatzfragen, die die Staatsrechtswissenschaft schon lange beschäftigen. ${ }^{35}$ Dass der Verfassungsauslegung zwischen normativem Anspruch und politischer Wirklichkeit eine gewisse Dynamik innewohnt, hat insbesondere 2007 die Freiburger Staatsrechtslehrertagung aufgegriffen. ${ }^{36}$ Bezogen auf Ehe und Familie war das Verhältnis von Verfassungsgarantie und sozialem Wandel bereits 1986 Thema in München. ${ }^{37}$

Wie immer man dies rechtstheoretisch bewerten mag: Unter dem Grundgesetz nahm die Grundrechtsdogmatik Fahrt auf. Neue Grundrechtsfunktionen entstanden im „Dialog“"38 von Bundesverfassungsgericht und Staatsrechtslehre, manche sprechen auch von deren „Erfindung“. 39

Zwar konnte bei der Deutung der Grundrechte als subjektive Freiheitsrechte und bei den institutionellen Garantien an Vorbilder angeknüpft werden. ${ }^{40}$ Schon früh wurden aber auch neue Weichen gestellt. Dies gilt

35 Grundlegend F. Müller Normstruktur und Normaktivität, 1966, 13 ff.; P. Häberle Verfassung als öffentlicher Prozeß, 3. Aufl. 1998; M. Jestaedt Grundrechtsentfaltung im Gesetz, 1999, 72 ff., 262 ff.; s.a. W. Leisner Von der Verfassungsmäßigkeit der Gesetze zur Gesetzmäßigkeit der Verfassung, 1964.

$36 \mathrm{~S}$. dazu die Referate von $C$. Hillgruber Verfassungsrecht zwischen normativem Anspruch und politischer Wirklichkeit, VVDStRL 67 (2008), 7 ff. und U. Volkmann ebd., $57 \mathrm{ff}$.

${ }^{37}$ A. v. Campenhausen Verfassungsgarantie und sozialer Wandel - Das Beispiel von Ehe und Familie, VVDStRL 45 (1987), 7 ff. und H. Steiger ebd., 55 ff.

38 M. Stolleis Geschichte des öffentlichen Rechts in Deutschland, Band 4, 2012, 241 ff. mwN; s.a. B.-O. Bryde Verfassungsentwicklung, 1982, insbes. $206 \mathrm{ff}$.

39 R. Wahl JZ 2013, 369 (371); O. Lepsius in: H. Schulze-Fielitz (Hrsg.) Staatsrechtslehre als Wissenschaft, DV, Beiheft 7, 2007, 319 (337 ff.), hat aber auch kritisch beschrieben, dass die deutsche Staatsrechtslehre sich jedenfalls z.T. dadurch auszeichnet, dass die materielle Rechtsordnung generell-abstrakt und damit in erster Linie statisch gedacht wird. Zum Systemdenken der deutschen Verfassungsrechtswissenschaft F. Schoch ebd., 177 (192) mwN; zu Eigenheiten der Schweizer Verfassungsentwicklung G. Biaggini ebd., 267 (270 ff.). Idealtypischerweise gibt es für so manchen auf jede offene (Grund-)Rechtsfrage nur eine einzige richtige Antwort. Kritisch hierzu R. Poscher JZ 2013, 1 ff. Auch andere haben eine allzu statische Rechtsdeutung kritisiert, s. nur M. Jestaedt Das mag in der Theorie richtig sein ..., 2006, 55 ff.; A. v. Arnauld Rechtstheorie 32 (2001), 465 ff.; S. Kirste Die Zeitlichkeit des positiven Rechts und die Geschichtlichkeit des Rechtsbewußtseins, 1998, 386 ff.; vgl. außerdem W. Brohm FS Maurer, 2001, 1079, insbes. 1085 ff.

$40 \mathrm{Zu}$ den institutionellen Garantien grundlegend C. Schmitt in: ders. (Hrsg.) Verfassungsrechtliche Aufsätze aus den Jahren 1924-1954, 1958, 140 ff.; s.a. M. Cornils Die 
insbesondere für die Figur der objektiven Dimension der Grundrechte, ${ }^{41}$ die auch als Ausdruck einer in der Nachkriegszeit vorhandenen Empfänglich- oder sogar Bedürftigkeit für die Etablierung einer objektiven Wertordnung gelesen wird. ${ }^{42}$

Genannt werden kann daneben die Etablierung von Art. 2 Abs. 1 GG als Auffanggrundrecht, ${ }^{43}$ später die Entwicklung staatlicher Schutzpflichten $^{44}$ und des prozeduralen Grundrechtsschutzes. ${ }^{45}$

Auch bei Art. 6 Abs. 1 GG lässt sich diese dogmatische Entwicklung nachzeichnen. Vielfach hat dabei das Bundesverfassungsgericht als Motor gewirkt. Grundlegend ist insbesondere die Entscheidung vom 17.01.1957, mit der die Zusammenveranlagung von Ehegatten als verfassungswidrig verworfen wurde ${ }^{46}$ Hervorgehoben wurde zunächst die in der Norm enthaltene Instituts- bzw. Einrichtungsgarantie. ${ }^{47}$ Bei der Zuerkennung eines subjektiven Freiheitsrechts konnte zwar an die klassische Eingriffsabwehrfunktion von Grundrechten angeknüpft werden. Bezogen auf Ehe und Familie zeigt sich hier aber die Abkehr vom bloßen Programmcharakter des Art. 119 WRV. Die Norm wurde dabei als Reaktion auf die „Allstaatlichkeit des Nationalsozialismus" verstanden. ${ }^{48}$

Darüber hinaus wurde die Figur der objektiven Wertordnung für Art. 6 Abs. 1 GG fruchtbar gemacht. Die Norm wurde als verbindliche Wertentscheidung für den gesamten Bereich des Ehe und Familie betreffenden privaten und öffentlichen Rechts angesehen. ${ }^{49} \mathrm{Ihr}$ besonderer Schutzcha-

Ausgestaltung der Grundrechte, 2005, 339 ff. mwN; s.a. BVerfGE 6, 55 (72); 24, 119 (135); 24, 367 (389); 26, 215 (222).

${ }^{41}$ BVerfGE 7, 198 (205); dazu nur M. Herdegen in: Maunz/Dürig, GG, 67. Erg.-Lfg., 2013, Art. 1 Abs. 3 Rn. 52.

42 R. Wahl JZ 2013, 369 (372, 375 ff.) mwN.

${ }^{43}$ Grundlegend BVerfGE 6, 32 (37) (sog. Elfes-Urteil) dazu nur H. Lang in: V. Epping/Ch. Hillgruber (Hrsg.) GG, 2009, Art. 2 Rn. 9. sowie U. Di Fabio in: Maunz/ Dürig, GG, 67. Erg.-Lfg., 2013, Art. 2 Rn. 21. Kritisch H. Ehmke Prinzipien der Verfassungsinterpretation, VVDStRL 20 (1963), $82 \mathrm{ff}$.

${ }^{44}$ Grundlegend BVerfGE 39, 1 (41 ff.) zu $§ 218$ StGB. Dazu Di Fabio in: Maunz/ Dürig (Fn. 43), Art. 2 Rn. 61 mwN.

${ }^{45}$ Grundlegend BVerfGE 53, $30 \mathrm{ff}$.

46 BVerfGE 6, 55 (insbes. $71 \mathrm{ff}$.). In der Schlechterstellung von Ehegatten durch die Zusammenveranlagung wurde ein Verstoß gegen Art. 6 Abs. 1 GG in seiner Wirkung als Schutznorm gesehen, BVerfGE 6, 55 (77).

47 BVerfGE 6, 55 (72).

48 BVerfGE 6, 55 (71).

${ }^{49}$ Vgl. auch BVerfGE 6, 386 (388). Ein bloßer Programmsatzcharakter wurde als nicht der Entstehungsgeschichte entsprechend abgelehnt. S. BVerfGE 6, 55 (73 ff.); unzutreffend insoweit JöR (Fn. 26), 97. In der Konsequenz dieser Entwicklung hat sich das BVerfG eine im internationalen Vergleich einzigartige umfassende Prüfungskompetenz und -intensität sowie eine herausragende Stellung gegenüber Fachgerichten und 
rakter kam darin zum Ausdruck, dass sie sich nicht negativ auf die Abwehr von Eingriffen beschränkt, sondern dem Staat auch eine positive Förderaufgabe auferlegt. Die Wertungen des Art. 3 Abs. 2 GG wurden einbezogen. Damit erfuhr die Ausgestaltungsbefugnis des Gesetzgebers eine umfassende Einbindung.

\section{b. Dynamisierungsfaktoren}

Dass die Auslegung von Verfassungsbestimmungen sich ändern kann, zeigt sich schon daran, dass die Verfassungsmäßigkeit einer gesetzlichen Regelung auch dann und damit nochmals überprüft werden kann, wenn eine Entscheidung des Bundesverfassungsgerichts bereits vorliegt. ${ }^{50}$ Dies gilt insbesondere dann, wenn sich soziale Umstände und Einstellungen ändern.

Das Bundesverfassungsgericht hat schon 1953 ausdrücklich angesprochen, dass soziale Entwicklungen die Auslegung des Grundgesetzes beeinflussen können. ${ }^{51}$ In anderen Entscheidungen griff es auf einen Wandel der gesellschaftlichen Anschauungen zurück, etwa auf die allgemein herr-

Gesetzgeber verschafft. Instruktiv dazu R. Wahl JZ 2013, 369 (371 ff.); M. Jestaedt in: ders./O. Lepsius/Ch. Möllers/Ch. Schönberger (Hrsg.) Das entgrenzte Gericht. Eine kritische Bilanz nach sechzig Jahren BVerfG, 2011, 77 (insbes. 96 ff.); s.a. die einzelnen Beiträge in: Stolleis (Hrsg.) Herzkammer der Republik, 2011; O. Lepsius in: Jestaedt/ Lepsius/Möllers/Schönberger, ebd., 159 (209 ff.). Schulze-Fielitz spricht insoweit auch von einer Verrechtlichung der politischen Gestaltungskraft, die zu Lasten der demokratischen Elemente des GG geht und attestiert Deutschland dabei einen Sonderweg in Europa ohne unmittelbar sichtbaren Gerechtigkeitsgewinn. H. Schulze-Fielitz in: D. Grimm/F. Longato/C. Mongardini/G. Vogt-Spira (Hrsg.) Verfassung in Vergangenheit und Zukunft: Sechs Jahrzehnte Erfahrung in Deutschland und Italien, 2011, 89 ff., zur wissenschaftsdominierenden Bedeutung des BVerfG, ders. in: ders. (Fn. 39), 11 (28 ff.).

${ }^{50}$ So BVerfGE 33, 199 (204); 39, 169 ff.; 70, 242 ff.; 94, 315 (323). Voraussetzung ist, dass sich die tatsächlichen Verhältnisse, die Verfassungswirklichkeit oder die allgemeine Rechtsauffassung zu der zu überprüfenden Norm so geändert haben, dass ein veränderter Verfassungsinhalt oder ein anderer Norminhalt der neuen verfassungsrechtlichen Prüfung zugrunde gelegt werden muss. $\mathrm{Zu}$ den Anforderungen an die Vorlage vgl. BVerfGE 65, 179 (181). Dazu auch G. Ulsamer in: T. Maunz/B. Schmidt-Bleibtreu/ F. Klein/H. Bethge (Hrsg.) BVerfGG, 40. Erg.-Lfg. 2013, § 80 Rn. 68 b. sowie G. Morgenthaler in: Epping/Hillgruber (Fn. 43), Art. 100 Rn. 16. Kritisch zur faktischen Bindungswirkung $O$. Lepsius in: R. Scholz/D. Lorenz/Ch. Pestalozza/M. Kloepfer/ H. D. Jarass/Ch. Degenhart/O. Lepsius (Hrsg.) Realitätsprägung durch Verfassungsrecht, 2008, 104 (insbes. 111 ff.) $\mathrm{mwN}$.

${ }^{51}, \ldots$ wenn in ihrem Bereich neue, nicht vorausgesehene Tatbestände auftauchen oder bekannte Tatbestände durch ihre Einordnung in den Gesamtablauf einer Entwicklung in neuer Beziehung oder Bedeutung erscheinen." So BVerfGE 2, 380 (401) zur Eigentumsgarantie im Rahmen der Verfassungsmäßigkeit des Gesetzes über das Beanstandungsrecht in Haftentschädigungssachen. 
schenden gesellschaftlichen Auffassungen, ${ }^{52}$ den Wandel der Verhältnisse und Anschauungen, ${ }^{53}$ oder auf die Volksanschauung. ${ }^{54}$ Auch in der Literatur ist anerkannt, dass soziale und wirtschaftliche Veränderungen, aber auch der Wertewandel in der Gesellschaft die Auslegung von Grundrechten und damit auch ihre Dogmatik beeinflussen. ${ }^{55}$ Besonders offen sind insoweit die Grundrechte, die schon von ihrer Struktur her auf eine Ausgestaltung durch den Gesetzgeber angelegt sind. Dies ist bei Art. 6 Abs. 1 GG der Fall, ebenso bei Art. 14 Abs. 1 GG. Bei anderen Grundrechten ist der Spielraum enger..$^{56}$

Damit ist allerdings noch nicht gesagt, welche dogmatischen Stellschrauben hierbei im Einzelnen zum Einsatz kommen. Bezogen auf die Grundrechtsdogmatik von Ehe und Familie ergibt sich insoweit ein differenziertes Bild.

\section{Grundrechtsdogmatik von Ehe und Familie im Wandel}

\section{Grundlinien}

Bis heute halten Rechtsprechung und in weiten Teilen auch die Literatur zwar im Wesentlichen an den in den fünfziger Jahren des letzten Jahrhunderts entwickelten Grundstrukturen fest. ${ }^{57}$ Art. 6 Abs. 1 GG beinhal-

52 BVerfGE 1, 264 (277 f.) zu Art. 14 GG im Rahmen der Verfassungsbeschwerden, die sich unmittelbar gegen das Bundesgesetz zur Ordnung des Schornsteinfegerwesens richteten.

${ }^{53}$ BVerfGE 10, 354 (368 f.) zur Pflichtmitgliedschaft der in Bayern tätigen Ärzte bei der Bayerischen Ärzteversorgung.

${ }^{54}$ BVerfGE 18, 112 (118), wonach allerdings gerade keine einheitliche Anschauung zur Todesstrafe festgestellt werden könnte.

${ }_{55}$ C. Degenhart in: Scholz/Lorenz/Pestalozza/Kloepfer/Jarass/Degenhart/Lepsius (Fn. 50), 89 (99 ff.), zu Art. 6 Abs. 1 GG. Ob das BVerfG sich bei seinen Entscheidungen auf empirisch belegte soziale Entwicklungen bezieht oder aber auf allgemeine Gerechtigkeitsvorstellungen zurückgreift, wird nicht immer ganz klar. T. Würtenberger Zeitgeist und Recht, 1987, 193; vgl. auch die Kritik von Landau und Kessal-Wulf in ihrer abweichenden Meinung zum Beschl. des 2. Senats vom 07.05.2013, 2 BvR 909/06 u.a. (Ehegattensplitting), Rn. 116 ff. (insbes. 145 ff.); zur Berücksichtigung statistischer Erkenntnisse G. Britz Einzelfallgerechtigkeit versus Generalisierung, 2008, insbes. 29 ff.; vgl. außerdem A. v. Arnauld in: A. Funke/J. Lüdemann (Hrsg.) Öffentliches Recht und Wissenschaftstheorie, 2009, $65 \mathrm{ff}$.

${ }^{56}$ Vgl. dazu die Einzeluntersuchungen von Cornils Die Ausgestaltung der Grundrechte (Fn. 40), 54 ff.; zu den Grenzen der Auslegungsbefugnis auch des BVerfG s. nur das Sondervotum des Richters Gaier zur Plenarentscheidung des BVerfG zum Einsatz der Bundeswehr im Inland, Beschl. v. 03.07.2012, 2 PBvU 1/11, juris-Rn. 60 ff. zu Vorlagefrage 2 juris-Rn. $23 \mathrm{ff}$.

${ }^{57}$ Hierzu D. Grimm Die Zukunft der Verfassung, 1991, $221 \mathrm{ff}$. 
tet auch weiterhin ein Freiheitsrecht, eine institutionelle Garantie und ist wertentscheidende Grundsatznorm. Die sich dahinter im Einzelnen verbergenden Inhalte haben sich jedoch gewandelt. ${ }^{58}$ Deutlich stärker geworden ist der Einfluss des Art. 3 GG und dies nicht nur bezüglich der Gleichberechtigung der Frau.

Art. 6 Abs. 1 GG ist auch deshalb auf eine dynamische Auslegung hin angelegt, weil das Schutzgebot der Verfassung die Institutionen der Ehe und Familie nicht abstrakt umfasst, sondern in ihrer Ausgestaltung durch den Gesetzgeber. ${ }^{59}$ Damit beeinflusst die soziale Realität die Auslegung der Verfassung stärker als dies bei anderen Grundrechten der Fall ist. Das Familienrecht, vielfach geprägt durch politische Kompromisse, bringt neue Inhalte in die Verfassung ein, ist aber selbst wiederum gebunden durch die Verfassung. ${ }^{60}$

Besonders deutlich wird die Entwicklungsoffenheit von Art. 6 GG in den Fällen, in denen gesetzliche Regelungen erst als verfassungswidrig, später dann als verfassungsgemäß angesehen wurden.

Ausdrücklich angesprochen wird ein Wertewandel vom Bundesverfassungsgericht u.a. in den Entscheidungen zu Witwerrenten. ${ }^{61}$

Im Jahr 1963 wurde es beispielsweise noch als mit Art. 6 GG vereinbar angesehen, dass ein Witwer nach dem Tode seiner versicherten Frau nur dann eine Rente erhielt, wenn diese den Unterhalt der Familie überwiegend bestritten hatte. Zwölf Jahre später wurde dagegen die veränderte Rollenverteilung in der Ehe hervorgehoben und dem Gesetzgeber aufgegeben, für die Zukunft einen Verstoß gegen Art. 3 Abs. 2 und 3 GG auszuschließen. Als Beispiele für einen Wandel kann auch auf die Rechtsprechung zum Ehenamen ${ }^{62}$ sowie zum Sorgerecht nicht miteinander verheirateter Eltern verwiesen werden. ${ }^{63}$

${ }^{58}$ Kritisch zur Entwicklung des Instituts der Ehe die Minderheitsvoten von Papier und Haas BVerfGE 105, 313 (357 ff.). Zum Kern der Institutsgarantie des Art. 6 GG s. insbes. BVerfGE 80, 80 (92).

${ }_{59}$ BVerfGE 31, 58 (82 f.); s.a. BVerfGE 105, 313 (345).

${ }^{60}$ Ausführlich dazu Cornils Die Ausgestaltung der Grundrechte (Fn. 40), 338 ff.; zum besonderen Schutz von Ehe und Familie im Privatrecht M. Ruffert Vorrang der Verfassung und Eigenständigkeit des Privatrechts, 2001, $398 \mathrm{ff}$.

${ }^{61}$ BVerfGE 17, 1 (12 f.); ferner auch BVerfGE 39, 148 (155).

${ }_{62}$ Es wurden zum einen Reformen zu Liberalisierung des Namensrechts angestoßen, aber auch eher konservativere gesetzliche Entscheidungen verfassungsrechtlich gebilligt, U. Sacksofsky FPR 2010, 15 (19) beschreibt die Linie der Rechtsprechung des BVerfG insoweit als „Zickzackkurs“. Einen Überblick zum deutschen Namensrecht gibt $N$. Spiegelhalder FPR 2010, 1 ff. Bis 1976 galt die Regelung, dass bei der Eheschließung der Mannesname gemeinsamer Familienname wird. Das BVerfG deutete zwar im Jahr 1963 Zweifel an der Vereinbarkeit mit Art. 3 Abs. 2 GG an, beschränkte die zu entscheidende Frage jedoch auf das abstrakte Gebot eines einheitlichen Ehe- und Familiennamens 
Als Reformbremse wird dagegen von vielen Erb- und Familienrechtlern eine Grundsatzentscheidung des Bundesverfassungsgerichts aus dem Jahre 2005 angesehen, wonach das Pflichtteilsrecht der Kinder von Art. 14 Abs. 1 S. 1 GG iVm Art. 6 Abs. 1 GG garantiert sein soll. ${ }^{64}$

und sah dieses als verfassungsgemäß an, BVerfGE 17, 168 (171 f.). Erst im Jahr 1978 erklärte das BVerfG die Regelung - allein mit Konsequenzen für Altehen - für verfassungswidrig, BVerfGE 48, 327 ff. Vgl. dazu auch $R$. Frank in: 40 Jahre Grundgesetz, Ringvorlesung der Rechtswissenschaftlichen Fakultät Freiburg, 1990, 113, (119) mwN. Durch Änderung des Namensrechts im Jahr 1976 wurde sodann nur noch subsidiär an den Vorrang des Mannesnamens angeknüpft, soweit keine Bestimmung des Ehenamens durch die Eheleute erfolgte. Im Jahr 1988 sah das BVerfG den Zwang zum einheitlichen Ehenamen als verfassungsrechtlich unbedenklich, jedoch nicht zwingend geboten an, äußerte in einem obiter dictum allerdings Zweifel am subsidiären Vorrang des Mannesnamens, vgl. BVerfGE 78, 38 (49 ff.). Erst im Jahr 1991 wurde die subsidiäre Anknüpfung an den Mannesnamen für verfassungswidrig erklärt, BVerfGE 84, 9 (17). Das gesetzliche Verbot, einen früheren Ehenamen auch zum Ehenamen einer neuen Ehe zu bestimmen wurde 2004 für verfassungswidrig erklärt. S. BVerfGE 109, 256 ff., dazu U. Sacksofsky FPR 2004, 371 ff. Der Ausschluss des Doppelnamens für Ehegatten und Kinder sowie das Verbot von drei- oder mehrgliedrigen Namen wurden dahingegen im Jahr 2002 und 2009 verfassungsrechtlich gebilligt, BVerfGE 104, 373 ff. und BVerfGE $123,90 \mathrm{ff}$.

${ }^{63}$ Nachdem der EGMR, Urt. v. 03.12.2009 - 22028/04, Zaunegger/Deutschland, NJW 2010, 501 ff., die in $§ 1626$ a BGB a.F. liegende Zurücksetzung des Kindesvaters gegenüber der Kindesmutter und ehelichen Vätern für unvereinbar mit Art. 8 und Art. 14 EMRK erklärt hat - dazu nur M. Coester NJW 2010, 482 ff., im Einzelnen weiter unten -, hat auch das BVerfG seine Haltung revidiert. Anders als noch in seinem Urt. v. 29.01.2003, BVerfGE 107, 105 ff. - kritisch dazu etwa schon K. Muscheler FS Frank (Fn. 10), 463 ff.; ferner auch S. Willutzki FPR 2013, 236 ff., der die Entscheidung des BVerfG insoweit als „weltfremd“ bezeichnet - hat es mit Beschl. v. 21.07.2010, 1 BvR 420/09, NJW 2010, 3008 ff. das bis dahin geltende Reglungskonzept zum Sorgerecht für Kinder nicht miteinander verheirateter Eltern als verfassungswidrig erklärt. Dem Vater muss nach der Entscheidung auch gegen den Willen der Mutter die Möglichkeit des Zugangs zur gemeinsamen elterlichen Sorge eröffnet werden. Dieser muss überprüfen lassen können, ob ihm (zum Teil) die alleinige elterliche Sorge zu übertragen ist. Nach Geltung der Übergangsregelung des BVerfG, ist zum 19.05.2013 § 1626a BGB n.F. in Kraft getreten. Zur Reform siehe nur S. Heilmann NJW 2013, 1473 ff. und C. Bruns FamFR 2013, 217 ff. Zur gesamten Entwicklung mit zahlreichen weiteren Nachweisen B. Veit in: H. G. Bamberger/H. Roth (Hrsg.) BeckOK BGB, Stand 01.11.2011, § 1626a Rn. 18 ff.

${ }^{64}$ BVerfGE 112, 332 (348 ff.); kritisch dazu T. Helms in: R. Zimmermann (Hrsg.) Freedom of Testation/Testierfreiheit, 2012, 1 (11 ff.) mwN; außerdem S. Stüber NJW 2005, 2122 ff. und D. Leipold JZ 2010, 802 (805 f.); dem BVerfG zustimmend dagegen G. Otte JZ 2005, 1001 (1007 ff.). In der Entscheidung wird das grundrechtliche Spannungsverhältnis zwischen Testierfreiheit des Erblassers und Pflichtteilsrecht der Kinder als Ausdruck der Solidarität zwischen den Generationen zwar thematisiert, letztlich aber einseitig zugunsten des letzteren entschieden. Das Pflichtteilsrecht der Abkömmlinge in seiner herkömmlichen Gestalt soll demnach als grundsätzlich unentziehbare 
Die Beispiele zeigen: Lebenswirklichkeit und veränderte Auffassungen haben (oft) Dynamik in die Verfassungsinterpretation gebracht. ${ }^{65}$ Ein Blick auf die Entwicklung der Auslegung der Schutzgüter des Art. 6 Abs. 1 GG liefert weitere Belege. ${ }^{66}$

\section{Schutzgut Ehe}

Ausdrücklich definiert wird der Begriff der Ehe im Grundgesetz nicht. In Anknüpfung an die Entstehungsgeschichte wird darunter grundsätzlich die auf Dauer angelegte Lebensgemeinschaft von Mann und Frau angesehen, die auf freiem Entschluss und der Gleichberechtigung der Partner beruht und unter staatlicher Mitwirkung geschlossen wird. ${ }^{67}$ Was unter den einzelnen Merkmalen verstanden wird, hat sich allerdings gewandelt. ${ }^{68}$

Ursprünglich wurde die Ehe auch unter dem Grundgesetz als grundsätzlich unauflösliche Lebensgemeinschaft angesehen, ${ }^{69}$ mittlerweile dagegen als ,,auf Dauer angelegt “" ${ }^{70}$ Stark gewandelt hat sich das Rollenbild der Eheleute. Im Juli 1959 sah das Bundesverfassungsgericht keinen

und bedarfsunabhängige wirtschaftliche Mindestbeteiligung am Nachlass anzusehen sein, BVerfGE 112, 349 ff. Die vom BVerfG daneben in Anspruch genommene Berufung auf die Rechtslage in anderen europäischen Staaten wird von Helms ebd., 1 (12 f.) durch Beispiele aus ebendiesen Rechtsordnungen in Frage gestellt.

${ }^{65}$ Frank in: 40 Jahre Grundgesetz (Fn. 62), 113 (120).

${ }^{66}$ Die Grundrechtsgewährleistungen von Ehe und Familie sind rechtlich voneinander unabhängig. Grundlegend R. Gröschner in: H. Dreier (Hrsg.) GG, 2. Aufl. 2004, Art. 6 Rn. 69 ff.; U. Steiner Handbuch der Grundrechte IV, 2011, § 108 Rn. 7; aA A. Uhle in Epping/Hillgruber (Fn. 43), Art. 6 Rn. 17. Ihr Schutz ist aber grundsätzlich gleichrangig. S. nur Brosius-Gersdorf in: Dreier (Fn. 11), Art. 6 Rn. 43, 46 jew. mwN; ausführlich dies. Demografischer Wandel und Familienförderung, 2011, insbes. 203; zum Ehe- und Familienleitbild in der DDR vgl. Erster Gleichstellungsbericht, BT-Drs. 17/6240, 62 f. mwN.

${ }^{67}$ BVerfGE 105, 313 (345); s.a. BVerfGE 10, 59 (66); 29, 166 (176); 37, 217 (248 ff.); 39, 169 (183); 48, 327 (338); 62, 323 (330); 66, 84 (94); 103, 89 (101); Badura in: Maunzl Dürig (Fn. 24), Art. 6 Rn. 42; s.a. Brosius-Gersdorf in: Dreier (Fn. 11), Art. 6 Rn. 49 mwN.

${ }^{68}$ Zur Wandlungsfähigkeit etwa BVerfGE 105, 313 (350) unter Verweis auf BVerfGE 31, 58 (82 f.) zur Verfassungsmäßigkeit des Lebenspartnerschaftsgesetzes; zu den gewandelten Ehebildern des BVerfG s.a. Erster Gleichstellungsbericht (Fn. 66), 63 f.

${ }^{69}$ BVerfGE 10, 59 (66).

70 BVerfGE 105, 313 (344). Diese auf den anfänglichen Willen der Eheschließenden abstellende Sichtweise erscheint realitätsnäher, zumal die Möglichkeit der Scheidung seit der Bismarckzeit anerkannt ist. Badura in: Maunz/Dürig (Fn. 24), Art. 6 Rn. 4; C. D. Classen DVBl 2013, 1086 (1087) mwN; zum Recht auf Scheidung s.a. Ruffert Vorrang der Verfassung und Eigenständigkeit des Privatrechts (Fn. 60), 401 ff.; F. Hufen Staatsrecht II, 2007, § 16 Rn. 5; Robbers in: v. Mangoldt/Klein/Starck (Fn. 23), Art. 6 Abs. 1 Rn. 62. 
Verfassungsversto $ß$ darin, dass nach dem familienrechtlichen Leitbild die Frau ihre familiären Unterhaltsverpflichtungen in der Regel durch die Führung des Haushalts, der Mann die seinigen dagegen durch Erwerbstätigkeit erfüllt. ${ }^{71}$ Ein gutes Jahrzehnt später wird hervorgehoben, dass die Aufteilung alleinige Angelegenheit der Ehepartner sei. ${ }^{72}$

Wie weit der Interpretationsspielraum reicht, zeigt sich bei der Diskussion um das Geschlecht der Eheleute. Das Bundesverfassungsgericht hält zwar in seinen neueren Entscheidungen daran fest, dass die Ehe allein der Verbindung zwischen Mann und Frau vorbehalten ist. ${ }^{73}$ Immer mehr Stimmen in der Literatur gehen aber mittlerweile davon aus, dass unter Art. 6 Abs. 1 GG auch gleichgeschlechtliche Partnerschaften in der Form der Ehe geführt werden können. ${ }^{74}$ Andere lehnen dies ab ${ }^{75}$ bzw. halten es nur nach einer Änderung des Grundgesetzes für möglich. ${ }^{76}$

${ }^{71}$ BVerfGE 10, 59 (75).

72 BVerfGE 37, 217 (251); s. außerdem BVerfGE 53, 224 (246 ff.); 105, 1 (10 f.)

${ }^{73}$ BVerfG, Urt. v. 07.05.2013, 2 BvR 909/06 u.a., insbes. Rn. 81, NJW 2013, 2257 (2258); s.a. BVerfGE 10, 59 (66); 105, 313 (345). In der Transsexuellen-Entscheidung vom Januar 2011 hat das BVerfG festgestellt, dass Voraussetzung einer Eheschließung die Verschiedengeschlechtlichkeit der Ehegatten ist, während die Eingehung einer Lebenspartnerschaft nur zwischen gleichgeschlechtlichen Personen möglich ist, BVerfG, Beschl. v. 11.01.2011, 1 BvR 3295/07, Rn. 58, NJW 2011, 909 (909). In der Entscheidung wurde zwar eine Anknüpfung an das personenstandsrechtliche Geschlecht als zulässig angesehen, als Verstoß gegen das allgemeine Persönlichkeitsrecht wurde es aber qualifiziert, dass Transsexuelle mit gleichgeschlechtlicher Orientierung zur rechtlichen Absicherung ihrer Partnerschaft entweder die Ehe eingehen oder sich geschlechtsändernden operativen Eingriffen aussetzen mussten, um personenstandsrechtlich im empfundenen Geschlecht anerkannt zu werden und damit eine eingetragene Lebenspartnerschaft begründen zu können, die ihrer als gleichgeschlechtlich empfundenen Partnerbeziehung Rechnung trägt. Kritisch zur „Gegengeschlechtlichkeit“ $S$. Baer in: A. Röthel/B. Heiderhoff (Hrsg.) Regelungsaufgabe Paarbeziehung: Was kann, was darf, was will der Staat?, 2012, 35 (39 f.); zu Entwicklungen in Europa, Amerika und Australien vgl. Basedow/Scherpe (Hrsg.) Transsexualität, Staatsangehörigkeit und internationales Privatrecht, 2004.

${ }^{74}$ S. etwa Brosius-Gersdorf in: Dreier (Fn. 11), Art. 6 Rn. 79 ff., die auch die Vielehe als von Art. 6 umfasst ansieht, einschränkend aber auf Art. 3 Abs. 2 Satz 1 GG verweist; aA H. Hofmann in: B. Schmidt-Bleibtreu/H. Hofmann/A. Hopfauf (Hrsg.) GG, 12. Aufl. 2011, Art. 6 Rn. 6 ff. Die Evangelische Kirche in Hessen und Nassau hat die Segnung homosexueller Paare weitgehend mit der Trauung gleichgestellt, vgl. Ordnung des kirchlichen Lebens in der EKHN vom 15. Juni 2013 (ABl. 2013 Nr. 8) Abschnitt 5, 2.3, 2.4, Rn. 255 ff. Im August 2013 wurde erstmals eine Ehezeremonie bei Lebenspartnern vollzogen, vgl. www. eknh.de (zuletzt abgerufen am 17.09.2013); A. Sanders NJW 2013, 2236 (2238 f.).

${ }^{75}$ Bezogen auf das Institut der Ehe hält etwa Würtenberger trotz Zunahme alternativer Formen des Zusammenlebens eine Neuinterpretation von Art. 6 Abs. 1 GG nicht für angebracht. Ein Wandel in den Wertvorstellungen und Verhaltensweisen könne hier 
Ehe und Familie sind grundsätzlich als gleichrangige Schutzgüter anzusehen. In der Praxis lässt sich aber vielfach eine Verschiebung des Schutzes von der Ehe hin zur Familie beobachten. ${ }^{77}$

\section{Schutzgut Familie}

Deutlich wird dies insbesondere im Sozialrecht. Früher knüpften beispielsweise die Rentenansprüche an den Ehestatus an. Gewährt wurden eine Witwen- bzw. eine Witwerrente. Mittlerweile wird dagegen unmittelbar auf die Betreuung von Kindern abgestellt und deshalb von der sog. Erziehungsrente gesprochen. ${ }^{78}$

Stark gewandelt hat sich der Begriff der Familie. Soziale Entwicklungen und veränderte Werte haben als Dynamisierungsfaktoren seine Auslegung beeinflusst. Die Familie muss nicht mehr aus der Ehe hervorgehen, um dem Schutz des Art. 6 Abs. 1 GG zu unterfallen. Das Bestehen einer tatsächlichen Lebens- und Erziehungsgemeinschaft von Eltern und Kindern genügt. ${ }^{79}$ Auf die biologische Herkunft kommt es nicht an. Vom

keine normative Kraft entfalten, weil Ehe und Familie als Keimzelle, als natürliche und sittliche Grundlage jeder menschlichen Gemeinschaft ohne Alternative seien, Würtenberger, Zeitgeist und Recht (Fn. 55), $228 \mathrm{mwN}$. Vgl. auch V. Epping Grundrechte, 5. Aufl. 2012, Kap. 10 Rn. 509; W. Frenz NVwZ 2013, 1200 (1201); M. Kloepfer Handbuch der Grundrechte II, 2006, $\S 43$ Rn. 68; B. Klein Das neue Eheverbot der bestehenden eingetragenen Lebenspartnerschaft, 2008, 18 ff.; s.a. EuGH, Urt. v. $31.05 .2001-$ C-122/99 P und C.125/99 PD, Königreich Schweden/Rat, DVB1. 2001, 1199 (1200). Zum Merkmal der Verschiedengeschlechtlichkeit auch B. Pieroth in: H. D. Jarass/B. Pieroth (Hrsg.) GG, 11. Aufl. 2011, Art. 6 Rn. 2; C. v. Coelln in: M. Sachs (Hrsg.) Grundgesetz Kommentar, 6. Aufl. 2011, Art. 6 Rn. 6; Robbers in: v. Mangoldt/Klein/Starck (Fn. 23), Art. 6 Rn. 45.

76 D. Coester-Waltjen in: I. v. Münch/P. Kunig (Hrsg.) GG, 6. Aufl. 2012, Art. 6 Rn. 9; P. Berens Der Grundrechtsschutz der Familie unter besonderer Berücksichtigung der kinderreichen Familie, 2004, 89.

77 Vgl. dazu N. Dethloff in: B. Zypries (Hrsg.) Verfassung der Zukunft, 2009, 132 ff;; der Erste Gleichstellungsbericht (Fn. 66), 68 f. weist aber auch darauf hin, dass dem Arbeits- und Sozialrecht vielfach noch traditionelle Rollenbilder zu Grunde liegen.

$78 \S 47$ SGB VI, zu den Auswirkungen und der Ausgestaltung des Sozialrechts vgl. den Ersten Gleichstellungsbericht (Fn. 66), 69, 76 und 202 ff., auf Seite 58 wird allerdings auch darauf hingewiesen, dass trotz rechtlicher Gleichstellung von Witwen und Witwern die Hinterbliebenensicherung bis heute dem rechtlichen Bild der nicht oder wenig erwerbstätigen Frau folgt.

${ }_{79}$ Grundlegend BVerfGE 10, 59 (66); kinderlose Ehen werden nicht unter den Familienbegriff gefasst, s. Brosius-Gersdorf in: Dreier (Fn. 11), Art. 6 Rn. 110 und M. Pechstein, Familiengerechtigkeit als Gestaltungsgebot für die staatliche Ordnung, 1994, 100; aA D. Pirson in: Bonner Kommentar GG, 36. Erg.-Lfg. 1976, Art. 6 Rn. 22. 
Schutz des Familiengrundrechts erfasst wird die „soziale Familie“, die unabhängig ist vom Bestehen rechtlicher Elternschaft. ${ }^{80}$ Dazu gehören auch nichteheliche Familien ${ }^{81}$ sowie Pflege- und Stieffamilien, ${ }^{82}$ ggfs. weitere Personen wie z.B. die Großeltern. ${ }^{83}$

Das durch Art. 6 Abs. 2 S. 1 GG geschützte Elternrecht schützt auch zwei Elternteile gleichen Geschlechts. Eingetragene Lebenspartnerschaften mit Kindern sind Familie iSd Art. 6 Abs. 1 GG. ${ }^{84}$ In seiner Entscheidung zur Sukzessivadoption ging das Bundesverfassungsgericht davon aus, dass die abweichende historische Vorstellung dieser Auslegung nicht entgegensteht. Maßgeblich ist vielmehr die veränderte rechtliche Einordnung der Homosexualität und der Einstellungswandel der Gesellschaft. ${ }^{85}$ Familie ist damit letztlich überall dort, wo Kinder sind. ${ }^{86}$ Auch eine Volladoption durch Lebenspartner muss konsequenterweise nun eingeführt werden. ${ }^{87}$

Die Zulassung der Sukzessivadoption und die Einbeziehung von Lebenspartnerschaften mit Kindern in den Schutzbereich von Art. 6 Abs. $1 \mathrm{GG}$ ist folgerichtig. Grundrechtsdogmatisch ist aber auffällig, dass die Entscheidung, und dies trotz umfangreicher Ausführungen zum Schutzbereich des Art. 6 Abs. 1 GG, letztlich nicht auf diese Norm gestützt wurde, sondern auf einen Verstoß gegen Art. 3 GG. Wegen der

80 BVerfG, Urt. v. 19.02.2013, 1 BvL 1/11 und 1 BvR 3247/09, Rn. 62, NJW 2013, 847 (850); vgl. nur BVerfGE 68, 176 (187); 79, 51 (59); 80, 81 (90).

81 BVerfG, Urt. v. 19.02.2013, 1 BvL 1/11 und 1 BvR 3247/09, Rn. 64, NJW 2013, 847 (851) unter Verweis u.a. auf BVerfGE 10, 59 (66); 18, 97 (105 f.); 79, 256 (267) und 108,82 (112).

82 BVerfG, Urt. v. 19.02.2013, 1 BvL 1/11 und 1 BvR 3247/09, Rn. 62, NJW 2013, 847 (850) unter Verweis auf BVerfGE 68, 176 (187) und 79, 51 (59) zur Pflegefamilie und BVerfGE 18, 97 (105 f.); 79, 256 (267) zur Stieffamilie. Auch auf die Ehefähigkeit kommt es danach nicht an; aA Uhle in: Epping/Hillgruber (Fn. 66), Art. 6 Rn. 18.

83 Zur Großfamilie als Pflege- und Erziehungs- sowie als Beistands- und Verantwortungsgemeinschaft Brosius-Gersdorf in: Dreier (Fn. 11), Art. 6 Rn. 112 mwN; aA G. Kirchhof AöR 129 (2004), 542 (550 f.).

84 BVerfG, Urt. v. 19.02.2013, 1 BvL 1/11 und 1 BvR 3247/09, Rn. 47, zum Begriff der Familie Rn. 60 ff., NJW 2013, 847 (849 f.).

85 Ein Anspruch auf Ermöglichung der Sukzessivadoption kann danach auch nicht aus Art. 6 Abs. 2 GG abgeleitet werden, weil das Elternrecht voraussetzt, dass ein durch Abstammung oder einfachgesetzlich begründetes Elternverhältnis zum Kind besteht, woran es jedoch in dem zu entscheidenden Fall fehlte. BVerfG, Urt. v. 19.02.2013, 1 BvL 1/11 und 1 BvR 3247/09, Rn. 58, NJW 2013, 847 (850) mwN aus der Rspr. des Gerichts.

86 Auch die Forderung nach einem Wahlrecht für Familien kann als Ausdruck des besonderen Stellenwerts von Kindern gesehen werden. Ausführlich zur Thematik, S. Müller-Franken Familienwahlrecht und Verfassung, 2013, mwN.

87 So auch C. D. Classen DVB1. 20131086 (1091). 
Zulässigkeit der Sukzessivadoption bei Eheleuten und der Stiefkindadoption auch bei gleichgeschlechtlichen Paaren wurde ein Verstoß gegen das Gleichheitsrecht des Kindes festgestellt. Bezüglich des adoptionswilligen Lebenspartners findet sich dann nur noch ein Satz zur Übertragung des Ergebnisses auch auf ihn. 88

\section{Gleichheitsrechte}

Der Bedeutungszuwachs der in Art. 3 GG verankerten Gleichheitsrechte für den Anwendungsbereich des Art. 6 GG ist bemerkenswert. Er hat dogmatisch weitreichende Auswirkungen. ${ }^{89}$

Der dynamisierende Einfluss des Art. 3 Abs. 2 GG auf die Auslegung des Art. 6 Abs. 1 GG wurde schon früh deutlich, etwa als das Bundesverfassungsgericht die Zusammenveranlagung von Ehegatten im Jahr 1957 verwarf. Der Versuch, die Norm damit zu begründen, dass es notwendig sei, „die Ehefrau ins Haus zurückzuführen“, wurde als weder mit Art. 6 Abs. 1 GG noch mit Art. 3 Abs. 2 GG vereinbar angesehen..$^{90}$ Es widerspreche nicht nur dem Grundsatz, sondern auch dem Wortlaut des Art. 3 Abs. 2 GG, die erwerbswirtschaftliche Tätigkeit von Frauen ,,von vornherein als ehezerstörend zu werten“. Die Zweckrichtung des Gesetzes, die Ehefrau von marktwirtschaftlicher Tätigkeit zurückzuhalten, sei ungeeignet, die Zusammenveranlagung zu rechtfertigen. ${ }^{91}$

88 BVerfG, Urt. v. 19.02.2013, 1 BvL 1/11 und 1 BvR 3247/09, Rn. 71 ff., NJW 2013, 847 (851 ff.). Der Gesetzgeber wurde als jedenfalls nicht ohne Weiteres verpflichtet angesehen, bei der Ausgestaltung der Familie im rechtlichen Sinne tatsächlich vorgefundene familiäre Gemeinschaften genau nachzuzeichnen. Die Ehe unterscheide sich nicht in einer Weise von der eingetragenen Lebenspartnerschaft, dass der generelle Ausschluss der Sukzessivadoption gerechtfertigt werden könnte. Das Kindeswohl stehe dem nicht entgegen, sondern spreche im Gegenteil dafür. BVerfG, Urt. v. 19.02.2013, 1 BvL 1/11 und 1 BvR 3247/09, Rn. 78, NJW 2013, 847 (852). Zur Bedeutung des Kindeswohls vgl. auch K. Tillmanns FS Frank (Fn. 10), $271 \mathrm{ff}$.

${ }^{89}$ Zur Wertungsoffenheit des Art. 3 Abs. 1 GG J. Kokott FS 50 Jahre BVerfG, 2001, 127 (129 ff.).

90 BVerfGE 6, 55 (79 ff.).

${ }^{91}$ BVerfGE 6, 55 (82); zu den Auswirkungen des Art. 3 Abs. 2 GG auf das Familienrecht in den Anfangsjahren der Bundesrepublik Deutschland H. Dölle Familienrecht, 1964, insbes. 15 ff., 26 ff.; zur Gleichstellung von Mann und Frau zwischen deutschem und europäischem Recht J. Kokott NJW 1995, 1049 ff. Zum Gleichheitsgrundsatz im Zusammenhang mit dem Schutz von Ehe und Familie in Österreich, wo eine verfassungsrechtliche Regelung zum Schutz dieser beiden Güter fehlt, W. Berka Verfassungsgarantie und sozialer Wandel - Das Beispiel von Ehe von Familie, VVDStRL 45, (1987), 94 (95). 
Mittlerweile sieht das Gericht es als Aufgabe des Staates an, der Wahlfreiheit der Familien insbesondere bezüglich der Vereinbarkeit von Familie und Beruf Rechnung zu tragen..$^{92}$ Darauf wird noch zurückzukommen sein.

Viele andere ehe- und/oder familienbezogenen Entscheidungen wurden nicht oder jedenfalls nicht allein auf Art. 6 Abs. 1 GG gestützt, sondern maßgeblich auf Art. 3 Abs. 1 GG. ${ }^{93}$ Dies gilt namentlich für das Sozialrecht, bei dem das Bundesverfassungsgericht es wiederholt ausdrücklich abgelehnt hat, konkrete Bindungen aus Art. 6 Abs. 1 GG herzuleiten. ${ }^{94}$

Grundsätzlich könnte man dies als richterliche Zurückhaltung gegenüber der Ausgestaltung des Grundrechts deuten. Im Ergebnis allerdings wurde der Gesetzgeber über den Hebel des Gleichheitssatzes wiederholt ${ }^{95}$ zur Korrektur bzw. nachhaltigen Umgestaltung gewachsener Strukturen u.a. im Sozialversicherungsrecht verpflichtet. ${ }^{96}$ Je höher die Regelungsdichte einer bestimmten Rechtsmaterie ist, desto differenzierter prüft das Bundesverfassungsgericht. ${ }^{97}$ Insbesondere die Einführung der Lebenspartnerschaft ${ }^{98}$ belegt, wie im Wechselspiel von innovativem Gesetzgeber

92 BVerfGE 99, 216 (234); s.a. Brosius-Gersdorf Demografischer Wandel und Familienförderung (Fn. 66), insbes. $365 \mathrm{ff}$.

93 Der in Art. 3 Abs. 1 GG festgeschriebene allgemeine Gleichheitssatz wurde ursprünglich meist als Willkürverbot umschrieben. Wesentlich Gleiches durfte danach nicht ohne sachlichen Grund willkürlich ungleich, wesentlich Ungleiches nicht gleich behandelt werden. Mittlerweile wird Art. 3 Abs. 1 GG in der Rspr. des BVerfG schon dann als verletzt angesehen, wenn Gruppen von Normadressaten unterschiedlich behandelt werden, obwohl zwischen beiden keine Unterschiede von solcher Art und solchem Gewicht bestehen, die die ungleiche Behandlung rechtfertigen könnten. S. etwa BVerfGE 55, 72 (88); 71, 146 (154 f.); 95, 267 (317).

94 BVerfGE 82, 60 (80); 87, 1 (35); 103, 242 (257 ff.); 103, 271 (291 ff.); s.a. Ruffert Vorrang der Verfassung und Eigenständigkeit des Privatrechts (Fn. 60), $414 \mathrm{f}$.

95 Und dies mit ,wesentlich größerer Wirkkraft" meint H.-J. Papier in: B. v. Maydell/F. Ruland/U. Becker (Hrsg.) Sozialrechtshandbuch, 5. Aufl. 2012, § 3 Rn. 120; kritisch zur dogmatischen Entwicklung G. Krings NVwZ 2011, 26 f.; J. Benedict JZ 2013, 477 (486); D. Gade/C. Thiele DÖV 2013, 142 (151); C. Hillgruber JZ 2010, $41 \mathrm{ff}$.

96 Papier in: v. Maydell/Ruland/Becker (Fn. 95), § 3 Rn. 100 ff.

97 Willkürliche Inkonsequenz ist dem Gesetzgeber verboten, Papier in: v. Maydell/ Ruland/Becker (Fn. 95), § 3 Rn. 96. Als Indiz für einen Gleichheitsverstoß wird die Verletzung einer vom Gesetz selbst gewählten Sachgesetzlichkeit angesehen. So schon BVerfGE 34, 103 (115); grundlegend F.-J. Peine Systemgerechtigkeit, 1985, 24 ff. Der Gleichheitssatz bezieht sich dabei aber nicht auf unterschiedliche Regelungsbereiche: ,ähnliche Sachverhalte in verschiedenen Ordnungsbereichen mit anderen systematischen und sozialgeschichtlichen Zusammenhängen" müssen deshalb nicht gleich geregelt werden. BVerfGE 43, 13 (21); s.a. BVerfGE 40, 121 (139 f.) mwN.

98 Die Gleichstellung begann mit dem Gesetz zur Beendigung der Diskriminierung gleichgeschlechtlicher Gemeinschaften: Lebenspartnerschaftsgesetz vom 16.02.2001 
und verfassungsrechtlicher Interpretation neue Justierungen erfolgten. Dass dabei externe Faktoren (Rechtsvergleich, EU-Recht und EMRK) eine nicht unerhebliche Rolle spielten, wird noch aufzuzeigen sein. ${ }^{99}$

Bei Lebenspartnerschaften kann Art. 6 Abs. 1 GG nicht mehr als Differenzierungskriterium im Rahmen von Art. 3 Abs. 1 GG herangezogen werden. Ein Abstandsgebot besteht insoweit nicht (mehr). Aus dem Förderauftrag des Art. 6 Abs. 1 GG kann kein Gebot hergeleitet werden, die Ehe gegenüber anderen Lebensformen zu bevorzugen, wenn diese nach dem geregelten Lebenssachverhalt und den verfolgten Zielen der Ehe vergleichbar sind. ${ }^{100}$

Schon im Jahr 2002 begründete das Bundesverfassungsgericht die Vereinbarkeit des LPartG mit Art. 6 Abs. 1 GG damit, dass der Gesetzgeber auch Rechte und Pflichten für eingetragene Lebenspartnerschaften festlegen darf, die denen der Ehe ,gleich oder nahe“ kommen. ${ }^{101}$ Die eingetragene Lebenspartnerschaft wurde als aliud zur Ehe angesehen, das Institut der Ehe und die in ihm enthaltenen Strukturprinzipien waren demnach nicht betroffen. ${ }^{102}$ Lebenspartnerschaft war nicht Ehe ,unter

(BGB1. I 266), in Kraft seit 01.08.2001 und dem Gesetz zur Überarbeitung des Lebenspartnerschaftsrechts vom 15.12.2004 (BGBl. I 3396), in Kraft seit 01.01.2005. Vgl. dazu schon BVerfGE 105, 313 (342 ff.) und BVerfGE 124, 199 (217 ff.).

99 Zum Spannungsfeld von Konstanz und Entwicklung im Verfassungsrecht und im Zusammenspiel mit dem EGMR s.a. A. Nußberger RS 2012, 197 (198 f.).

100 BVerfGE 124, 199 ff. In zwei Kammerentscheidungen des zweiten Senats war dies zuvor anders gesehen worden. Danach war die Versagung des Verheiratetenzuschlags bei eingetragenen Lebenspartnerschaften verfassungsrechtlich nicht $\mathrm{zu}$ beanstanden. BVerfG, Beschl. v. 20.09.2007, 2 BvR 855/06 und v. 06.05.2008, 2 BvR 1830/06. Mittlerweile hat sich aber der 2. Senat der Rspr. des 1. Senats angeschlossen. BVerfG, Beschl. v. 19.06.2012, 2 BvR 1397/09, NVwZ 2012, 1304 ff.; zustimmend N. Dethloff NJW Editorial, Heft 37, 2012; vgl. auch R. Bömelburg NJW 2012, 2753 (2758); kritisch G. Krings NVwZ 2011, $26 \mathrm{f}$.

101 BVerfGE 105, 313 ff. Kritisch zur Ablehnung des Betroffenseins der Institutsgarantie die abweichenden Voten des Richters Papier und der Richterin Haas, BVerfGE 105, 313 (357 ff.). Dies wurde so gedeutet, dass damit die Existenz eines Abstandsgebots abgelehnt wurde, s. etwa G. D. Gade/Ch. Thiele DÖV 2013, 142 (149); BVerfGE 124, 199 (226). Zum Abstandsgebot siehe nur Stern Staatsrecht (Fn. 11), 488 ff. und Ipsen HStR (Fn. 23), § 154 Rn. 55.

102 BVerfGE 105, 313 (350 f.). Die Förderpflicht des Staates hat sich danach am Schutzzweck des Art. 6 Abs. 1 GG auszurichten. Trüge der Gesetzgeber selbst durch Normsetzung dazu bei, dass die Ehe ihre Funktion einbüßte, würde er das Fördergebot aus Art. 6 Abs. 1 GG verletzen. Eine solche Gefahr könnte bestehen, wenn der Gesetzgeber in Konkurrenz zur Ehe ein anderes Institut mit derselben Funktion schüfe und es etwa mit gleichen Rechten und geringeren Pflichten versähe, so dass beide Institute austauschbar wären. Eine derartige Austauschbarkeit ist mit der Schaffung der eingetragenen Lebenspartnerschaft jedoch nicht verbunden. Sie kann mit der Ehe schon des- 
falschem Etikett“", die Auseinandersetzung wurde auf diese Weise entemotionalisiert. ${ }^{103}$

In der Sache aber war vorgezeichnet, dass der bloße Verweis auf die Ehe die Benachteiligung der Lebenspartnerschaft nicht rechtfertigen kann. ${ }^{104}$ Auch in der Entscheidung des Bundesverfassungsgerichts zur Hinterbliebenenrente wurde festgestellt, dass Ungleichbehandlungen von Ehe und eingetragener Lebenspartnerschaft am Maßstab des Art. 3 Abs. $1 \mathrm{GG}$ zu messen sind. ${ }^{105}$ Differenzierungen sind nur unter strengen Voraussetzungen zulässig. Werden gleichgeschlechtliche Lebenspartner gegenüber Ehegatten benachteiligt, ist von einer Ungleichbehandlung auf Grund der sexuellen Orientierung auszugehen. Wegen der besonderen Nähe zu Art. 3 Abs. 3 GG ist bei der Prüfung ein besonders enger Maßstab anzuwenden. ${ }^{106}$ Ebenso wurde, wie bereits erwähnt, bei der Sukzessivadoption entschieden und auch in der jüngsten Entscheidung des Bundesverfassungsgerichts zum Ehegattensplitting. ${ }^{107}$

Den Ausschluss von nichtehelichen Lebensgemeinschaften bei der Kostenübernahme für künstliche Befruchtungen sah das Bundesverfassungs-

halb nicht in Konkurrenz treten, weil der Adressatenkreis, an den sich das Institut richtet, nicht den der Ehe berührt. Die eingetragene Lebenspartnerschaft ist wegen dieses Unterschieds auch keine Ehe mit falschem Etikett, wie dies in beiden Minderheitenvoten angenommen wird, sondern ein aliud zur Ehe.

103 Wahl FS Frank (Fn. 10), 31 (50).

104 BVerfG, Urt. v. 07.05.2013, 2 BvR 909/06 u.a., insbes. Rn. 84 ff., NJW 2013, 2257 (2259 ff.) mwN. Von der Senatsmehrheit gilt dies bereits seit ihrer Einführung 2001, s. insbes. Rn. 91 ff. Die damals noch bestehenden Unterschiede wurden als unerheblich angesehen. Wenn der Gesetzgeber Lebenspartnerschaft und Ehe in vergleichbarer Weise als umfassende institutionalisierte Verantwortungsgemeinschaft verbindlich gefasst habe, müsse er sich daran auch festhalten lassen. Das Splittingverfahren mit seinem Grundgedanken der Ehe als Gemeinschaft des Erwerbs und Verbrauchs müsse deshalb auch für Lebenspartnerschaften gelten und dies auch rückwirkend. In einer kritischen abweichenden Meinung des Richters Landau und der Richterin Kessal-Wulf wurden die Voraussetzungen erst mit der Reform im Jahr 2005 als erfüllt angesehen, eine Rückwirkung des Urteils wurde abgelehnt, s. insbes. Rn. $116 \mathrm{ff}$.

105 BVerfGE 124, 199 (218); hierzu auch W. Frenz NVwZ 2013, 1200 (1201 f.).

106 BVerfGE 124, 199 (220 f.); s. ebenso BVerfGE 126, 400 (419); vgl. auch BVerfG, Urt. v. 19.02.2013, 1 BvL 1/11 und 1 BvR 3247/09, Rn. 104 f., NJW 2013, 847 (855), mwN aus der Rspr. des BVerfG, s.a. BVerfGE 105, 313 (345 f. und 351 ff.); 107, 205, (215 ff.). Brosius-Gersdorf spricht insoweit von einem interinstitutionellen Diskriminierungsverbot, Brosius-Gersdorf Demografischer Wandel und Familienförderung (Fn. 66), 216 ff. mwN.

${ }_{107}$ BVerfG, Urt. v. 07.05.2013, 2 BvR 909/06 u.a., insbes. Rn. 72 ff., Rn. 78 ff., NJW 2013, 2257 (2258); das BVerfG ging dabei davon aus, dass jedenfalls mittelbar an die sexuelle Orientierung angeknüpft werde, weil der Splittingtarif an den Familienstand anknüpfe. 
gericht unter Bezugnahme auf die besondere rechtliche Verfasstheit der Ehe dagegen als sachlich gerechtfertigt an. ${ }^{108}$

\section{Wahlfreiheit}

\section{a. Eingriffsabwehr und Fördergebot}

Das Ehe- und Familiengrundrecht beinhaltet sowohl die Gründungsals auch die Gestaltungsfreiheit. ${ }^{109}$ Umfasst ist davon der Schutz vor Eingriffen durch den Staat. ${ }^{110}$ Abgeleitet wird aus Art. 6 Abs. 1 GG sowie dem Sozialstaatsprinzip aber auch ein Fördergebot des Staates. ${ }^{111}$ Von Bedeutung ist dies insbesondere im Hinblick auf die Vereinbarkeit von Familie und Beruf. ${ }^{112}$ Förderung der Wahlfreiheit in diesem Sinne ist in

108 BVerfGE 117, 316 (325 ff.).

109 Dazu nur Brosius-Gersdorf in: Dreier (Fn. 11), Art. 6 Rn. 115 ff. mwN.

110 S. etwa BVerfGE 6, 55 (71); 80, 81 (92); 103, 242 (257); 107, 27 (53). Gewährt wird aber auch der Schutz vor Eingriffen Privater. Die Eheschließungsfreiheit darf nicht unzulässig durch Verträge eingeschränkt werden. Vgl. BVerfGE 15, 328 (335) und BVerfG, Beschl. v. 22.03.2004, 1 BvR 2248/01, Rn. 39 ff., NJW 2004, 2008 (2010 f.) zum Erbverlust wegen Ebenbürtigkeitsklausel. S.a. BVerfGE 103, 89 (101 ff.). Vgl. außerdem A. Röthel in: dies./Heiderhoff (Fn. 73), 17 (32) mwN und Baer ebd., 35 (42 f.). Eine Zwangsverheiratung ist unzulässig, $F$. Edinger StAZ 2012, 194 ff.

111 Vgl. BVerfGE 82, 60 (85 ff.); 99, 216 (233); 107, 205 (213); aus der Lit. Badura in: Maunz/Dürig (Fn. 24), Art. 6 Rn. 62; Brosius-Gersdorf in: Dreier (Fn. 11), Art. 6 Rn. 129. Steiger hat dies in seinem Referat Verfassungsgarantie und sozialer Wandel Das Beispiel Ehe und Familie, kritisch hinterfragt, VVDStRL 45 (1987), 55 (84 ff.); zum Fördergebot s.a. Kokott FS 50 Jahre BVerfG (Fn. 89), 127 (137 f.); Ipsen HStR (Fn. 23), $\S 154$ Rn. 86, $109 \mathrm{f}$.

112 Eltern muss es danach gleichermaßen möglich sein, ,teilweise und zeitweise auf eine eigene Erwerbstätigkeit zugunsten der persönlichen Betreuung ihrer Kinder zu verzichten wie auch Familientätigkeit und Erwerbstätigkeit miteinander zu verbinden. Der Staat muss die Voraussetzungen dafür schaffen, dass die Wahrnehmung der familiären Erziehungsaufgabe nicht zu beruflichen Nachteilen führt, dass eine Rückkehr in eine Berufstätigkeit ebenso wie ein Nebeneinander von Erziehung und Erwerbstätigkeit für beide Elternteile einschließlich eines beruflichen Aufstiegs während und nach Zeiten der Kindererziehung ermöglicht und dass die Angebote der institutionellen Kinderbetreuung verbessert werden“, BVerfGE 99, 216 (234). Zur Wahlfreiheit vgl. auch den Ersten Gleichstellungsbericht (Fn. 66), 76 ff.; Badura in: Maunz/Dürig (Fn. 24), Art. 6 Rn. 85; Brosius-Gersdorf in: Dreier (Fn. 11), Art. 6 Rn. 137 ff.; aus der Rspr. des BVerfG s. etwa BVerfGE 97, 332 (340 ff.); 99, 216 (230 ff.); BVerfG Nichtannahmebeschl. v. 09.11.2011, 1 BvR 1853/11, Rn. 7 ff., NJW 2012, 214 (214 ff.); BVerfG, Nichtannahmebeschl. v. 26.10.2011, 1 BvR 2075/11, Rn 4 ff., NJW 2012, 216 (216 f.). Zur Notwendigkeit eines familienfreundlichen Arbeitsrechts s. M. Roth RdA 2012, 1 (13) und ders. zur Drittwirkung der Grundrechte im Arbeitsrecht, in: A. Baumbach/K. J. Hopt (Hrsg.) Handelsgesetzbuch, 35. Aufl. 2012, §59 Rn. 3. 
weiten Teilen monetäre Förderung durch direkte und indirekte finanzielle Zuwendungen oder Erleichterungen. Daneben ist damit aber auch die strukturelle Förderung etwa durch Kinderbetreuungseinrichtungen angesprochen.

Das Bundesfamilienministerium hat in einer Bestandsaufnahme der staatlichen ehe- und familienbezogenen Leistungen 148 familienbezogene Maßnahmen mit einem finanziellen Gesamtvolumen von 125,5 Mrd. Euro aufgelistet. ${ }^{113}$ Werden die ehebezogenen Maßnahmen dazugerechnet, wurden 2010 über $200 \mathrm{Mrd}$. Euro für diesen Bereich eingesetzt. Darunter fallen u.a. auch Kinder- und Elterngeld, der Familienlastenausgleich, Kinderfreibeträge, die Steuerfreistellung des Existenzminimums von Kindern sowie Beiträge des Bundes für Kindererziehungszeiten an die gesetzliche Rentenversicherung. ${ }^{114}$ Ein erheblicher Teil dieser Posten mit einem Gesamtvolumen von fast $60 \mathrm{Mrd}$. Euro ist allerdings verfassungsrechtlich zwingend geboten. ${ }^{115} \mathrm{Er}$ sollte deshalb nicht als Leistung, sondern als Ausgleich bezeichnet werden.

Die einzelnen Instrumente stellen kein in sich geschlossenes System dar. Die Förderziele sind vielgestaltig, die Fördereignung ist in weiten Teilen umstritten. Dies haben gerade auch die die Veröffentlichung des Berichts begleitenden Diskussionen gezeigt. ${ }^{116}$

\section{b. Verfassungsrechtliche Vorgaben für finanzielle staatliche Leistungen}

Grundsätzlich kommt dem Staat eine weite Gestaltungsfreiheit sowohl bei der Schaffung von Ausgleichsregelungen von kindbezogenen Lasten (Familienlastenausgleich) als auch bei der Förderung von Familienleistungen (Familienleistungsausgleich) zu. ${ }^{117}$ Grenze ist Art. 3 GG, ${ }^{118}$ der Vorgaben für Typisierungsmaßstäbe setzt. ${ }^{119}$

113 Bundesministerium für Familie, Senioren, Frauen und Jugend Gesamtevaluation der ehe- und familienbezogene Leistungen (Fn. 15), 4.

114 Dazu kommen Fördermaßnahmen der Länder, z.B. nach dem BayLandeserziehungsgeldgesetz, s. dazu BVerfGE 130 (240 ff.).

$115 \mathrm{~S}$. insbes. BVerfGE 82, $60 \mathrm{ff}$; 87, $153 \mathrm{ff}$; 99, $246 \mathrm{ff}$.

116 Hierzu s. nur Zukunftsforum Familie e.V. Sonder-Info zur Gesamtevaluation eheund familienbezogener Leistungen 21.06.2013, http://zukunftsforum-familie.de/_data/ Sonder-Info_Gesamtevaluation.pdf (zuletzt abgerufen am 17.09.2013).

117 Brosius-Gersdorf in: Dreier (Fn. 11), Art. 6 Rn. $130 \mathrm{mwN}$; ein Vergleich zum Familienlastenausgleich in Frankreich findet sich bei J. Borchert Sozialstaatsdämmerung, 2013, $107 \mathrm{ff}$.

118 Brosius-Gersdorf unterscheidet insoweit zwischen einem interinstitutionellen und einem intrainstitutionellem Diskriminierungsverbot, Brosius-Gersdorf in: Dreier (Fn. 11), Art. 6 Rn. 133 f., ausführlich dies. Demografischer Wandel und Familienförderung (Fn. 66), 216 ff. und 220 ff. Da die Gewährung des Steuersplittings nicht an 
Aus dem Willkürverbot wird außerdem der Grundsatz der Folgerichtigkeit gesetzlicher Regelungen abgeleitet. ${ }^{120}$ Dies heißt aber nicht, dass alle Ehe und Familie betreffenden Regelungen ein einheitliches Konzept verfolgen müssen. Insbesondere ein in sich konsistentes Ehe- und Familiensteuerrecht zu schaffen, wäre keine ganz einfache Aufgabe, vor allem wenn man auch das Ehegatten- und Unterhaltsrecht einbeziehen würde. ${ }^{121}$

Fraglich erscheint aber, ob der Staat tatsächlich jegliche selbstgewählte Form der Ausgestaltung von Ehe und Familie nicht nur zu respektieren, sondern auch finanziell zu unterstützen hat. Im Jahre 1998 ist das Bundesverfassungsgericht noch davon ausgegangen, dass sich die Förderpflicht jedenfalls auf jede von den Eltern gewählte Form der Kinderbetreuung bezieht und damit grundsätzlich auch die rein häusliche Kinderbetreuung bei Verzicht auf die Berufstätigkeit eines Ehepartners einschließt. ${ }^{122}$ Aus der Perspektive des Art. 3 Abs. 2 GG wird es dagegen mehr und mehr als bedenklich angesehen, wenn der Staat Anreize gegen eine gleichzeitige Berufstätigkeit beider Ehepartner setzt. Das kürzlich eingeführte Betreuungsgeld steht insoweit in der Kritik. ${ }^{123}$ Auch gibt es

einen kindbedingten Bedarf von Ehepaaren anknüpft, wurde die Ungleichbehandlung von Ehen und eingetragenen Lebenspartnerschaften vom BVerfG in seiner Entscheidung zum Ehegattensplitting nicht als durch familienpolitische Intentionen rechtfertigbar angesehen. Das Splittingverfahren sollte zwar ursprünglich eine „besondere Anerkennung der Aufgabe der Ehefrau als Hausfrau und Mutter" bezwecken. Der Gedanke der Familienförderung rechtfertige aber keine Schlechterstellung von eingetragenen Lebenspartnerschaften im Vergleich zu Ehen. BVerfG, Urt. v. 07.05.2013, 2 BvR 909/0 u.a., insbes. Rn.100, NJW 2013, 2257 (2262) unter ausdrücklicher Bezugnahme auf BVerfG, Urt. v. 19.02.2013, 1 BvL 1/11 und 1 BvR 3247/09, Rn. 80, NJW 2013, 847 (852 f.).

119 BVerfG, Urt. v. 19.02.2013, 1 BvL 1/11 und 1 BvR 3247/09, Rn.101 ff., NJW 2013, 847 (855) zu den Maßstäben der Typisierung. Die Privilegierung der Ehe lässt sich danach nicht mit der grundsätzlichen Typisierungsbefugnis des Gesetzgebers im Steuerrecht begründen.

${ }^{120}$ S. nur BVerfGE 122, 210 ff. zur Pendlerpauschale; vgl. auch A. Leisner Kontinuität als Verfassungsprinzip, 2005, insbes. $233 \mathrm{f}$.

121 Ausführlich dazu N. Dethloff Unterhalt, Zugewinn, Versorgungsausgleich Sind unsere familienrechtlichen Ausgleichssysteme noch zeitgemäß?, Gutachten zum 67. Deutschen Juristentag, 2008, insbes. 46 ff.

122 BVerfGE 99, 216 (231 und 234).

123 J. Wieland Verfassungsfragen des Betreuungsgeldes, Rechtsgutachten für die Fraktion der SPD im Deutschen Bundestag, August 2012; F. Brosius-Gersdorf NJW 2013, $2316 \mathrm{ff}$., dies. sieht auch die beitragsfreie Mitversicherung von Ehegatten in der gesetzlichen Kranken- und Pflegeversicherung als verfassungswidrig an, im Jahr 2009 umfassten diese ein Gesamtvolumen von elf Milliarden Euro, vgl. Brosius-Gersdorf in: Dreier (Fn. 11), Art. 6 Rn. 96 mwN, und ausführlich zum verfassungsrechtlichen Reformbedarf bei der Familienförderung dies. Demografischer Wandel und Familienförderung 
Stimmen, die von einem Verstoß des Ehegattensplittings gegen Art. 3 Abs. 2 GG ausgehen. ${ }^{124}$ Das Bundesverfassungsgericht hat dies bislang nicht aufgegriffen, aber - und dies zu Recht - jedenfalls den Ausschluss eingetragener Lebenspartnerschaften vom Ehegattensplittung als verfassungswidrig angesehen. ${ }^{125}$ Verfassungsrechtlich geboten ist die derzeitige Ausgestaltung des Splittings damit aber nicht, zumindest Modifizierungen sind möglich. ${ }^{126}$

Rechtspolitisch ist das derzeitige Modell stark umstritten. Im Bericht des Familienministeriums wird positiv hervorgehoben, dass das Ehegattensplitting und die beitragsfreie Mitversicherung für Ehepartner in der gesetzlichen Krankenversicherung den finanziellen Druck zur Arbeitsaufnahme reduzieren. ${ }^{127}$ Nicht nur, aber gerade auch die Neuregelung des nachehelichen Unterhalts mit einer faktisch weitgehenden Verpflichtung zur eigenverantwortlichen Unterhaltssicherung lassen derartige Anreize angesichts der Höhe der Scheidungsquote allerdings als äußerst risikoreich erscheinen. ${ }^{128}$ Betroffen davon sind auch weiterhin vor allem Ehefrauen, die ihren Schwerpunkt in der Familie sehen und zumindest vorübergehend lediglich in Teilzeit oder gar nicht berufstätig sind. ${ }^{129}$ Das Ehegattensplitting wird von vielen als Karrierebremse für Frauen angese-

(Fn. 66), 513 ff.; zum Betreuungsgeld außerdem M. Schuler-Harms „Verfassungsrechtlich prekär“: Expertise zur Einführung eines Betreuungsgeldes, 2010, http://library.fes. de/pdf-files/do/07492.pdf (zuletzt abgerufen am 17.09.2013); zum Elterngeld s. C. Fuchsloch FS Pfarr, 2010, $378 \mathrm{ff}$.

124 U. Sacksofsky NJW 2000, 1896 ff.; s.a. dies. in: B. Seel (Hrsg.) Ehegattensplitting und Familienpolitik, 2007, 333 ff.; verfassungsrechtliche Bedenken äußert auch Dethloff in: Zypries (Fn. 77), 132 (139 f.); s.a. M. Jachmann Der Betrieb 5/2010, 1.

125 BVerfG, Beschl. v. 07.05.2013, 2 BvR 909/06 u.a. insbes. Rn. 82, NJW 2013, 2257 (2259). Auch die „Alleinverdienerehe“ ist danach unter den Schutz des Art. 6 Abs. 1 GG gestellt.

126 Dethloff in: Zypries (Fn. 77), 132 (138 f.); M. Schuler-Harms FPR 2012, 297 (299); aA P. Kirchhof NJW 2000, 2792 (2793 f.), der ein Familiensplitting nur als zusätzliche Option ansieht; s.a. ders. ZRP 2003, 73 ff.; kritisch C. Hillgruber JZ 2013, 843 ff.

127 Bundesministerium für Familie, Senioren, Frauen und Jugend Gesamtevaluation der ehe- und familienbezogene Leistungen (Fn. 15), 10.

${ }_{128}$ Durch die Reform des Unterhaltsrechts zum 01.01.2008, BGBl. 2007 I 3189, wurde insbes. der Grundsatz der wirtschaftlichen Eigenverantwortung der Ehegatten nach der Scheidung gestärkt, die Voraussetzungen für einen Unterhaltsanspruch wegen Bedürftigkeit wurden verschärft, zur Reform W. Born NJW 2008, 1 ff.; s.a. C. D. Classen DVBl. 2013, 1086 (1087 f.); kritisch dazu auch der Erste Gleichstellungsbericht (Fn. 66), 75 ff. mwN. Kritisch zur Neuregelung B. Heiderhoff in: Röthel/Heiderhoff (Fn. 73), 9 ff., 14.

129 S. nur C. D. Classen DVB1. 2013, 1086 (1088). 
hen. ${ }^{130}$ Schwerer wiegt allerdings schlicht das Armutsrisiko nach dem Scheitern einer Ehe und dies durchaus für beide Ehepartner. ${ }^{131}$

Bei der Ausgestaltung finanzieller staatlicher Leistungen ist stärker auf den Kernbereich des Schutzes des Art. 6 Abs. 1 GG abzustellen. Der private Rückzugsbereich, den Ehe und Familie darstellen, ist vor allem vor Eingriffen zu schützen. Bei der finanziellen Förderung spielt er dagegen keine vergleichbare Rolle. Hervor zu heben ist dagegen die Reproduktionsfunktion.

Auf dieser Grundlage spricht vieles für eine stärkere Orientierung der Besteuerung an den vorhandenen Kindern. ${ }^{132}$ Steuerlich freigestellt werden muss zumindest das Existenzminimum des Kindesbedarfs. ${ }^{133} \mathrm{Zu}$ Recht wird aber vor dem Hintergrund des Art. 6 Abs. 1 GG gefordert, weitere unvermeidbare wirtschaftliche Belastungen steuerlich zu berücksichtigen. ${ }^{134}$ Gesellschafts- und gleichstellungspolitisch bedenklich erscheint es, dass Fahrtkosten ${ }^{135}$ in größerem Umfang als Betreuungsaufwendungen ${ }^{136}$ steuerlich absetzbar sind.

130 C. D. Classen DVB1. 2013, 1086 (1088 f.). Zum Neutralitätsgebot aus Art. 6 GG Brosius-Gersdorf in: Dreier (Fn. 11), Art. 6 Rn. 137 mwN; vgl. außerdem S. Huster Die ethische Neutralität des Staates, 2002, 533; umfassend zur Thematik C. Maurer Verfassungsrechtliche Anforderungen an die Besteuerung von Ehegatten und Familien: eine Prüfung der Familienförderungsgesetzgebung und ihrer Konsequenzen, 2004.

131 Bundesministerium für Arbeit und Soziales Lebenslagen in Deutschland (Fn. 21), XXIX.

132 Für die Einführung eines Familienrealsplittings Dethloff in: Zypries (Fn. 77), 132 (138 ff.), s.a. dies. NJW 37/2012 Editorial; kritisch zu Familienreal- und -divisorensplitting M. Jachmann/K. Liebl DStR 2010, 2009 (2012); M. Schuler-Harms FPR 2012, 297 (300 f.); aus der älteren Lit. s. K. Vogel StuW 1999, 201 ff. und H. Söhn FS Vogel, 2000, $639 \mathrm{ff}$.

133 S. insbes. BVerfGE 82, 60 ff.; 87, 153 ff.; 99, $246 \mathrm{ff}$.

134 Dethloff in: Zypries (Fn. 77), 132 (138). Vgl. außerdem J. Wieland Verfassungsfragen der steuerrechtlichen Behandlung von Kindesexistenzminimum und Betreuungs-, Erziehungs- und Ausbildungsbedarf, 2011. Für eine Berücksichtigung jedenfalls des erwerbsbedingten Betreuungsaufwands sprechen sich u.a. Jachmann/Liebl DStR 2010, 2009 (2011) aus; s.a. U. Sacksofsky FR 2010, 119 (122); außerdem Schuler-Harms FPR 2012, 297 (299 f.); Sanders NJW 2013, 2236 (2238).

135 S. nur BVerfGE 122, 210 ff. zur Pendlerpauschale.

136 Nach BVerfGE 47, 1 ff. haben berufstätige Ehegatten jedenfalls keinen verfassungsrechtlichen Anspruch darauf, dass Betreuungsaufwendungen durch Hausgehilfen Betriebsausgaben oder Werbungskosten gleichgestellt werden, dagegen schon das Sondervotum des Verfassungsrichters Simon, BVerfGE 47, 1 (34 ff., insbes. 45 f.). Ob in der Praxis tatsächlich die Wahlfreiheit angemessen unterstützt wird, erscheint fraglich. Eine auch monetär ausgeglichene Aufgabenverteilung stellt insbes. die Eltern kleiner Kinder vor Herausforderungen. Eine qualitativ hochwertige Kinderbetreuung ist teuer, wenn sie denn überhaupt verfügbar ist. Realitätsgerechte steuerliche Absatzmöglichkeiten 
Auch ohne Kinder umfasst die Ehe allerdings die gegenseitige Sorge und Solidarität der Ehepartner. ${ }^{137}$ Der Staat macht sich dies zu Nutze, indem er entsprechende Unterhaltspflichten festschreibt. ${ }^{138}$ Die Ehe ist nicht nur Erwerbs-, sondern gerade auch Unterhaltsgemeinschaft. Dies ist im Rahmen des Steuerrechts zu berücksichtigen. Ob sich bei Abschaffung des Ehegattensplittings finanziell im Ergebnis große Änderungen ergeben würden, ist deshalb zweifelhaft. ${ }^{139}$ Außerdem sollte darüber nachgedacht werden, nichteheliche Lebensgemeinschaften im Gegenzug zu ihrer Heranziehung im Sozialrecht auch in das Splitting aufzunehmen. ${ }^{140}$

\section{Zwischenfazit}

Bislang wurde die Grundrechtsdogmatik im Wesentlichen aus nationaler Sicht behandelt. Als roter Faden hat sich dabei herauskristallisiert, dass sich die Grundstrukturen der Dogmatik von Art. 6 GG bereits in den Anfangsjahren der Bundesrepublik Deutschland herausgebildet haben. Sie sind bis heute relativ stabil. Innerhalb dieses Rahmens aber hat eine erhebliche Entwicklung stattgefunden. Externe Dynamisierungsfaktoren haben dabei eine wichtige Rolle gespielt.

\footnotetext{
bestehen nur in begrenztem Rahmen. Von der Politik wird zwar der Eindruck erweckt, dass hier immer mehr getan wird. Halbwegs realistische Absetzoptionen wurden allerdings um die Jahrtausendwende abgeschafft. Verkauft wurde dies unter dem Ressentiments schürenden Begriff des „Dienstmädchenprivilegs“, s. D. Felix NJW 2001, 3073 (3074); C. Hölzer NJW 2008, 2145 (2149). Betroffen waren allerdings weniger hochherrschaftliche Haushalte als vielmehr die breite Masse berufstätiger Eltern. Für die Absetzbarkeit auch Dethloff in: Zypries (Fn. 77), 132 (138); s.a. Erster Gleichstellungsbericht (Fn. 66), 81; R. Ahmann NJW 2002, 633 ff.; J. Hey NJW 2006, 2001 ff.; Hölzer NJW 2008, 2145 ff.; M. Jachmann/K. Liebl DStR 2010, 2009 (2011); U. Sacksofsky FS Pfarr (Fn. 123), $363 \mathrm{ff}$.

137 S. nur BVerfGE 117, 316 (327).

138 Dazu auch BVerfG, Urt. v. 07.05.2013, 2 BvR 909/0 u.a., Rn. 83, NJW 2013, 2257 (2259).

139 Vgl. dazu Söhn FS Vogel (Fn. 132), 639 ff.; K. Vogel StuW 1999, 201 ff.

${ }^{140}$ Ein sozialrechtlicher Rückgriff wird jedenfalls als zulässig angesehen, vgl. nur BVerfG, Beschl. v. 21.06.2013, 1 BvR 1083/09, nach dem eine Verfassungsbeschwerde gegen Einkommensanrechnung des ,unechten Stiefvaters“ bei „Hartz IV-Leistungen“ nicht zur Entscheidung angenommen wurde. Im Gegensatz zu vielen anderen Staaten in Europa und weltweit fehlt es in Deutschland bislang an gesetzlichen Regelungen bei nicht formalisierten Lebensgemeinschaften, vgl. dazu nur $N$. Dethloff FS Frank (Fn. 10), 81 ff. und zu Defiziten des geltenden Rechts dies., Unterhalt, Zugewinn, Versorgungsausgleich (Fn. 121), $131 \mathrm{ff}$.
} 


\section{Externe Dynamisierungsfaktoren}

\section{Rechtsvergleich}

Nicht überall auf der Welt oder auch nur in Europa sind Ehe und Familie unter den Schutz der Verfassung gestellt. ${ }^{141}$ Aus der Sicht der Rechtsvergleichung sind gleichwohl die großen Entwicklungslinien im deutschen, europäischen und nordamerikanischen Familienrecht in weiten Teilen homogen verlaufen. ${ }^{142}$

Als Beispiel wird das eheliche Güterrecht genannt, das sich von der Gütertrennung zu verschiedenen Formen der Errungenschaftsgemeinschaft verschoben hat. ${ }^{143}$ Im Scheidungsrecht ist das Verschuldensprinzip

141 Vorschriften zum Schutz der Ehe und Familie finden sich außer in Art. 6 GG auch in den Verfassungen anderer Staaten, so etwa in Art. 21 Abs. 1 Verf. Griechenland, Art. 29 ff. Verf. Italien, Art. 41 f. Verf. Irland, Art. 67 f. Verf. Portugal und Art. 39 Verf. Spanien; in der Schweizer Verfassung findet sich eine Regelung insbes. in Art. 41. Über die Auslegung der Bundesverfassung und ihr Verhältnis zur EMRK G. Biaggini ZB1 114/2013, 316 ff. Keine Regelungen finden sich in Staaten wie Dänemark, Frankreich und den Niederlanden. Ausführlich zum verfassungsrechtlichen Schutz von Ehe und Familie insbes. in Europa, G. Bouverat Ehe und Familie in den Verfassungen Europas, 1989; s.a. Badura in: Maunz-Dürig (Fn. 24), Art. 6 Rn. 21; Brosius-Gersdorf in: Dreier (Fn. 11), Art. 6 Rn. 33; P. Häberle Verfassungsschutz der Familie - Familienpolitik im Verfassungsstaat, 1984, 19 ff.; speziell zum Elternrecht M. Jestaedt in: Bonner Kommentar GG, 75. Erg.-Lfg. Dezember 1995, Art. 6 Abs. 2 und 3 Rn. 384 ff. Ein Überblick über die Entwicklungen in Österreich und der Schweiz bis 1986 findet sich bei W. Berka und D. Thürer Verfassungsgarantie und sozialer Wandel (Fn. 91), 94 ff. und $100 \mathrm{ff}$.

142 Frank in: 40 Jahre Grundgesetz (Fn. 62), 113 (114 ff.); differenzierter M. V. Antokolskaia in: dies. (Hrsg.) Convergence and Divergence of Family Law in Europe, 2007, 11 ff.; s.a. Berka Verfassungsgarantie und sozialer Wandel (Fn. 91), 94 (95); allgemein zur Rechtsvergleichung K.-P. Sommermann Handbuch der Grundrechte I, 2004, § 16; zur Rechtsvergleichung im Familienrecht Gernhuber/Coester-Waltjen Familienrecht (Fn. 11), § 2 I.

143 Ein Überblick über die Entwicklung des Güterrechts findet sich bei $P$. Mankowski in: J. v. Staudinger (Hrsg.) BGB, Internationales Eherecht, 2011, Art. 15 EGBGB Rn. 236 ff.; zum Güterrecht in europäischen Staaten s.a. B. Braat in: Antokolskaia (Fn. 142), 145 ff.; Süß/Ring (Hrsg.) Eherecht in Europa, 2006; s.a. die Beiträge bei Heinrich/Schwab (Hrsg.) Eheliche Gütergemeinschaft, Partnerschaft und Vermögen im europäischen Vergleich. Beiträge zum europäischen Familienrecht, 1999. Zur Familienrechtsreform in Frankreich C. Steindorff-Classen FuR 2010, 319 ff.; zum Güterrecht im sozialistischen System $A$. Wirsing Das eheliche Güterrecht der DDR - Teil einer sozialistischen Gesetzgebung, 1973; zur Regelung der Paarbeziehungen im neuen spanischen Familienrecht, C. G. Beifuss in: Röthel/Heiderhoff (Fn. 73), 89 ff.; für die ältere Entwicklung in Italien s. G. Gabrielli ZfRV 1979, 172 ff. Als singulär ist dagegen der bis 1953 in Deutschland geltende, dann gleichberechtigungswidrige gesetzliche Güterstand der Nutzverwaltung des Mannes am Vermögen seiner Frau anzusehen, Frank in: 
international durch das Zerrüttungsprinzip abgelöst worden. ${ }^{144}$ Beobachten ließ sich außerdem eine Entwicklung von der elterlichen Gewalt zur elterlichen Sorge. ${ }^{145}$ Parallelen gab es beim Nichtehelichenrecht. ${ }^{146}$ In vielen Teilen der Welt wuchs die Bedeutung der Gleichberechtigung von Mann und Frau. ${ }^{147}$

Signifikant ist die Verschiebung des Fokus von der Ehe zur Familie, bei der wiederum mehr und mehr auf das Kriterium des tatsächlichen $\mathrm{Zu}$ -

40 Jahre Grundgesetz (Fn. 62), 113 (114 f.). Kritisch zum deutschen Zugewinnausgleich M. Wellenhofer in: Röthel/Heiderhoff (Fn. 73), 47 (59 ff.). Zur Arbeitsweise der Commission on European Family Law, K. Boele-Weolki in: Röthel/Heiderhoff (Fn. 73), $67 \mathrm{ff}$.

${ }^{144}$ Hierzu D. Henrich FS Ferid, 1978, 525 ff.; nur das Zerrüttungsprinzip für grundgesetzkonform hielt T. Ramm Grundgesetz und Eherecht, 1972, 22. Das BVerfG sah den Übergang vom Verschuldens- zum Zerrüttungsprinzip sowie Änderungen des Scheidungsfolgenrechts als verfassungsgemäß an. Ebenso den zur Überprüfung stehenden $\S 1568$ Abs. 2 BGB (zeitliche Begrenzung der Härtefallklausel), wenn auch in einer $4 \mathrm{zu}$ 4-Entscheidung, s. BVerfGE 53, 224 ff. Frank in: 40 Jahre Grundgesetz (Fn. 62), 113 (115), verweist insbes. auf das spanische Recht, nach dem die Ehescheidung erst wieder seit 1981 möglich war. Obwohl es dem traditionellen Denken dieser romanischen Rechtsordnung eher entsprochen hätte, auf das Schuldprinzip abzustellen, wurde dort unmittelbar das Zerrüttungsprinzip eingeführt. Ausführlich zur Entwicklung in Spanien D. Langner Eheschließung und Ehescheidung nach spanischem Recht, 1984, insbes. $111 \mathrm{ff}$. Zum Scheidungsrecht in europäischen Staaten s.a. Süß/Ring Eherecht in Europa (Fn. 143).

${ }^{145}$ So wurde auch in Großbritannien aus der parental power erst die parental authority und letztlich die parental responsibility. In Frankreich heißt es heute nicht mehr puissance paternelle, sondern autorité parentale. Hierzu R. Frank FamRZ 2004, 841 (846); ein umfassender Überblick über die Entwicklung in den europäischen Staaten findet sich bei Boele-Woelki/Braat/Curry-Summer (Hrsg.) European Family Law in Action, Vol. III, Parental Responsibilities, 2005, $77 \mathrm{ff}$.

146 Frank in: 40 Jahre Grundgesetz (Fn. 62), 113 (116 ff.) mwN, der dies u.a. am Bsp. der grundlegenden Reformen des Nichtehelichenrechts in den Jahren 1968-1975 sowohl in Westeuropa als auch in den USA belegt. In Deutschland wurde mit dem Nichtehelichengesetz von 1969 insbes. § 1589 BGB a.F., wonach ein uneheliches Kind und dessen Vater als nicht verwandt galten, abgeschafft. Zurück ging diese Gesetzesänderung auf eine Entscheidung des BVerfG, das mit Blick auf den Gleichstellungsauftrag des Art. 6 Abs. 5 GG die Legislative aufforderte, nichtehelichen Kindern die gleichen Entwicklungsbedingungen zu schaffen wie ehelichen Kindern, BVerfGE 25, 167 ff. Zur Entwicklung der Stellung nichtehelicher Kinder in europäischen Staaten Antokolskaia in: dies. (Fn. 142), 11 (19).

${ }^{147}$ Frank in: 40 Jahre Grundgesetz (Fn. 62), 113 (118 ff.), der auch belegt, wie wechselvoll diese Entwicklung zuweilen verlief. Vgl. dazu Art. 23 GR-Charta und die Präambel der Allgemeinen Erklärungen der Menschenrechte sowie die Diskriminierungsverbote in Art. 23 GR-Charta, Art. 14 EMRK und Art. 2 Allgemeinen Erklärungen der Menschenrechte. 
sammenlebens abgestellt wird. ${ }^{148}$ Die Anerkennung eheähnlicher Lebensgemeinschaften kann insoweit als Beispiel genannt werden. ${ }^{149}$

Rechtsvergleichende Einflüsse lassen sich auch in der Rechtsprechung des Bundesverfassungsgerichts nachweisen. In seiner Entscheidung zur Sukzessivadoption etwa hat das Gericht darauf verwiesen, dass auch die Gesetzgebung in anderen europäischen Staaten, insbesondere in den Mitgliedstaaten der EU, zu einer Gleichbehandlung verschieden- und gleichgeschlechtlicher Paare tendiere. ${ }^{150}$

Mittlerweile können homosexuelle Paare in einigen Staaten sogar eine Ehe eingehen. ${ }^{151}$ Etwa in den Niederlanden, Belgien und einigen US-Bun-

148 Aber nur wenige Rechtsordnungen räumen dem biologischen Vater eines in eine Ehe hineingeborenen Kindes ein Anfechtungsrecht ein, R. Frank FamRZ 2004, 841 (841 und 844). In Deutschland sprach das BVerfG dem leiblichen Vater ein solches Recht mit Verweis auf sein natürliches Elternrecht, Art. 6 Abs. 2 S. 1 GG, zu, sofern dem nicht der Schutz der familiären Beziehung zwischen dem Kind und seinen rechtlichen Eltern entgegen steht. Außerdem bilde auch der leibliche Vater mit seinem Kind eine von Art. 6 Abs. 1 GG geschützte Familie, wenn zwischen ihnen eine soziale Beziehung derart besteht, dass der biologische Vater zumindest zeitweise tatsächlich Verantwortung für das Kind trug, BVerfG 108, 82 ff.; hierzu Badura in: Maunz-Dürig (Fn. 24), Art. 6 Rn. 61 und 101.

149 Antokolskaia in: dies. (Fn. 142), 11 (17); Frank in: 40 Jahre Grundgesetz (Fn. 62), 113, $115 \mathrm{mwN}$; zu heutigen Lebensgemeinschaften s.a. Gernhuber/Coester-Waltjen Familienrecht (Fn. 11), §41-§44.

150 BVerfG, Urt. v. 19.02.2013, 1 BvL 1/11 und 1 BvR 3247/09, Rn. 56, NJW 2013, 847 (850). So seien etwa gemeinsame Adoptionen durch gleichgeschlechtliche Paare wie auch die Sukzessivadoption derzeit in Belgien, Dänemark, Island, den Niederlanden, Norwegen, Schweden, Spanien und dem Vereinigten Königreich zulässig. Zu den Adoptionsmöglichkeiten homosexueller Paare in europäischen Staaten s.a. I. Schwenzer in: Antokolskaia (Fn. 142), 145 (150 ff.). Ausführliche Länderberichte finden sich bei Basedow/Hopt/Kötz/Dopffel (Hrsg.) Die Rechtsstellung gleichgeschlechtlicher Lebensgemeinschaften, 2000.

${ }^{151}$ Ein Schaubild über die rechtliche Anerkennung gleichgeschlechtlicher Paare weltweit findet sich in Forced Migration Review 42/2013, 32 f.; s.a. die Übersicht bei Mankowski in: Staudinger (Fn. 143), Art. 17b EGBGB Rn. 9 ff.; s. außerdem Badura in: Maunz/Dürig (Fn. 24), Art. 6 Rn. 57; Brosius-Gersdorf in: Dreier (Fn. 11), Art. 6, Rn. 81; E. M. Hohnerlein RdJB 2011, 450 (453 f.); Schwenzer in: Antokolskaia (Fn. 150), 145 ff. In anderen Ländern, wie in Deutschland, Österreich und der Schweiz mit dem Institut der eingetragenen Lebenspartnerschaft, stehen gleichgeschlechtlichen Paaren eheähnliche Rechtsinstrumente zur Verfügung. Zur eingetragenen Lebenspartnerschaft etwa D. Schwab Familienrecht, 20. Aufl. 2012, 459 ff. Rn. 999 ff.; kritisch zur Angleichung von Ehe und eingetragener Lebenspartnerschaft v. Coelln in: Sachs (Fn. 75), Art. 6 Rn. 48 ff.; zum Eingetragene Partnerschaft-Gesetz in Österreich J. Scherpe FPR 2010, 211 ff. In Russland trat dagegen am 30.06.2013 ein Gesetz gegen „Propaganda nicht-traditioneller sexueller Beziehungen“ in Kraft. Dies hat insbes. im Zusammenhang mit in Russland stattfindenden internationalen Sportwettkämpfen weltweit zu Diskussionen geführt. 
desstaaten ${ }^{152}$ ist dies schon länger der Fall. In Frankreich trat im Mai ein entsprechendes Gesetz in Kraft, abgesegnet durch eine Entscheidung des Conseil Constitutionnel. ${ }^{153}$ Schon im letzten Jahr bestätigte das spanische Verfassungsgericht ein Gesetz über die gleichgeschlechtliche Ehe. ${ }^{154}$ Rechtsvergleichend gesehen zeichnet sich damit auch beim Begriff der Ehe ein Auffassungswandel ab.

Die deutsche Verfassungsdogmatik wird außerdem vom EU-Recht und der EMRK beeinflusst. ${ }^{155}$

\section{Recht der Europäischen Union}

Unmittelbare Kompetenzen der EU für das Ehe- und Familienrecht bestehen nicht. ${ }^{156}$ Ehe- und familienbezogene Regelungen gibt es aber zur Bewältigung der Freizügigkeit. ${ }^{157}$ Jedenfalls bei der Ausführung von EU-

${ }^{152}$ In den USA ist die rechtliche Anerkennung homosexueller Paare vor allem auf Bundesstaatenebene geregelt. Aber jüngst erklärte das oberste US-amerikanische Gericht, der Supreme Court, den Defense of Marriage Act (kurz DOMA), der die Ehe als Bund zwischen Mann und Frau definierte und in der Folge gleichgeschlechtlichen Ehepartnern mit der traditionellen Hetero-Ehe einhergehende juristische, finanzielle und soziale Vorteile verweigerte, für unvereinbar mit dem Gleichheitsgebot des Fifth Amendment to the United States Constitution und damit verfassungswidrig, Supreme Court, United States v. Windsor, executor of the Estate of Spyer, et al., 12-307, June 26, 2013. Am selben Tag kippte der Supreme Court eine kalifornische Norm, welche die Ehe zwischen gleichgeschlechtlichen Partnern verbot, Supreme Court, Hollingsworth et al. v. Perry et al., 12-144, June 26, 2013.

${ }^{153}$ Siehe LOI ${ }^{\circ}$ 2013-404 du 17 mai 2013 ouvrant le mariage aux couples de personnes de même sexe und die Entscheidung des Conseil Constitutionnel 2013-699 DC vom 17.05.2013. Eine deutsche Übersetzung des Urteils ist abrufbar unter http://www. conseil-constitutionnel.fr/conseil-constitutionnel/deutsch/entscheidungen/ entscheidung-nr-2013-669-dc-vom-17-mai-2013.137559.html.

${ }_{154}$ Am 05.11.2012 erklärte das spanische Verfassungsgericht ein 2005 von der sozialistischen Regierung eingeführtes Gesetz, das die Ehe zwischen Homosexuellen gestattete, für verfassungsgemäß. Eine englische Übersetzung des Urteils ist abrufbar unter http://www.tribunalconstitucional.es/es/jurisprudencia/restrad/Paginas/JCC1982012en. aspx; s. hierzu auch S. Rixen JZ 2013, $871 \mathrm{ff}$.

${ }_{155}$ S. außerdem auf globaler Ebene Art. 23 Abs. 1 und 2 Internationaler Pakt über bürgerliche und politische Rechte und Art. 10 Abs. 1 Internationaler Pakt über wirtschaftliche, soziale und kulturelle Rechte.

${ }^{156}$ Gleichwohl ist ein erheblicher Einfluss festzustellen. Vgl. etwa zur Europäisierung des Namensrechts F. Lipp FS Frank (Fn. 10), 393 ff.; s.a. N. Lowe FS Frank (Fn. 10), 513 ff.; zur richterlichen Grundrechtsverantwortung in Europa s. U. Steiner FS Maurer (Fn. 39), 1005 ff.; s.a. J. Kokott/T. Henze FS Spindler, 2011, 279 ff.

${ }^{157}$ Als relativ weitreichend sei hier nur auf die Rspr. des EuGH verwiesen, wonach einer Drittstaatenangehörigen gestützt auf die Dienstleistungsfreiheit iVm Art. 8 EMRK ein Aufenthaltsrecht wegen Achtung des Familienlebens zuerkannt wurde, das 
Recht ist außerdem die EU-Grundrechte-Charta (GR-Charta) zu beachten. ${ }^{158}$ Deren Beeinflussung durch die EMRK wird sich durch den bevorstehenden Beitritt der EU weiter steigern. ${ }^{159}$

Regelungen finden sich bei den Freiheitsrechten. Art. 7 GR-Charta statuiert ein Recht auf Achtung des Familienlebens. In Art. 9 GR-Charta wird das Recht, eine Ehe einzugehen und eine Familie zu gründen, geschützt. Daneben wird unter dem Abschnitt Solidarität in den Art. 33 und 34 GR-Charta der rechtliche, wirtschaftliche und soziale Schutz der Familie gewährleistet. Die Vereinbarkeit von Familien- und Berufsleben wird ausdrücklich erwähnt. Da durch die Charta die Kompetenzen der EU nicht erweitert werden dürfen, ${ }^{160}$ ist bei der Anwendung der Bestim-

das nationale Recht ihr verwehrt hatte. S. RL 73/148/EWG v. 21.05.1973, L 172/14 und das dazu ergangene Urteil des EuGH, Urt. v. 11.07.2002 - C-60/00, Mary Carpenter/ Secretary of State for the Home Department, Slg. 2002, I-6279. Auch aus Art. 6 Abs. 1 GG hätte ein entsprechender Anspruch nicht abgeleitet werden können, BVerfGE 76, 1 ff.; aus der Lit. nur Pieroth in: Jarass/Pieroth (Fn. 75), Art. 6 Rn. 11. S.a. die Freizügigkeitsrichtlinie RL 2004/38/EG v. 29.04.2004, L 158/77, und einige hierzu ergangene Urteile EuGH, Urt. v. 25.07.2008 - C-127/08, Blaise Baheten Metock u.a./Minister for Justice, Equality and Law Reform, Slg. 2008, I-6241; EuGH, Urt. v. 05.09.2012 C-83/11, Secretary of State for the Home Department/Rahman, NVwZ 2012, 1532 ff.; EuGH, Urt. v. 08.11.2012 - C-40/11, Yoshikazu Iida/Stadt Ulm, NVwZ 2013, 357 ff. Zur Familienzusammenführung s. außerdem RL 2003/86 v. 22.09.2003, L 251/15. Zur Problematik unterschiedlicher nationaler Grundrechtsstandards bei der Vollstreckung von Gerichtsentscheidungen in Familiensachen im Rahmen der justiziellen Zusammenarbeit G. Britz JZ 2013, 105 ff. Zum europäischen Kinderrechtsschutz nach dem EUReformvertrag von Lissabon C. Steindorff-Classen Europarecht 2013, 19 ff. Kritisch zur Rolle der nationalen Verfassungsgerichte in der europäischen Demokratie insbes. auf der Ebene der Ausübung von EU-Kompetenzen und der Rechtsanwendung D. Grimm Die Zukunft der Verfassung II, 2012, $131 \mathrm{ff}$.

158 Die GR-Charta bindet nach ihrem Art. 51 die Organe der Union. Ob die Spielräume der Mitgliedstaaten gewahrt werden, hängt dabei vor allem von der Rspr. des EuGH ab. S. hierzu jüngst die Entscheidung des BVerfG zur Antiterrordatei, BVerfG, Urt. v. 24.04.2013, 1 BvR 1215/07, NJW 2013, 1499 ff.; hierzu P. Kasiske NJW 2013, 312 f.; und die Entscheidung des EuGH zum Verbot der Doppelbestrafung, EuGH, Urt. v. 11.12.2008 - C-297/07, Klaus Bourquain, Slg. 2008, I-9425; grundlegend zum Kooperationsverhältnis zwischen BVerfG und EuGH, BVerfGE 126, 286 ff.; hierzu auch P. M. Huber in: R. Streinz (Hrsg.) EUV/AEUV, 2. Aufl. 2012, Art. 19 EUV Rn. 50 ff.; M. Polzin JuS 2012, 1 ff.

${ }_{159}$ Die Begriffe in Art. 7 und 9 GR-Charta knüpfen ohnehin an Art. 8 und 12 EMKR und damit auch die Rspr. des EGMR an, L. Jarass Charta der Grundrechte der Europäischen Union, Kommentar, 2. Aufl. 2013, Art. 7 Rn. 2, Art. 9 Rn. 1. S.a. Art. 52 Abs. 3 GR-Charta.

160 So ausdrücklich auch Art. 51 Abs. 2 GR-Charta. Zum Anwendungsbereich T. v. Danwitz FS Stern, 2012, 669 (676 ff.). 
mungen den Kompetenzen und Gestaltungsspielräumen der Mitgliedstaaten Rechnung zu tragen.

Über einen Umweg hat das EU-Sekundärrecht in Form der europäischen Gleichstellungsrichtlinien die Auslegung von Art. 6 GG stark beeinflusst. Und dies, obwohl Ehe und Familie insoweit an sich gar nicht erfasst werden. ${ }^{161}$ Gestützt auf das Verbot der Diskriminierung wegen der sexuellen Orientierung in Beschäftigung und Beruf ${ }^{162}$ verlangte der Europäische Gerichtshof (EuGH) die Gleichstellung gleichgeschlechtlicher Lebenspartnerschaften bei der Hinterbliebenenversorgung, ${ }^{163}$ rügte die diskriminierende Berechnungsmethode für Zusatzversorgungsbezüge ${ }^{164}$ und den Ausschluss der Beihilfe für eingetragene Lebenspartner. ${ }^{165}$ Die tatsächliche Wirkung der Entscheidungen weist weit über diese Bereiche hinaus.

Über den allgemeinen Gleichheitssatz wurden ihre Inhalte in das deutsche Recht integriert. Besonders gut beobachten lässt sich dies an der Entscheidung zur Sukzessivadoption, in der ausdrücklich auf die Rechtsprechung des EuGH zur Hinterbliebenenversorgung Bezug genommen wurde. ${ }^{166}$

161 Zur Dynamik des Europarechts I. Pernice DV Beiheft (Fn. 39), 225 (236) mwN, der dabei insbes. das Abstellen des EuGH auf den gegenwärtigen Stand des Gemeinschaftsrechts sowie Besonderheiten bestimmter Sachgebiete hervorhebt. S.a. M. Ruffert DV Beiheft (Fn. 39), 253 ff.

162 S. insbes. Art. 4 der RL 2004/113/EG v. 13.12.2004, L 373/37, sog. Gleichstellungsrichtlinie. Die Richtlinie dient der Verwirklichung des Grundsatzes der Gleichbehandlung von Männern und Frauen beim Zugang zu und bei der Versorgung mit Gütern und Dienstleistungen.

163 EuGH, Urt. v. 01.04.2008 - C-267/06, Tadao Maruko/Versorgungsanstalt der deutschen Bühnen, Slg. 2008, I-1757. Die erste Entscheidung bezog sich noch auf eine mittelbare Diskriminierung von Frauen beim Ruhegehalt. EuGH, Urt. v. 23.10.2003 C-4/02 und C-5/02, Hilde Schönheit/Stadt Frankfurt am Main, und Silvia Becker/Land Hessen, Slg. 2003, I-12575.

164 EuGH, Urt. v. 10.05.2011 - C-147/08, Jürgen Römer/Freie und Hansestadt Hamburg, Slg. 2011, I-359.

165 EuGH, Urt. v. 06.12.2012 - C-124/11, C-125/11, C-143/11, R. Dittrich u.a., NVwZ 2013, 132 ff. Ein von der EU-Kommission 2007 in Gang gesetztes Vertragsverletzungsverfahren wegen unzureichender Umsetzung der Richtlinie wurde eingestellt.

166 BVerfG, Urt. v. 19.02.2013, 1 BvL 1/11 und 1 BvR 3247/09, Rn. 56, NJW 2013, 847 (850) verweist auf EuGH, Urt. v. 01.04.2008 - C-267/06, Tadao Maruko/Versorgungsanstalt der deutschen Bühnen, Slg. 2008, I-1757. S.a. BVerfGE 124, 199 (222). In dem Beschluss aus dem Jahre 2009 entschied der erste Senat, dass es der allgemeine Gleichheitssatz aus Art. 3 Abs. 1 GG gebiete, Ehe und eingetragene Lebenspartnerschaft bei der betrieblichen Hinterbliebenenrente gleich zu behandeln. 


\section{Europäische Menschenrechtskonvention}

In ebendieser Entscheidung wurde außerdem der Europäische Gerichtshof für Menschenrechte (EGMR) zitiert, und dies sogar mehrfach. Zunächst mit einem Hinweis auf die Rechtsprechung des Gerichts zur Adoption durch Homosexuelle, wonach ein genereller Ausschluss homosexueller Menschen von der Einzeladoption gegen die EMRK verstößt. ${ }^{167}$ Dann aber auch auf die Rechtsprechung bezüglich der Einbeziehung gleichgeschlechtlicher Elternpaare in den Familienschutz. ${ }^{168}$

Im Vorgehen der beiden Gerichte lassen sich Parallelen feststellen. Grundsätzlich stellt der EGMR wie das Bundesverfassungsgericht häufig nicht nur auf das Grundrecht auf Ehe und Familie, sondern auch auf den Gleichheitssatz und damit auf Art. 8 und Art. 14 EMRK ab. ${ }^{169}$ Verän-

167 BVerfG, Urt. v. 19.02.2013, 1 BvL 1/11 und 1 BvR 3247/09, Rn. 56, 66, 81, NJW 2013, 847 (850 f., 853) unter Hinweis auf EGMR, Urt. v. 26.02.2002 - 35615/97, Fretté/ Frankreich, FamRZ 2003, 149 ff.; EGMR, Urt. v. 22.01.2008 - 43546/02, E. B./Frankreich, NJW 2009, 3637 ff.; und EGMR, Urt. v. 24.06.2010 - 30141/04, Schalk u. Kopf/ Österreich, NJW 2011, $1421 \mathrm{ff}$.

168 Nach dem EGMR ist der Familienbegriff heute nicht mehr auf eheliche Beziehungen beschränkt, sondern kann auch andere tatsächliche Verbindungen, bei denen die Beteiligten zusammenleben, umfassen. So schon EGMR Urt. v. 13.06.1979 6833/74, Marckx/Belgien, EGMR-E 1, 396 (398); EGMR, Urt. v. 18.12.1986 - 9697/82, Johnston u.a./Irland, EuGRZ 1987, 313 (317); seitdem st. Rspr., s. etwa EGMR, Urt. v. 26.05.1994 - 16/1993/411/490, Keegan/Irland, NJW 1995, 2153 (2153); EGMR, Urt. v. 03.12.2009 - 22028/04, Zaunegger/Deutschland, NJW 2010, 501 (502); EGMR, Urt. v. 24.06.2010 - 30141/04, Schalk u. Kopf/Österreich, NJW 2011, 1421 (1424). Gleiches gelte für gleichgeschlechtliche Paare (auf Kinder wird hier nicht eingegangen!). EGMR, Urt. v. 24.06.2010 - 30141/04, Schalk u. Kopf/Österreich, NJW 2011, 1421 (1425); EGMR, Urt. v. 19.02.2013 - 19010/07, X. u.a./Österreich, NJW 2013, 2173 (2175); EGMR, Urt. v. 15.03.2012 - 25951/07, Gas und Dubois/Frankreich, NJW 2013, 2171 (2171). Außerdem könne schon das nur beabsichtigte Familienleben unter Art. 8 EMRK fallen, insbes. wenn der biologische Vater nicht dafür verantwortlich sei, dass sich bisher noch keine tatsächliche sozial-familiäre Beziehung entwickeln konnte. S. etwa EGMR Urt. v. 21.12.2010 - 20578/07, Anayo/Deutschland, NJW 2010, 3565 (3566); EGMR Urt. v. 15.09.2011 - 17080/07, Schneider/Deutschland, NJW 2012, 2781 (2784). S. zu diesen beiden Entscheidungen L. M. Peschel-Gutzeit NJW 2013, 2465 ff. Jedenfalls fallen enge Beziehungen, bei denen es sich nicht um Familien iSd Art. 8 EMRK handelt, unter den Schutz des ebenfalls von Art. 8 EMRK umfassten Privatlebens, EGMR, Urt. v. 02.06.2005 - 77785/01, Znamenskaya/Russland; EGMR Urt. v. 21.12.2010 - 20578/07, Anayo/Deutschland, NJW 2010, 3565 (3566); EGMR Urt. v. 15.09.2011 - 17080/07, Schneider/Deutschland, NJW 2012, 2781 (2784).

169 S. etwa EGMR, Urt. v. 21.12.1999 - 33290/96, Salgueiro da Silva Mouta/Portugal, Slg. 1999-IX; EGMR, Urt. v. 26.02.2002 - 35615/97, Fretté/Frankreich, FamRZ 2003, 149 ff.; EGMR, Urt. v. 24.10.2003 - 40016/98, Karner/Österreich; EGMR, Urt. v. 22.01.2008 - 43546/02, E. B./Frankreich, NJW 2009, 3637 ff.; EGMR, Urt. v. 24.06. 
derte gesellschaftliche Rahmenbedingungen und Einstellungen waren Motor auch für die Rechtsprechung des EGMR zu Ehe und Familie. ${ }^{170}$ Die EMRK wird von ihm ausdrücklich als „Living Instrument“ bezeichnet. ${ }^{171}$ Entwicklungen in den Konventionsstaaten finden so Eingang in die Rechtsprechung des EGMR. ${ }^{172}$

2010 - 30141/04, Schalk u. Kopf/Österreich, NJW 2011, 1421 ff.; EGMR, Urt. v. 19.02. 2013 - 19010/07, X. u.a./Österreich, NJW 2013, 2173 ff.; EGMR, Urt. v. 15.03.2012 25951/07, Gas und Dubois/Frankreich, NJW 2013, 2171 ff. Andere Fälle zur Diskriminierung aufgrund der sexuellen Orientierung stützte der EGMR nur auf Art. 8 EMRK: s. etwa EGMR, Urt. v. 22.10.1981 - 7525/76, Dudgeon/United Kingdom, EuGRZ 1983, 488 ff.; EGMR Urt. v. 26.10.1988 - 10581/83, Norris/Irland, in: EGMR-E 4, 156 ff.; EGMR, Urt. v. 22.04.1993 - 15070/89, Modinos/Zypern; EGMR, Urt. v. 27.09.1999 33985/96 und 33986/96, Smith und Grady/Vereinigtes Königreich, NJW 2000, 2089 ff.; EGMR Urt. v. 09.01.2003 - 39392/98 und 39829/9, L. u. V./Österreich. Verboten sind hiernach insbes. Diskriminierungen aufgrund der sexuellen Orientierung und ehelichen oder nichtehelichen Geburt. Dies gilt sowohl für das nichteheliche Kind als auch seinen Vater. Zur Diskriminierung des nichtehelichen Kindes im Erbrecht EGMR Urt. v. 13.06.1979 - 6833/74, Marckx/Belgien, EGMR-E 1, 396 ff.; jüngere Entscheidungen des EGMR stellen insofern nur auf eine Verletzung von Art. 14 EMRK iVm Art. 1 1. Zusatzprotokoll zur EMRK ab, EGMR, Urt. v. 01.02.2000 - 34406/07, Mazurek/ Frankreich, NJOZ 2005, 1048 ff., EGMR Urt. v. 07.02.2013 - 16574/08, Fabris/Frankreich. Zur Diskriminierung des nichtehelichen Vaters s. etwa EGMR, Urt. v. 11.10.2001 - 34045/96, Hoffmann/Deutschland; EGMR, Urt. v. 08.07.2003 - 31871/96, Sommerfeld/Deutschland; EGMR, Urt. v. 03.12.2009 - 22028/04, Zaunegger/Deutschland, NJW 2010, 501 ff.; EGMR, Urt. v. 03.02.2011 - 35637/03, Sporer/Österreich. Andere Fälle zur Diskriminierung nichtehelicher Väter stützte der EGMR allein auf Art. 8 EMRK: s. etwa EGMR Urt. v. 21.12.2010 - 20578/07, Anayo/Deutschland, NJW 2011, 3565 ff.; EGMR Urt. v. 15.09.2011 - 17080/07, Schneider/Deutschland, NJW 2012, $2781 \mathrm{ff}$.

170 T. Helms in: M. Löhnig/D. Schwab/D. Heinrich/P. Gottwald (Hrsg.) Kindesrecht und Elternkonflikt, 2013, 53 (62). Die Lebenswirklichkeit wird dabei einbezogen, s. etwa EGMR, Urt. v. 03.12.2009 - 22028/04, Zaunegger/Deutschland, NJW 2010, 501 (503 f.), zur Diskriminierung des leiblichen Vaters eines nichtehelichen Kindes beim Sorgerecht; EGMR, Urt. v. 24.06.2010 - 30141/04, Schalk u. Kopf/Österreich, NJW 2011, 1421 (1423 ff.), zur Einbeziehung gleichgeschlechtlicher Paare in das Recht auf Eheeingehung, Art. 12 EMRK, und homosexueller Elternpaare in den Schutz der Familie, Art. 8 EMRK.

171 S. etwa zu Art. 12 EMRK EGMR, Urt. v. EGMR, Urt. v. 24.06.2010 - 30141/04, Schalk u. Kopf/Österreich, NJW 2011, 1421 (1423); und zu Art. 14 EMRK iVm Art. 8 EMRK EGMR, Urt. v. 22.01.2008 - 43546/02, E. B./Frankreich, NJW 2009, 3637 (3641); s.a. Präambel EMRK.

172 Als zentrale Argumentationsgrundlagen wird zum einen ein etwaiger Konsens der Konventionsstaaten, zum anderen der Ermessensspielraum der von der Klage betroffenen Staaten berücksichtigt. Dazu A. Nußberger RW 2012, 197 (200 ff.); zu Innovationsgrenzen dies. FS Stern (Fn. 160), 117 (124 ff.). Zur Rolle des EGMR s. J. A. Frowein in: ders./W. Peukert, Europäische Menschenrechtskonvention, 3. Aufl. 2009, Einl. Rn. 12; s. außerdem Helms in: Löhnig/Schwab/Heinrich/Gottwald (Fn. 170), 53 (54). 
Da der EGMR die durch die EMRK geschützten Rechtsgüter autonom definiert, kommt es allerdings auch zu Konflikten. ${ }^{173}$ Dies umso mehr, als der EGMR zuweilen auf Grund eines eher kursorischen Rechtsvergleichs entscheidet und den Mitgliedstaaten bei Abweichungen eine strenge Rechtfertigungslast aufbürdet. ${ }^{174}$ Um übermäßige Eingriffe in die nationale Rechtsordnung zu vermeiden, wird deshalb gefordert, dass der EGMR seine eigene Rechtsprechung zurückstellt, solange die nationale Verfassungsgerichtsbarkeit in dem betroffenen Bereich ein der Konvention vergleichbares Schutzniveau bietet. ${ }^{175}$

Gegenüber der Bundesrepublik Deutschland wird der Gerichtshof dieser Forderung im Wesentlichen gerecht, auch wenn einige seiner Entscheidungen zu Recht kritisch rezipiert werden. Die Sicherungsverwahrung ${ }^{176}$ mag als Beispiel genügen. Insgesamt aber sind deutsche Verurteilungen relativ selten. ${ }^{177}$ In den langen Jahren seit Bestehen der Konvention wurde die Bundesrepublik Deutschland erst in 19 Fällen wegen Verletzung des

173 H. Landau/M. Trésoret DVB1. 2012, 1329 (1332), zu den dadurch bei der Sicherheitsverwahrung entstehenden Problemen.

174 Instruktiv dazu A. Nußberger RW 2012, 197 (206 ff.).

$175 \mathrm{Im}$ Verhältnis zum EuGH ist der Gerichtshof entsprechend verfahren. Der Grundrechtsschutz der EU wird dabei als der EMRK grundsätzlich gleichwertig anerkannt, die Einzelfallprüfung deshalb auf Fälle offensichtlich unzureichenden Menschenrechtsschutzes beschränkt. S. EGMR, Urt. v. 30.06.2005 - 45036/98, Bosphorus Hava Yollari Turizm ve Ticaret Anonim Sirketi/Irland, NJW 2006, 197 (202), dazu aus der Lit. O. Klein NVwZ 2010, 221 (224); M. Kloth EuR-Beiheft 2012, 155 (insbes. 158 f.); s.a. W. Weiß EuZW 2013, 287 ff.

176 Zum Verhältnis von BVerfG und EGMR s. O. Klein NVwZ 2010, 221 ff.; H. Landau/M. Trésoret DVB1. 2012, 1329 (1331 ff.). In der Konsequenz änderte das BVerfG seine Rspr. zur Sicherungsverwahrung. Ursprünglich sah das BVerfG zumindest die verlängerte Sicherungsverwahrung als verfassungsrechtlich unbedenklich an, BVerGE 109, 133 (166); unter Berücksichtigung des Urteils EGMR, Urt. v. 17.12.200919359/04, M./Deutschland, NJW 2010, 2495 ff., und einer Reihe darauf folgender Entscheidungen des EGMR erklärte das BVerfG dann die nachträgliche Verlängerung der Sicherungsverwahrung über die frühere Zehnjahreshöchstgrenze und die nachträgliche Anordnung der Sicherungsverwahrung für verfassungswidrig, BVerfGE 128, 326 (365 ff.); s. dazu U. Volkmann JZ 2011, 835 ff.

177 Der größte Teil der eingelegten Beschwerden gegen Deutschland wird vom EGMR auf Grund der von den Beschwerdeführern vorgelegten Unterlagen schon als unzulässig angesehen. Nur etwa $2 \%$ der eingehenden Verfahren werden dem für die Vertretung der Bundesrepublik zuständigen Justizministerium zur Stellungnahme übersandt. Im Jahr 2012 waren dies ganze 22 Fälle. Erfahrungsgemäß führt wiederum nur ein Teil dieser Fälle zu einer Verurteilung. Ausgewählte Entscheidungen des EGMR und Rechtsprechungsberichte finden sich unter http://www.bmj.de/DE/Recht/OeffentlichesRecht/Menschenrechte/AusgewaehlteEntscheidungendesEGMRundRechtsprechungsberichte/_node.html. 
Art. 8 EMRK vom EGMR verurteilt, im Zentrum standen dabei kindschaftsrechtliche Fragestellungen. ${ }^{178}$

Der Grund für die auch in anderen Bereichen geringe Zahl deutscher Verurteilungen dürfte in der für den Gerichtsraum der EMRK vermutlich singulären Überprüfungsdichte von Grundrechtsverletzungen durch das Bundesverfassungsgericht liegen. ${ }^{179}$ Regelmäßig kann der EGMR erst nach dessen Entscheidungen angerufen werden. ${ }^{180}$

Auch wenn die Verurteilungen sich zahlenmäßig in Grenzen halten, dürfen ihre Auswirkungen nicht nur für die Einzelfälle, sondern für die Auslegung des Grundgesetzes insgesamt aber nicht unterschätzt werden. Die deutsche Grundrechtsdogmatik wurde mittlerweile gegenüber europäischen Einflüssen weit geöffnet. ${ }^{181}$ Das Bundesverfassungsgericht hat

178 Helms in: Löhnig/Schwab/Heinrich/Gottwald (Fn. 170), 53 (54, 61); s.a. Violations by Article and by respondent State (1959-2012), http://www.echr.coe.int/ Documents/Stats_violation_1959_2012_ENG.pdf (zuletzt abgerufen am 17.09.2013). S. insbes. zum Umgangs- und Sorgerecht: EGMR Urt. v. 13.07.2000 - 25735/94, Elsholz/ Deutschland, NJW 2001, 2315 ff.; EGMR, Urt. v. 11.10.2001 - 34045/96, Hoffmann/ Deutschland; EGMR, Urt. v. 26.02.2002 - 46544/99, Kutzner/Deutschland; EGMR, Urt. v. 26.02.2004 - 74969/01, Görgülü/Deutschland, NJW 2004, 3397 ff.; EGMR, Urt. v. 08.05.2004 - 11057/02, Haase/Deutschland, NJW 2004, 3401 ff.; EGMR Urt. v. 10.11.2005 - 40324/98, Süss/Deutschland, NJW 2006, 2241 ff.; EGMR, Urt. v. 03.12. 2009 - 22028/04, Zaunegger/Deutschland, NJW 2010, 501 ff.; EGMR Urt. v. 21.12. 2010 - 20578/07, Anayo/Deutschland, NJW 2011, 3565 ff.; EGMR Urt. v. 15.09.2011 17080/07, Schneider/Deutschland, NJW 2012, 2781 ff.; EGMR, Urt. v. 22.03 .2012 23338/09, Kautzor/Deutschland, NJW 2013, 1937 ff.; s. zu Verfahren, insbes. der überlangen Verfahrensdauer, Art. 6 Abs. 1 EMRK, in Familiensachen: EGMR, Urt. v. 24.02.2005 - 60534/00, Wimmer/Deutschland; EGMR, Urt. v. 04.12.2008 - 44036, Adam/Deutschland; EGMR, Urt. v. 09.04.2009 - 1182/05, Hub/Deutschland; EGMR, Urt. v. 21.01.2010 - 42402/05 und 42423/05, Wildgruber/Deutschland; EGMR, Urt. v. 24.06.2010 - 39444/08, Afflerbach/Deutschland; EGMR, Urt. v. 20.01.2011 - 21980/06, 26944/07, 3694/08, Kuhlen-Rafsandjani/Deutschland, FamRZ 2011, 533 ff.; EGMR, Urt. v. 10.02.2011 - 1521/06, Tsikakis/Deutschland, FamRZ 2011, 1125 ff.; EGMR Urt. v. 21.04.2011 - 41599/09, Kuppinger/Deutschland, FamRZ 2011, 1283 ff.; s.a. EGMR, Urt. v. 08.07.2003 - 31871/96, Sommerfeld/Deutschland, FamRZ 2004, 337 ff.; EGMR, Urt. v. 08.07.2003 - 30943/96, Sahin/Deutschland, FamRZ 2004, 337 ff.; zu den EGMR-Entscheidungen s.a. P.-C. Kunkel FPR 2012, 358 ff. Bislang gibt es - soweit ersichtlich - aber noch keine Verurteilung wegen Verletzung der Ehefreiheit nach Art. 12 EMRK.

179 A. Weber Europäische Verfassungsvergleichung, 2010, 333 Rn. 57; vgl. auch U. Volkmann JZ 2011, 835 (841 f.).

${ }^{180}$ Gem. Art. 35 Abs. 1 EMRK kann sich der EGMR erst nach Erschöpfung aller innerstaatlichen Rechtsbehelfe mit einer Angelegenheit befassen. In Deutschland gehört hierzu insbes. die Verfassungsbeschwerde, J. Meyer-Ladewig in: ders. (Hrsg.) Europäische Menschenrechtskonvention, Handkommentar, 3. Aufl. 2011, Art. 35 Rn. 19.

181 H. Landau/M. Trésoret DVB1. 2012, 1329 (1332); s.a. U. Volkmann JZ 2011, 835 ff. 
2004 im sog. Görgülü-Beschluss, und damit gerade im Rahmen einer familienrechtlichen Streitigkeit, deutlich gemacht, dass deutsche Behörden und Gerichte Entscheidungen des EGMR in derselben Sache bei ihrer Entscheidungsfindung zu berücksichtigen, sich mit ihnen auseinanderzusetzen und ein etwaiges Abweichen gegebenenfalls nachvollziehbar zu begründen haben. ${ }^{182}$ Obwohl die EMRK nur auf der Stufe eines einfachen Bundesgesetzes steht, ${ }^{183}$ beeinflusst - oder sollte man besser sagen bestimmt - sie damit auch die Auslegung der Grundrechte und der rechtsstaatlichen Grundsätze des Grundgesetzes. ${ }^{184}$ Die Entscheidungen des EGMR wirken zweifach als Dynamisierungsfaktoren: Zum einen bei Verurteilungen, zum anderen als Erkenntnisquelle für Rechtsvergleiche, die beim Grundrecht auf Ehe und Familie wiederum vor allem bei der Anwendung des Gleichheitssatzes wirksam werden.

\section{Schlussfolgerungen}

Die Grundpfeiler der Grundrechtsdogmatik von Ehe und Familie wurden schon früh, nämlich in den fünfziger Jahren des letzten Jahrhunderts gelegt: Freiheitsfunktion, Institutsgarantie, objektive Wertordnung und die Verknüpfung mit Art. 3 GG.

Auch wenn der Einfluss des Gleichheitssatzes stark zugenommen hat, sind die Pfeiler an sich im Wesentlichen über die Jahre stabil geblieben. Sie haben sich allerdings als offen für die Aufnahme neuer Inhalte erwiesen. Insofern war und ist die Grundrechtsdogmatik von Ehe und Familie dynamisch.

Inhaltliche Änderungen haben insbesondere die Schutzgüter Ehe und Familie und auch ihr Verhältnis zueinander erfahren. Die soziale Entwicklung wurde dabei ebenso aufgenommen und integriert wie ein Wandel der gesellschaftlichen Einstellungen. Als Beschleuniger hat wiederholt

182 BVerfGE 111, 307 (324).

183 St. Rspr. des BVerfG, s. etwa BVerfGE 74, 358 (370); 111, 307 (316 f.); 128, 326 (366 f.); zur EMRK als Auslegungshilfe für das GG etwa BVerfGE 74, 358 (370); 82, 106 (120); 111, 307 (317); 128, 326 (367 ff.).

184 BVerfGE 128, 326 (367 ff.). Das Gericht erreicht dieses Ergebnis, indem es die in den Art. 1 sowie 23 bis 25 GG zum Ausdruck kommende Völkerrechtsfreundlichkeit der deutschen Verfassungsordnung betont. Aufgezeigt wurden aber auch die Grenzen der Völkerrechtsfreundlichkeit. Die konventionskonforme Interpretation darf nicht zu einer Verkürzung des Grundrechtsschutzes führen. Bei mehrpoligen Grundrechtsverhältnissen sind die Grundrechte aller Betroffenen zu beachten. Außerdem darf der in der Lissabon-Entscheidung des Gerichts herausgearbeitete Kerngehalt der Verfassungsidentität nicht berührt werden. 
Art. 3 GG gewirkt, wobei rechtsvergleichende Erkenntnisse eingingen und europäische Vorgaben sowie die Rechtsprechung des EuGH und des EGMR integriert wurden. ${ }^{185}$

Um am Gesamtthema der Tagung anzuknüpfen: Was Ehe und Familie angeht, ist das öffentliche Recht damit sicher zukunftsfähig. Über die Grenzen einer dynamischen Grundrechtsdogmatik aber wird weiter gestritten werden müssen.

${ }^{185}$ Dass eine national introvertierte Norm- und Rechtsprechungsexegese überholt ist, hat der Präsident des BVerfG Andreas Voßkuhle schon 2002 beschrieben, s. A. Voßkuhle FS Schmidt, 2002, 171 (insbes. 177 ff.); ders. JuS 2004, 1 ff. 
Leitsätze der 1. Referentin über:

\section{Dynamische Grundrechtsdogmatik von Ehe und Familie?}

\section{Einleitung}

(1) Grundrechtsdogmatik befasst sich mit der Definition von Schutzgütern und Eingriffen, mit Grundrechtsfunktionen und Grundrechtskonkurrenzen. Legt man dieses Verständnis zugrunde, können jedenfalls neuere Entwicklungen der Dogmatik von Ehe und Familie nur als dynamisch bezeichnet werden.

\section{Ehe und Familie im Wandel}

(2) Lange Zeit wurde die Ehe als lebenslange Verbindung von Mann und Frau, die Familie als ihre quasi natürliche Folge angesehen. Vorherrschend war eine klare Rollenverteilung. Tatsächlich nahm die Zahl der Eheschließungen in den vergangenen Jahrzehnten ab. Bei den Scheidungen ist der Trend steigend. Mit einem Anteil von $71 \%$ ist die Ehe mit Kind(ern) noch immer die meistgelebte Familienform. $9 \%$ der Familien leben ohne Trauschein zusammen und weitere $20 \%$ sind alleinerziehend.

(3) In den meisten Familien ist zwar noch immer der Mann der Haupternährer. Die Erwerbstätigkeit von Frauen ist in den letzten 50 Jahren aber kontinuierlich von 47,2\% im Jahr 1960 auf $65 \%$ im Jahr 2009 gestiegen. Davon arbeiten $35 \%$ in Vollzeit. Viele Frauen würden gern auch in der Familienphase mehr berufstätig sein.

\section{Entwicklungsoffenheit des Grundgesetzes}

1. Ehe und Familie in der deutschen Verfassungsentwicklung

(4) Die Weimarer Reichsverfassung enthielt zumindest einen Programmsatz zum Schutz von Ehe und Familie. Als Ehe wurde dabei ausdrücklich die Verbindung von Mann und Frau bezeichnet. Sie wurde als Grundlage der Familie hervorgehoben und sollte der Erhaltung und Vermehrung der Nation dienen. 
(5) Bei den Verhandlungen zum Grundgesetz kamen Regelungen zu Ehe und Familie spät zur Sprache. Auch wenn die Väter und Mütter des Grundgesetzes an einem traditionellen Bild von Ehe und Familie anknüpften, wurden Gegengeschlechtlichkeit und die enge Verbindung von Ehe und Familie in der letztlich verabschiedeten Fassung nicht erwähnt. Der Wortlaut eröffnet damit Auslegungspotentiale. Dynamisierungsfaktoren, die später eine wichtige Rolle spielen sollten, scheinen in den Verhandlungen schon auf: die Gleichberechtigung der Frau und die Anbindung an die EMRK.

2. Statische oder dynamische Verfassungsauslegung?

(6) Unter dem Grundgesetz nahm die Grundrechtsdogmatik Fahrt auf. Zwar konnte bei der Deutung der Grundrechte als subjektive Freiheitsrechte und bei den institutionellen Garantien an Vorbilder angeknüpft werden. Schon früh wurden aber auch neue Weichen gestellt. Dies gilt insbesondere für die Figur der objektiven Dimension der Grundrechte. Auch bei Art. 6 Abs. 1 GG lässt sich diese dogmatische Entwicklung nachzeichnen.

IV. Grundrechtsdogmatik von Ehe und Familie im Wandel

1. Grundlinien

(7) Bis heute halten Rechtsprechung und in weiten Teilen auch die Literatur zwar im Wesentlichen an den in den fünfziger Jahren des letzten Jahrhunderts entwickelten Grundstrukturen fest. Die sich dahinter im Einzelnen verbergenden Inhalte haben sich jedoch gewandelt. Deutlich stärker geworden ist der Einfluss des Art. 3 GG und dies nicht nur bezüglich der Gleichberechtigung der Frau.

(8) Art. 6 Abs. 1 GG ist auf eine dynamische Auslegung hin angelegt, weil das Schutzgebot der Verfassung die Institutionen der Ehe und Familie nicht abstrakt umfasst, sondern in ihrer Ausgestaltung durch den Gesetzgeber. Damit beeinflusst die soziale Realität die Auslegung der Verfassung stärker als dies bei anderen Grundrechten der Fall ist.

\section{Schutzgut Ehe}

(9) Ausdrücklich definiert wird der Begriff der Ehe in Art. 6 Abs. 1 GG nicht. Ursprünglich wurde sie als grundsätzlich unauflösliche Lebensgemeinschaft angesehen, mittlerweile dagegen als ,,auf Dauer angelegt". Stark gewandelt hat sich das Rollenbild der Eheleute. Wie weit der Interpretationsspielraum reicht, zeigt sich bei der Diskussion um das Geschlecht der Eheleute. 
(10) Ehe und Familie sind grundsätzlich als gleichrangige Schutzgüter anzusehen. In der Praxis lässt sich aber vielfach eine Verschiebung des Schutzes von der Ehe hin zur Familie beobachten.

\section{Schutzgut Familie}

(11) Stark gewandelt hat sich auch der Begriff der Familie. Soziale Entwicklungen und veränderte Werte haben als Dynamisierungsfaktoren seine Auslegung beeinflusst. Die Familie muss nicht mehr aus der Ehe hervorgehen, um dem Schutz des Art. 6 Abs. 1 GG zu unterfallen. Das Bestehen einer tatsächlichen Lebens- und Erziehungsgemeinschaft von Eltern und Kindern genügt. Auf die biologische Herkunft kommt es nicht an.

(12) Das durch Art. 6 Abs. 2 Satz 1 GG geschützte Elternrecht schützt auch zwei Elternteile gleichen Geschlechts. Eingetragene Lebenspartnerschaften mit Kindern sind Familie i.S.d. Art. 6 Abs. 1 GG.

\section{Gleichheitsrechte}

(13) Der dynamisierende Einfluss des Art. 3 Abs. 2 GG auf die Auslegung des Art. 6 Abs. 1 GG wurde schon früh deutlich. Viele ehe-undloder familienbezogene Entscheidungen des Bundesverfassungsgerichts wurden zudem nicht oder jedenfalls nicht allein auf Art. 6 GG gestützt, sondern maßgeblich auf Art. 3 Abs. 1 GG. Der Gesetzgeber wurde über den Hebel des Gleichheitssatzes wiederholt zur Korrektur bzw. nachhaltigen Umgestaltung gewachsener Strukturen u.a. im Sozialversicherungsrecht verpflichtet.

(14) Bei Lebenspartnerschaften kann Art. 6 Abs. 1 GG nicht mehr als Differenzierungskriterium im Rahmen von Art. 3 Abs. 1 GG herangezogen werden. Ein Abstandsgebot besteht insoweit nicht (mehr). Differenzierungen sind nur unter strengen Voraussetzungen zulässig.

\section{Wahlfreiheit}

(15) Das Ehe- und Familiengrundrecht beinhaltet sowohl die Gründungs- als auch die Gestaltungsfreiheit. Umfasst ist davon der Schutz vor Eingriffen durch den Staat. Abgeleitet wird daneben aus Art. 6 Abs. 1 GG sowie dem Sozialstaatsprinzip ein Fördergebot des Staates.

(16) Grundsätzlich kommt dem Staat eine weite Gestaltungsfreiheit sowohl bei der Schaffung von Ausgleichsregelungen von kindbezogenen Lasten (Familienlastenausgleich) als auch bei der Förderung von Familienleistungen (Familienleistungsausgleich) zu. Grenze ist Art. 3 Abs. 1 GG, der Vorgaben für Typisierungsmaßstäbe setzt. Aus dem Willkürverbot wird außerdem der Grundsatz der Folgerichtigkeit gesetzlicher Regelungen abgeleitet. 
Dies heißt aber nicht, dass alle Ehe und Familie betreffenden Regelungen ein einheitliches Konzept verfolgen müssen.

(17) Bei der Ausgestaltung finanzieller staatlicher Leistungen ist stärker auf den Kernbereich des Schutzes des Art. 6 Abs. 1 GG abzustellen. Der private Rückzugsbereich, den Ehe und Familie darstellen, ist vor allem vor Eingriffen zu schützen. Bei der finanziellen Förderung spielt er keine vergleichbare Rolle. Hervorzuheben ist dagegen die Reproduktionsfunktion. Auf dieser Grundlage spricht vieles für eine stärkere Orientierung der Besteuerung an den vorhandenen Kindern.

(18) Auch ohne Kinder umfasst die Ehe die gegenseitige Sorge und Solidarität der Ehepartner. Der Staat macht sich dies zu Nutze, indem er entsprechende Unterhaltspflichten festschreibt. Dies ist auch im Rahmen des Steuerrechts zu berücksichtigen.

\section{Externe Dynamisierungsfaktoren}

\section{Rechtsvergleich}

(19) Nicht überall auf der Welt oder auch nur in Europa sind Ehe und Familie unter den Schutz der Verfassung gestellt. Aus der Sicht der Rechtsvergleichung sind gleichwohl die großen Entwicklungslinien im deutschen, europäischen und nordamerikanischen Familienrecht in weiten Teilen homogen verlaufen.

(20) Rechtsvergleichende Einflüsse lassen sich in der Rechtsprechung des Bundesverfassungsgerichts zu Ehe und Familie nachweisen. Die deutsche Verfassungsdogmatik wird außerdem vom Recht der Europäischen Union und der EMRK beeinflusst.

\section{Recht der Europäischen Union}

(21) Unmittelbare Kompetenzen der Europäischen Union für das Eheund Familienrecht bestehen nicht. Ehe- und familienbezogene Regelungen gibt es aber zur Bewältigung der Freizügigkeit. Jedenfalls bei der Ausführung von EU-Recht ist außerdem die Grundrechte-Charta zu beachten.

(22) Über einen Umweg hat das EU-Sekundärrecht in Form der europäischen Gleichstellungsrichtlinien die Auslegung von Art. 6 GG stark beeinflusst. Und dies, obwohl Ehe und Familie insoweit an sich gar nicht erfasst werden. Über den allgemeinen Gleichheitssatz wurden ihre Inhalte in das deutsche Recht integriert. 


\section{Europäische Menschenrechtskonvention}

(23) Veränderte gesellschaftliche Rahmenbedingungen und Einstellungen waren Motor auch für die Rechtsprechung des EGMR zu Ehe und Familie. Die EMRK wird von ihm ausdrücklich als „Living Instrument“ bezeichnet. Entwicklungen in den Konventionsstaaten finden so Eingang in die Rechtsprechung des EGMR. Die deutsche Grundrechtsdogmatik wurde mittlerweile gegenüber europäischen Einflüssen weit geöffnet.

(24) Die Entscheidungen des EGMR wirken zweifach als Dynamisierungsfaktoren: zum einen bei Verurteilungen, zum anderen als Erkenntnisquelle für Rechtsvergleiche, die bezüglich Ehe und Familie wiederum vor allem bei der Anwendung des Gleichheitssatzes wirksam werden.

\section{Schlussfolgerungen}

(25) Die Grundpfeiler der Grundrechtsdogmatik von Ehe und Familie wurden schon früh, nämlich in den fünfziger Jahren des letzten Jahrhunderts gelegt: Freiheitsfunktion, Institutsgarantie, objektive Wertordnung und die Verknüpfung mit Art. 3 GG.

(26) Auch wenn der Einfluss des Gleichheitssatzes stark zugenommen hat, sind die Pfeiler im Wesentlichen über die Jahre stabil geblieben. Sie haben sich allerdings als offen für die Aufnahme neuer Inhalte erwiesen. Insofern war und ist die Grundrechtsdogmatik von Ehe und Familie dynamisch.

(27) Inhaltliche Änderungen haben insbesondere die Schutzgüter Ehe und Familie und auch ihr Verhältnis zueinander erfahren. Als Beschleuniger hat wiederholt Art. 3 GG gewirkt, wobei rechtsvergleichende Erkenntnisse eingingen und europäische Vorgaben sowie die Rechtsprechung des EuGH und des EGMR integriert wurden.

(28) Was Ehe und Familie angeht, ist das öffentliche Recht damit sicher zukunftsfähig. Über die Grenzen einer dynamischen Grundrechtsdogmatik aber wird weiter gestritten werden müssen. 

Dritter Beratungsgegenstand:

\section{Dynamische Grundrechtsdogmatik von Ehe und Familie?}

2. Referat von Professor Dr. Michael Germann, Halle/Saale

Inhalt

Seite

I. Vom ,sozialen Wandel“ zur ,dynamischen Grundrechtsdogmatik" von Ehe und Familie .......... . . . . . . . 257

II. Gegenstand der Dynamik: Grundrechtsdogmatik von Ehe und Familie . . . . . . . . . . . . . . . . . . . 262

1. Die dynamische und die antidynamische Intention der Grundrechtsdogmatik . . . . . . . . . . . 262

2. Elemente der Grundrechtsdogmatik von Ehe und Familie . 263

3. Der Schutzbereich von Institutsgarantie und Wertentscheidung: Ansätze einer Leitbildgarantie . . . . . . . . 266

4. Intentionen einer Leitbildgarantie . . . . . . . . . . . . . 270

III. Wirksamkeit der Dynamik: Grundrechtsdogmatik von Ehe und Familie unter Spannung . . . . . . . . . . . . . . . . . 274

1. Dynamik im Schutzbereich von Familien- und Elternrecht 274

2. Dynamik in den Maßstäben der Familiengerechtigkeit. . . 278

3. Dynamik im systematischen Verhältnis des Ehe- und Familienschutzes zum allgemeinen Gleichbehandlungsgebot .................... 280

4. Dynamik im Begriff der Ehe. . . . . . . . . . . . . . 284

IV. Zukunft der Dynamik: Grundrechtsdogmatik von Ehe und Familie in der Karawane des Verfassungswandels . . . . . . . 287

\section{Vom „sozialen Wandel“6 zur „dynamischen Grundrechtsdogmatik“ von Ehe und Familie}

Dynamik macht sich im Recht von Ehe und Familie dort besonders bemerkbar, wo sie die Grenzen der ihm zugrundeliegenden Vorstellungen übersteigt. Nur ein Schlaglicht auf solche Dynamik wirft die Begründung des Bundesverfassungsgerichts für die im Februar 2013 getroffene Ent- 
scheidung, da $\beta$ die seit Menschengedenken kulturell verwurzelte und rechtlich geltende Verteilung der Elterneigenschaft auf einen Vater und eine Mutter ab sofort für das Elternrecht im Sinne des Art. 6 Abs. 2 GG nicht mehr von Bedeutung ist: „Zwar ist [...] davon auszugehen“, so das Bundesverfassungsgericht, „dass bei Abfassung von Art. 6 Abs. 2 GG ausschließlich an verschiedengeschlechtliche Eltern gedacht war. In der Norm liegt deshalb aber nicht eine bewusste Entgegensetzung zur Anerkennung gleichgeschlechtlicher Eltern; vielmehr lag diese schlicht außerhalb des damaligen Vorstellungshorizonts. [...] Die Grenzen der damaligen Vorstellungswelt und des dabei unterlegten historischen Begriffsverständnisses sind indessen mit der Veränderung der rechtlichen Einordnung von Homosexualität nach und nach entfallen."1 Diese Veränderung ist nur ein paradigmatischer Ausschnitt aus der Dynamik im Recht von Ehe und Familie. Wie sich zu solcher Dynamik die Grundrechtsdogmatik des Art. 6 GG verhält, ob und inwiefern sie sich etwa ihrerseits als dynamisch erweist, und welchen Beitrag sie dabei zur Zukunftsgestaltung durch öffentliches Recht leistet, ist die diesem Referat gestellte Frage.

Es geht dabei wieder um das Verhältnis zwischen Verfassungsgarantie und sozialem Wandel am Beispiel von Ehe und Familie, Gegenstand der Staatsrechtslehrertagung 1986 in München mit Vorträgen von Herrn von Campenhausen und Herrn Steiger. ${ }^{2}$ Viele Fragen von damals sind auch die von heute; der seinerzeit diagnostizierte soziale Wandel hat sich seitdem fortgesetzt, verstärkt und beschleunigt. ${ }^{3}$ Zur rechtlichen Gleichstellung gleichgeschlechtlicher Partnerschaften mit der Ehe findet sich in den Vorträgen der Staatsrechtslehrertagung von 1986 ein einziger Satz, nämlich von Herrn Steiger: „Für Gleichstellungen homosexueller Verbindungen

${ }^{1}$ BVerfG, U. vom 19.2.2013 - 1 BvL 1/11 - [Sukzessivadoption], Abs. 55.

2 A. Frhr. v. Campenhausen und H. Steiger Verfassungsgarantie und sozialer Wandel - Das Beispiel von Ehe und Familie, VVDStRL 45 (1987), 7-54 bzw. 55-93.

${ }^{3}$ Vgl. mit den bei $v$. Campenhausen Verfassungsgarantie und sozialer Wandel (Fn. 2), 8-10, wiedergegebenen Zahlen die aus dem Statistischen Jahrbuch 2012, hrsg. vom Statistischen Bundesamt, abrufbar unter <http://www.destatis.de/jahrbuch $>$, Kapitel 2.6 („Familien, Kinder und Lebensformen“, 51-64). Zusammenfassend etwa F. Gräfin Nesselrode Das Spannungsverhältnis zwischen Ehe und Familie in Artikel 6 des Grundgesetzes, 2007, 27-61; K. Stern Der Schutz von Ehe, Familie und Eltern/KindBeziehung (§ 100), in: ders./M. Sachs/J. Dietlein, Das Staatsrecht der Bundesrepublik Deutschland, Bd. IV/1, 2006, 315-649 (330 f.). Mit kulturkritischem Akzent P. J. Tettinger Der grundgesetzlich gewährleistete besondere Schutz von Ehe und Familie, in: H. Marré/D. Schümmelfeder/B. Kämper (Hrsg.) Ehe und Familie unter veränderten gesellschaftlichen Rahmenbedingungen, Essener Gespräche zum Thema Staat und Kirche, Bd. 35, 2001, 117-157 (117-126). 
sehe ich weder Notwendigkeit noch Raum." ${ }^{4}$ Das dürfte einem breiten gesellschaftlichen, politischen und rechtswissenschaftlichen Konsens entsprochen haben. Die heute insoweit völlig veränderte Lage ist gekennzeichnet durch die Einführung der eingetragenen Lebenspartnerschaft als familienrechtliches Institut neben der Ehe durch das Lebenspartnerschaftsgesetz von $2001,{ }^{5}$ dessen verfassungsgerichtliche Bestätigung durch die Entscheidung des Bundesverfassungsgerichts vom 17. Juli 2002, ${ }^{6}$ die nachfolgende Übertragung fast aller Rechtsfolgen der Ehe auf die eingetragene Lebenspartnerschaft teils durch den Gesetzgeber, ${ }^{7}$ teils durch das Bundesverfassungsgericht, bis hin zu den beiden wichtigen Entscheidungen zur Adoption und zum einkommensteuerrechtlichen Splittingverfahren aus diesem Jahr $2013,{ }^{8}$ und eine diesen Rechtsänderungen teils voraus-, teils nachlaufende breite politische, gesellschaftliche und rechtswissenschaftliche ${ }^{9}$ Akzeptanz. Selbstverständlich gibt es noch etliche

${ }^{4}$ Steiger Verfassungsgarantie und sozialer Wandel (Fn. 2), 79. In der Aussprache dazu nur R. Steinberg, 139.

${ }^{5}$ Gesetz über die Eingetragene Lebenspartnerschaft (Lebenspartnerschaftsgesetz LPartG), erlassen als Art. 1 des Gesetzes zur Beendigung der Diskriminierung gleichgeschlechtlicher Gemeinschaften: Lebenspartnerschaften vom 16.2.2001 (BGBl. I 266).

${ }^{6}$ BVerfGE 105, 313-357, mit abweichenden Meinungen Papier, 357-359; Haas, 359-365.

${ }^{7}$ Gesetz zur Überarbeitung des Lebenspartnerschaftsrechts vom 15.12.2004 (BGBl. I 3396).

${ }^{8}$ BVerfG, B. vom 7.7.2009 - 1 BvR 1164/07 - [Hinterbliebenenversorgung] = E 124, 199-235; B. vom 21.7.2010 - 1 BvR 611/071, 2464/07 - [Erbschafts- und Schenkungssteuer $]=$ E 126, 400-433; B. vom 19.6.2012 -2 BvR 1397/09 - [Familienzuschlag] $=$ E 131, 239-267; B. vom 18.7.2012 - 1 BvL 16/11 - [Grunderwerbsteuerbefreiung] = E 132, 179-194; U. vom 19.2.2013 - 1 BvL 1/11 - [Sukzessivadoption]; B. vom 7.5.2013 - 2 BvR 909/06, 1981/06, 288/07 - [Lebenspartner-Splitting].

${ }_{9}$ Repräsentativ C. D. Classen Dynamische Grundrechtsdogmatik von Ehe und Familie?, DVB1. 2013, 1086-1093 (1089). Zur Erinnerung seien hier aber noch einige kritischen Stimmen aufgeführt: J. Benedict Die Ehe unter dem besonderen Schutz der Verfassung - Ein vorläufiges Fazit, JZ 2013, 477-487; G. D. Gade/C. Thiele Ehe und eingetragene Lebenspartnerschaft: Zwei namensverschiedene Rechtsinstitute gleichen Inhalts? - 10 Jahre Rechtsprechung des Bundesverfassungsgerichts zur eingetragenen Lebenspartnerschaft, DÖV 2013, 142-151; K. F. Gärditz Gemeinsames Adoptionsrecht Eingetragener Lebenspartner als Verfassungsgebot?, JZ 2011, 930-939; C. Hillgruber Anmerkung [zu BVerfG, B. vom 7.7.2009 - 1 BvR 1164/07 - Hinterbliebenenversorgung], JZ 2010, 41-44; R. Scholz/A. Uhle „Eingetragene Lebenspartnerschaft“ und Grundgesetz, NJW 2001, 393-400; U. Steiner Schutz von Ehe und Familie (§ 108), in: D. Merten/H.-J. Papier (Hrsg.) Handbuch der Grundrechte in Deutschland und Europa, Bd. IV, 2011, 1249-1278 (Rn. 32-39); Stern (Fn. 3), 486-490; P. J. Tettinger Kein Ruhmesblatt für „Hüter der Verfassung“, JZ 2002, 1146-1152; A. Uhle in: V. Epping/ C. Hillgruber (Hrsg.) Grundgesetz. Kommentar, 2. Aufl. 2013, auch als: Beck'scher Online-Kommentar, Edition 18 (Stand 15.5.2013), Art. 6 Rn. 36-38. 
andere Bewegungen im Recht von Ehe und Familie als diese; ${ }^{10}$ aber wenn wir nach Dynamik suchen, finden wir sie hier in exemplarischer Prägnanz.

Das Grundgesetz rechnet mit Veränderungen des gesellschaftlichen Konsenses. Es organisiert dessen Dynamik in der Macht der parlamentarischen Mehrheit, durch Gesetzgebung die Zukunft zu gestalten. Der Wandel des gesellschaftlichen Konsenses erreicht die Entscheidungen der Verfassung selbst unter der Bedingung, daß er in den qualifizierten Mehrheiten des Art. 79 Abs. 2 GG signifikant wird.

Wo die politische Dynamik für eine Änderung der Verfassung zu schwach ist, sucht sie Eingang in die Auslegung der Verfassung. Sie kleidet sich in die These, daß der gleichbleibende Sinn der Verfassung ihr schon immer entsprochen habe oder ihr jedenfalls jetzt entspreche. Soweit sie damit keinen Erfolg hat, wird sie als verfassungswidrig zurückgewiesen. Soweit sie sich durchsetzt, gilt ihr Erfolg als Verfassungswandel. ${ }^{11}$

10 Konzis und zugleich material- wie gedankenreich erörtert von Classen (Fn. 9) mit dem Gesamtergebnis: Im Hinblick auf die „Funktionen, die die Garantien von Ehe und Familie nach Art. 6 Abs. 1 GG erfüllen sollen“, sei ,keine ,besondere“ Dynamik zu verzeichnen" (1093).

11 Hierzu allgemein $P$. Badura Verfassungsänderung, Verfassungswandel, Verfassungsgewohnheitsrecht ( $§ 160)$, in: J. Isensee/P. Kirchhof (Hrsg.) Handbuch des Staatsrechts der Bundesrepublik Deutschland (HStR), 1. Aufl., Bd. VII, 1992, 57-77 (Rn. 13-15); B.-O. Bryde Verfassungsentwicklung. Stabilität und Dynamik im Verfassungsrecht der Bundesrepublik Deutschland, 1982; W. Fiedler Sozialer Wandel, Verfassungswandel, Rechtsprechung, 1972; K. Hesse Grenzen der Verfassungswandlung, FS Scheuner, 1973, 123-141; P. Lerche Stiller Verfassungswandel als aktuelles Politikum, FS Maunz, 1971, 285-300; J. Masing Zwischen Kontinuität und Diskontinuität: Die Verfassungsänderung, in: R. Wahl (Hrsg.) Verfassungsänderung, Verfassungswandel, Verfassungsinterpretation, 2008, 131-146 (142-146); H. Schulze-Fielitz Verfassung als Prozeß von Verfassungsänderungen ohne Verfassungstextänderungen, ebd., 219-232 (223 f., 227 f., 229-232); C. Walter Hüter oder Wandler der Verfassung? Zur Rolle des Bundesverfassungsgerichts im Prozeß des Verfassungswandels, AöR 125 (2000), 517550; kritisch E. W. Böckenförde Anmerkungen zum Begriff Verfassungswandel, FS Lerche, 1993, 3-14; C. Hillgruber Verfassungsrecht zwischen normativem Anspruch und politischer Wirklichkeit, VVDStRL 67 (2008), 7-56 (8-20, 45-51); M. Jestaedt Verfassungsgerichtspositivismus. Die Ohnmacht des Verfassungsgesetzgebers im verfassungsgerichtlichen Jurisdiktionsstaat, FS Isensee, 2002, 185-228 (188-203); A. Voßkuhle Gibt es und wozu nutzt eine Lehre vom Verfassungswandel?, in: Wahl (Hrsg.) a.a. O., 201-216. - Allgemein mit Blick auf Art. 6 GG kritisch M. Burgi in: K. H. Friauf/W. Höfling (Hrsg.) Berliner Kommentar zum Grundgesetz, Losebl., 2000 ff. (Stand: 42. Lieferung, 2013), Art. 6 GG (Stand: 2002-2007), Rn. 15; C. von Coelln in: M. Sachs (Hrsg.) Grundgesetz. Kommentar, 6. Aufl. 2011, Art. 6 Rn. 3; H. Lecheler Verfassungsgarantie und sozialer Wandel. Das Beispiel von Ehe und Familie, DVB1. 1986, 905-911; eingehend $C$. Rijsbergen Der besondere Schutz von Ehe und Familie. Die verfassungsrechtliche Einordnung nichtehelicher Lebensgemeinschaften und Lebenspartnerschaften 
Ausweis ihres Erfolgs ist eine ausreichend stabile Bestätigung durch das Verfassungsgericht und deren bleibender Eindruck auf die Verfassungsrechtswissenschaft. Wessen Vorstellungshorizont das etwa überschreiten sollte, der darf sich - passend zum Richard-Wagner-Jahr - in eine Szene aus der „Walküre“ einfühlen, wo - passend zu unserem Thema - ein saftiger Ehekrach zwischen Fricka und Wotan tobt, in dessen Verlauf Fricka, die Hüterin von Ehe und Familie, sich über den ehebrecherischen Inzest der Wälsungenzwillinge, ihrerseits übrigens Resultat einer außerehelichen Eskapade Wotans, beschwert und ihn anschreit: „Mir schaudert das Herz, es schwindelt mein Hirn: bräutlich umfing die Schwester der Bruder! Wann - ward es erlebt, dass leiblich Geschwister sich liebten?", worauf sie die trockene Antwort erhält: „Heut' - hast du's erlebt: erfahre so[,] was von selbst sich fügt, sei zuvor auch nie es gescheh'n." ${ }^{2}$

Die Inanspruchnahme eines Verfassungswandels als verfassungsrechtliches Argument ist prekär. Insbesondere das Bundesverfassungsgericht, von dem viele erwarten, daß es sich bei seinen Beiträgen zur Zukunftsgestaltung an die Verfassung hält, statt sie zu wandeln, muß alle Dynamik im Verfassungsrecht als durch die Verfassung determiniert vorstellen. Hierfür kommt es auf die Grundrechtsdogmatik an. Grundrechtsdogmatik kann „dynamisch" heißen, wenn sie die Reichweite und die Wirkungen des Grundrechts an dynamische Veränderungen seines Gegenstands anzu-

unter dem Blickwinkel des Verfassungswandels, 2005. Besonders mit Blick auf den jüngeren Verständniswandel zu Art. 6 Abs. 1 GG kritisch Steiner (Fn. 9), Rn. 3; mit besonderem Verweis auf die demokratische Funktion des Verfahrens zur Verfassungsänderung nach Art. 79 Abs. 1 und 2 GG zum Beispiel Benedict (Fn. 9), 481-487; Gade/Thiele (Fn. 9), 144 f., 151; Gärditz (Fn. 9), 934, 938. Für ein Verständnis des Art. 6 Abs. 1 GG als Ermächtigung des einfachen Gesetzgebers zur „Verfassungsentwicklung“ S. Rixen Das Ende der Ehe? - Neukonturierung der Bereichsdogmatik von Art. 6 Abs. 1 GG: ein Signal des spanischen Verfassungsgerichts, JZ 2013, 864-873 (872 f.); ähnlich schon W. Höfling Offene Grundrechtsinterpretation. Grundrechtsauslegung zwischen amtlichem Interpretationsmonopol und privater Konkretisierungskompetenz, 1987, $194 \mathrm{f}$. Für eine Befugnis des Bundesverfassungsgerichts, „die Grenzen des Verfassungswandels“ im Sinne „einer sehr europarechtsfreundlichen dynamischen Auslegung des nationalen Verfassungsrechts“ hinter sich zu lassen, um „europäische Tendenzen“ vorwegnehmend mitzugestalten, wozu ein "Grundrechtswandel kraft europäischer Integration [...] als eigenständige Kategorie der Verfassungsinterpretation begriffen werden" solle, L. Michael Lebenspartnerschaften unter dem besonderen Schutze einer (über-)staatlichen Ordnung. Legitimation und Grenzen eines Grundrechtswandels kraft europäischer Integration, NJW 2010, 3537-3542 (zit.: 3539, 3540).

${ }^{12}$ R. Wagner Die Walküre. Erster Tag aus der Trilogie: Der Ring des Nibelungen, Zweiter Aufzug, zitiert nach der Ausgabe: R. Wagner, Der Ring des Nibelungen. Vollständiger Text mit Notentafeln der Leitmotive, hrsg. von J. Burghold, 1913 (Nachdruck 1981, 6. Aufl. 1994), 107. 
passen fähig ist. In einem gesteigerten Sinn kann sie „dynamisch“ heißen, wenn sie darüber ihre eigene Gestalt verändert.

Durch die vielfältigen Aspekte des Themas kann ich nur eine schmale Spur legen. Ich konzentriere mich darauf, die Grundrechtsdogmatik zu Art. 6 Abs. 1 und 2 GG erstens als Gegenstand der Dynamik in den Blick zu nehmen (II.), zweitens an ausgewählten Punkten auf Wirksamkeit der Dynamik zu untersuchen (III.) und schließlich mit einem Vorschlag für die Zukunft der Dynamik auszustatten (IV.).

\section{Gegenstand der Dynamik: Grundrechtsdogmatik von Ehe und Familie}

\section{Die dynamische und die antidynamische Intention der Grundrechtsdogmatik}

Grundrechtsdogmatik ${ }^{13}$ erschließt der Auslegung und Anwendung von Grundrechtsnormen in der Darstellung von Tatbestand und Rechtsfolge, Ratio und Systematik Formen der Verallgemeinerung. Damit wirkt Grundrechtsdogmatik auf die Auslegung und Anwendung der Grundrechte stabilisierend, vermittelt sie mit der Allgemeinheit der Norm, weist ihre Rationalität, Konsistenz und Kontinuität aus. Soweit sie sich entwickeln, verändern und anpassen muß, um ihre Funktion dauerhaft zu erfüllen, ${ }^{14}$ hat sie eine dynamische Intention. Doch gegenüber der Dynamik politischer Ansprüche auf Zukunftsgestaltung wirkt Grundrechtsdogmatik widerständig, dämpfend und bremsend. ${ }^{15}$ Insofern sperrt sich Grundrechtsdogmatik dagegen, dynamisch zu sein.

So lassen denn auch die Elemente der Grundrechtsdogmatik zu Art. 6 GG in Rechtsprechung und Literatur äußerlich wenig Dynamik erkennen. Sie sind zwar selbst Produkt einer dynamischen Aufbauarbeit vor

13 Als eine jüngere Reflexion über die Aufgaben, Leistungen und Versuchungen der Rechtsdogmatik siehe nur G. Kirchhof/S. Magen/K. Schneider (Hrsg.) Was weiß Dogmatik? Was leistet und wie steuert die Dogmatik des Öffentlichen Rechts?, 2012.

14 Mit Blick auf Art. 6 GG: G. Robbers in: H. von Mangoldt (Begr.)/F. Klein/ C. Starck (Hrsg.) Kommentar zum Grundgesetz, Bd. 1, 6. Aufl. 2010, Art. 6 Rn. 32; Steiger Verfassungsgarantie und sozialer Wandel (Fn. 2), 77; R. Zippelius Verfassungsgarantie und sozialer Wandel - Das Beispiel von Ehe und Familie, DÖV 1986, 805-810 (806-808).

15 Entsprechend zur „Funktion der Verfassungsgarantie des Gegebenen“ gegenüber dem sozialen Wandel mit Verweis auf die „Erfahrung der bewährten Vernünftigkeit des Gegebenen als Gewordenem“ Steiger Verfassungsgarantie und sozialer Wandel (Fn. 2), 74 f. Siehe auch Lerche (Fn. 11), 292 f., der eine Begrenzung zulässigen Verfassungswandels im „Zeitfaktor“ sucht, da ein „Neuverständnis der Verfassung“ nicht aufgehalten, sondern nur ,,verlangsamt" werden könne. 
allem in den ersten Jahren der Auslegung des Grundgesetzes. ${ }^{16}$ Doch jeder Aufbau und Ausbau der Grundrechtsdogmatik verengt nach und nach die Räume für weitere dynamische Entwicklungen. Die Mittel zum Verständnis davon, was die Verfassung determiniert, werden mit ihrem Gebrauch selbst zu Determinanten des Verständnisses. Eine festgefügte Grundrechtsdogmatik erhöht die Determinierungsdichte der Verfassungsnorm. Will ihr gegenüber neue Dynamik Platz greifen, muß sie kräftig genug sein, um den Altbestand mit Umbau, Abbau oder auch Teilabriß zu überwinden. Mit dem dafür jeweils erforderlichen Veränderungsaufwand steigen die argumentativen Kosten.

\section{Elemente der Grundrechtsdogmatik von Ehe und Familie}

Entsprechend stabil sind die Definitionen, die die Tatbestände des Art. 6 Abs. 1 und 2 GG beschreiben. „Ehe“ ist „die Vereinigung eines Mannes mit einer Frau zu einer auf Dauer angelegten Lebensgemeinschaft [...], begründet auf freiem Entschluss unter Mitwirkung des Staates“". ${ }^{17}$

${ }^{16}$ Zur Abgrenzung von einem Verständnis des Art. 6 GG als unverbindliche Programmnorm, gegen das die Kategorie der ,wertentscheidenden Grundsatznorm“ überhaupt erst ausgeprägt wurde, siehe die Leitentscheidung BVerfGE 6, 55 (71-77); entsprechend gewürdigt bei Stern (Fn. 3), 406. Zum vorausgehenden Stand der Grundrechtsdogmatik des Art. 6 GG siehe H. von Mangoldt Das Bonner Grundgesetz, 1953, Anm. 2, 4; T. Maunz Deutsches Staatsrecht, 6. Aufl. 1957, 112; K.-G. Wernicke in: Bonner Kommentar zum Grundgesetz, Art. 6 (Erstbearbeitung 1950), Erl. vor 1. - Zur Abgrenzung gegen Versuche, den vorkonstitutionell überkommenen Vorrang des Ehemannes und Vaters auch nach Ablauf des Moratoriums gemäß Art. 117 Abs. 1 GG über Art. 6 GG gegen die Gleichberechtigung von Männern und Frauen nach Art. 3 Abs. 2 GG auszuspielen, siehe BVerfGE 3, 225 (241 f.). Für die gesetzgeberische Nacharbeit am vorkonstitutionellen Recht stehen das Gesetz über die Gleichberechtigung von Mann und Frau auf dem Gebiete des bürgerlichen Rechts (Gleichberechtigungsgesetz) vom 18.7.1957 (BGBl. I 609), das Erste Gesetz zur Reform des Ehe- und Familienrechts vom 14.6.1976 (BGBl. I 1421), das Gesetz zur Neuregelung des Rechts der elterlichen Sorge vom 18.7.1979 (BGBl. I 1061) und das Zweite Gleichberechtigungsgesetz vom 24.6.1994 (BGBl. I 1406). Zusammenfassend C. Franzius Bonner Grundgesetz und Familienrecht. Die Diskussion um die Gleichberechtigung von Mann und Frau in der westdeutschen Zivilrechtslehre der Nachkriegszeit (1945-1957), 2005; Stern (Fn. 3), 379-383. - Zur Teilnahme der Auslegung des Art. 6 GG an der dynamischen Entwicklung der freiheitsrechtlichen Schutzbereichs-, Eingriffs- und Schrankendogmatik sowie der Schutzpflichtendogmatik siehe zusammenfassend $P$. Häberle Verfassungsschutz der Familie - Familienpolitik im Verfassungsstaat, 1984, $28 \mathrm{f}$.

${ }_{17}$ BVerfGE 105, 313-357 (345) [Lebenspartnerschaftsgesetz], insoweit mit Verweisen auf BVerfGE 10, 59 (66); 29, 166 (176); 62, 323 (330). Näher Robbers (Fn. 14), Rn. 38; Stern (Fn. 3), 370-372, jeweils mit weiteren Nachweisen - Anderer Ansicht F. BrosiusGersdorf in: H. Dreier (Hrsg.) Grundgesetz - Kommentar, Bd. I, 3. Aufl. 2013, Art. 6 Rn. 49 f. 
„Familie“ ist die „Gemeinschaft von Eltern und Kindern“.18 „Eltern“ eines Kindes sind die Personen, von denen das Kind unmittelbar abstammt oder die das Gesetz ihm als Eltern zuordnet. ${ }^{19}$

Ebenso stabil ist die grundrechtsdogmatische Darstellung der Rechtsfolgen des Art. 6 Abs. 1 GG. Der „,besondere Schutz“ von Ehe und Familie bindet die staatliche Gewalt als subjektives Abwehrrecht, als Institutsgarantie und als „wertentscheidende Grundsatznorm“. ${ }^{20}$ Das subjektive Abwehrrecht verbietet dem Staat nichtgerechtfertigte Eingriffe in die Schutzbereiche von Ehe und Familie. ${ }^{21}$ Die Institutsgarantie gebietet es dem Gesetzgeber, das Ehe- und Familienrecht so zu gestalten und in seinem „Normenkern“ ${ }^{22}$ zu erhalten, daß Ehe und Familie im Sinne der Verfassung rechtlich wirksam werden können. Die Qualifikation des Art. 6 Abs. 1 GG als „wertentscheidende Grundsatznorm“ verallgemeinert das Gebot des „besonderen Schutzes“ zu einer „verbindliche[n] Wertentscheidung für den gesamten Bereich des Ehe und Familie betreffenden privaten und öffentlichen Rechts". 23

Die Ratio des besonderen Schutzes von Ehe und Familie in Art. 6 Abs. 1 GG umfaßt zum einen, gemäß der Ratio aller Freiheitsrechte, die privaten Interessen der Grundrechtsträger an ihrer Freiheitsentfaltung in Ehe und Familie. ${ }^{24}$ Zum anderen umfaßt sie zugleich ein öffentliches

18 BVerfGE 10, 59 (66); 48, 327 (339); 79, 256 (267); 80, 81 (90); 108, 82 (112); 127, 263 (287); BVerfG, U. vom 19.2.2013 - 1 BvL 1/11 - [Sukzessivadoption], Abs. 62; Robbers (Fn. 14), Rn. 81; Stern (Fn. 3), 395 f. mit umfassenden Nachweisen.

19 BVerfG, U. vom 19.2.2013 - 1 BvL 1/11 - [Sukzessivadoption], Abs. 58, im Anschluß an die differenzierten Ausführungen über das Verhältnis zwischen leiblicher Elternschaft und Elternrecht bei BVerfGE 108, 82 (99-104). Für die Elternschaft aufgrund Abstammung siehe BVerfGE 24, 119 (135) - Eltern des ehelichen und Mutter des nichtehelichen Kindes; BVerfGE 92, 158 (176-179) - nichtehelicher Vater; für das Elternrecht kraft Adoption BVerfGE 24, 119 (150).

${ }^{20}$ Vom Bundesverfassungsgericht im Anschluß an die entsprechende Auslegung des Schutzgebots in BVerfGE 6, 55 (71-77) so aufgezählt seit BVerfGE 24, 119 (135); siehe etwa BVerfGE 31, 58 (67); 62, 323 (329); 76, 1 (49); 80, 81 (92 f.); zugrundegelegt auch in BVerfGE 105, 313 (342, $344 \mathrm{f} ., 346)$ [Lebenspartnerschaftsgesetz].

${ }^{21}$ Burgi (Fn. 11), Rn. 24-28; Nesselrode (Fn. 3), 132-138; Robbers (Fn. 14), Rn. 8; Stern (Fn. 3), 407.

22 BVerfGE 6, 55 (72); bzw. „Strukturprinzipien“: BVerfGE 10, 59 (66); 31, 58 (69); 36, 146 (162); 53, 224 (245); 105, $313(345,348)$.

${ }^{23}$ BVerfGE 6, 55 (72); zuletzt wiederholt in BVerfG, B. vom 7.5.2013 - 2 BvR 909/06, 1981/06, 288/07 - [Lebenspartner-Splitting], Abs. $81 \mathrm{mwN}$; jeweils wortgleich zum Beispiel BVerfG, B. vom 21.7.2010 - 1 BvR 611/071, 2464/07 - [Erbschafts- und Schenkungssteuer], Abs. 90 = E 126, 400 (420); B. vom 19.6.2012 - 2 BvR 1397/09 [Familienzuschlag], Abs. 65 = E 131, 239 (259); B. vom 18.7.2012 - 1 BvL 16/11 [Grunderwerbsteuerbefreiung], Abs. 48 = E 132, 179 (191: Rn. 39).

${ }^{24}$ D. Pirson in: W. Kahl/C. Waldhoff/C. Walter (Hrsg.) Bonner Kommentar zum Grundgesetz, Losebl., 1950 ff. (Stand: 162. Aktualisierung, Juli 2013), Art. 6 Abs. 1 
Interesse an Ehe und Familie als elementaren Sozialstrukturen, auf deren regenerative, soziale und kulturelle ${ }^{25}$ Leistungen Staat und Gesellschaft für ihr physisches Fortbestehen, ${ }^{26}$ ihre ethische Substanz ${ }^{27}$ und ihre volkswirtschaftliche Wohlfahrt angewiesen sind. ${ }^{28}$ Das öffentliche Interesse

(Zweitbearbeitung, Stand: 36.-77. Lieferung, 1976-1996), Rn. 27, 51 f.; Robbers (Fn. 14), Rn. 11, 33, 34; Steiger Verfassungsgarantie und sozialer Wandel (Fn. 2), 56-70, 76 f.; Stern (Fn. 3), 408; kritisch P. Badura in: T. Maunz/G. Dürig (Begr.) Grundgesetz - Kommentar, Losebl., Art. 6 (Stand: 69. Lieferung, Mai 2013), Rn. 38; anders (hinsichtlich der Eheschließungsfreiheit) auch R. Gröschner in: H. Dreier (Hrsg.) Grundgesetz - Kommentar, Bd. I, 2. Aufl. 2004, Art. 6 Rn. 53. - Die Familie ist geschützt als eine anthropologische Konstante, ,eine Gemeinschaft, die der auf Dialog angelegten geistigen Natur des Menschen entspricht"; so BVerfGE 80, 81 (91), im Anschluß an BVerfGE 76, 1 (51); dazu Robbers (Fn. 14), Rn. 83 f. Insoweit geht es um den „Schutz der spezifisch psychologischen und sozialen Funktion familiärer Bindungen“; BVerfG, U. vom 19.2.2013 - 1 BvL 1/11 - [Sukzessivadoption], Abs. 62.

${ }_{25}$ Häberle (Fn. 16), 7, 14 f., 30-32, 55.

${ }^{26}$ Robbers (Fn. 14), Rn. 46. Für die Ehe hervorgehoben in der abweichenden Meinung Landau/Kessal-Wulf zu BVerfG, B. vom 7.5.2013 - 2 BvR 909/06, 1981/06, 288/07 - [Lebenspartner-Splitting], Abs. 118. Ähnlich J. Ipsen Ehe und Familie, in: HStR (Fn. 11), 3. Aufl., Bd. VII, 2009, 431-476, Rn. 14-17; Scholz/Uhle (Fn. 9), 393 f. Auf die Familie beschränkt und zu einer ,staatlichen Pflichtaufgabe“ „Reproduktion der Bevölkerung" gesteigert bei F. Brosius-Gersdorf Demografischer Wandel und Familienförderung, 2011, 181-191, 247-254; moderater erkennt W. Kluth Demografischer Wandel und Generationengerechtigkeit, VVDStRL 68 (2009), 246-289 (279), Art. 6 Abs. 1 GG als ,in die Zukunft gerichtet“ und ,eine ausreichende Grundlage für alle staatlichen Maßnahmen der Familienförderung". Einschränkend Burgi (Fn. 11), Rn. 38.

${ }_{27}$ H. Lecheler Schutz von Ehe und Familie (§ 133), in: HStR (Fn. 11), 1./2. Aufl., Bd. VI, 1989/2001, 211-264, Rn. 14: Ehe und Familie berühren die „sittlichen Fundamente eines Staates und eines Volkes"; dem folgend Stern (Fn. 3), 405; siehe als einen Brückenschlag von einer individualethischen zu einer sozialethischen Bestimmung der Ehe P. Mikat, Ethische Strukturen der Ehe in unserer Zeit - Zur Normierungsfrage im Kontext des abendländischen Eheverständnisses, in: H. Marré/J. Stüting (Hrsg.) Der Schutz von Ehe und Familie, Essener Gespräche zum Thema Staat und Kirche, Bd. 21, 1986, 9-49.

${ }^{28}$ Im Parlamentarischen Rat wurde resümiert, „daß in den Debatten eine Meinungsverschiedenheit darüber, daß Ehe und Familie die wichtigste Grundlage des Staates sind [...], eigentlich nicht bestand"; Abg. Weber, Dritte Lesung am 8.5.1949, in: Der Parlamentarische Rat, 1948-1949. Akten und Protokolle, hrsg. vom Deutschen Bundestag und vom Bundesarchiv, Bd. 9: Plenum, 1996, 578 f.; in diesem Sinne etwa Abg. Wessel (Z), ebd., 556. - Die vom Bundesverfassungsgericht hierzu anfangs aufgenommene Kennzeichnung von „Ehe und Familie als die Keimzelle jeder menschlichen Gemeinschaft, deren Bedeutung mit keiner anderen menschlichen Bindung verglichen werden kann" - BVerfGE 6, 55 (71); wiederholt in BVerfGE 24, 119 (149) - benutzt mit der „Keimzelle“ zwar ein vielleicht etwas derbes biologisches Bild, das inzwischen aus der Mode gekommen ist, gehört aber der Sache nach durchgängig zur Beschreibung der Ratio des Art. 6 Abs. 1 GG, etwa über die "Gemeinschaftsfunktion“ von Ehe und 
erkennt in diesen Leistungen von Ehe und Familie Verfassungsvoraussetzungen ${ }^{29}$ und verbindet mit dem Schutz der Freiheitsentfaltung in Ehe und Familie entsprechende Verfassungserwartungen. ${ }^{30}$ So betrachtet, zielt die Ratio von Art. 6 GG auf Zukunftsgestaltung durch öffentliches Recht.

\section{Der Schutzbereich von Institutsgarantie und Wertentscheidung: Ansätze einer Leitbildgarantie}

Die antidynamische Intention des grundrechtsdogmatischen Gebäudes von Art. 6 GG hat in den Wirkungen des Ehe- und Familienschutzes als Institutsgarantie und wertentscheidende Grundsatznorm eine spezifische Gestalt.

Die Institutsgarantie ${ }^{31}$ sichert den Vorrang der Verfassungsnorm vor einer Dynamik, welche über das einfache Gesetzesrecht die auf normative Ausformung angewiesenen Schutzgegenstände des Art. 6 GG in ihrem „Ordnungskern“32 umzuformen unternähme. Die Strukturmerkmale des

Familie bei Robbers (Fn. 14), Rn. 35, 85; sozialphilosophisch ausgeleuchtet von $U . D i$ Fabio Der Schutz von Ehe und Familie: Verfassungsentscheidung für die vitale Gesellschaft, NJW 2003, 993-998; aufgeschlüsselt bei Nesselrode (Fn. 3), 100-111; Pirson (Fn. 24), Rn. 26-30. Anders, nämlich die Funktion dem „Wesen“ von Ehe und Familie unterordnend, Badura (Fn. 24), Rn. 38. Zum Zusammenhang mit dem Subsidiaritätsprinzip S. Westermeyer Die Herausbildung des Subsidiaritätsverhältnisses zwischen Familie und Staat und seine heutige Bedeutung im Grundgesetz, 2010.

${ }_{29}$ Dagegen $S$. Baer Demografischer Wandel und Generationengerechtigkeit, VVDStRL 68 (2009), 290-354 (300-307), mit zutreffenden Vorbehalten gegenüber weltanschaulichen Fixierungen, aber auch mit Verweis auf die Rolle des Gesetzgebers (der sich vielleicht auch für den besonderen Schutz von Ehe und Familie entscheiden könnte) und auf die „produktivere“ „Frage nach den Wirksamkeitsbedingungen von Verfassungsstaatlichkeit" (zu denen vielleicht auch das Heranwachsen der jeweils nächsten Generation und die Erziehung von Kindern gehört). An die Stelle von Eheund Familienschutz setzt sie eine ,systematische Orientierung auf individuelle reproduktive Rechte" (315-327).

${ }^{30} \mathrm{Zu}$ dieser Kategorie mit allen nötigen Abgrenzungen gegen eine Vereinnahmung der Freiheit $J$. Isensee Grundrechtsvoraussetzungen und Verfassungserwartungen an die Grundrechtsausübung (§ 190), in: HStR (Fn. 11), 3. Aufl., Band IX, 2011, 265-411, Rn. 204-321, speziell zum Schutz der Ehe und des Elternrechts: Rn. 219, 230.

${ }^{31}$ Grundlegend aufgearbeitet und in einen dogmatischen Zusammenhang gebracht von U. Mager Einrichtungsgarantien. Entstehung, Wurzeln, Wandlungen und grundgesetzgemäße Neubestimmung einer dogmatischen Figur des Verfassungsrechts, 2003, 195-223, 421-425, 451-458.

${ }^{32}$ Mit einem „Ordnungskern“ oder „Normenkern“ des Ehe- und Familienrechts (siehe oben Fn. 22) formuliert die Grundrechtsdogmatik zu Art. 6 Abs. 1 GG die Grenze zwischen verfassungsgemäßer Ausgestaltung und verfassungswidriger Umgestaltung. - Der Einsicht, daß das Institut jenseits dieser Strukturmerkmale der einfach- 
garantierten Instituts berühren sich weitgehend mit den Schutzbereichsmerkmalen des Freiheitsrechts, sind aber systematisch davon zu unterscheiden und nicht deckungsgleich. Zum Beispiel gehört zu den Strukturmerkmalen der Ehe die Monogamie; ${ }^{33}$ die Institutsgarantie verpflichtet insoweit den Gesetzgeber, eine Eheschließung bei bereits bestehender Ehe zu versagen (§ 1306 BGB). Die Festlegung der Institutsgarantie auf die Einehe hindert aber nicht daran, eine nach ausländischem Recht gültig geschlossene Mehrehe unter den Schutzbereich des Abwehrrechts aus Art. 6 Abs. 1 GG zu subsumieren. ${ }^{34}$ Der Gegenstand der Institutsgarantie hat also gegenüber dem des Abwehrrechts einen Überschuß an Merkmalen.

Als wertentscheidende Grundsatznorm soll Art. 6 Abs. 1 GG über die Rechtsgestalt der Institute hinaus den ,Wert' von Ehe und Familie im „gesamten Bereich des Ehe und Familie betreffenden privaten und öffentlichen Rechts“"35 der gesellschaftspolitischen Wertedynamik entziehen und

gesetzlichen Regelung bedarf, gilt der Verweis auf die „Ausgestaltung, wie sie den herrschenden, in der gesetzlichen Regelung maßgebend zum Ausdruck gelangten Anschauungen entspricht“; BVerfGE 31, 58 (82 f.); 53, 224 (245); kritisch dazu Lecheler Schutz von Ehe und Familie (Fn. 27), Rn. 15 f.; Mager (Fn. 31), 204 f.; ähnlich in Unterscheidung von einem nur überkommenen, aber nicht mehr herrschenden „Vorstellungsbild" von der Ehe BVerfGE 36, 146 (163 f.); weiter gelockert durch einen Verweis auf die ,jeweils herrschenden Anschauungen“ in BVerfGE 105, 313 (345) [Lebenspartnerschaftsgesetz]; kritisch dazu die abweichende Meinung Papier, 357-359; Stern (Fn. 3), 369. - Die Garantie in Art. 6 GG soll zugleich offen für den Wandel gesellschaftlicher Anschauungen und unwandelbar in ihrem Ordnungskern sein; K. H. Friauf Verfassungsgarantie und sozialer Wandel - das Beispiel von Ehe und Familie, NJW 1986, 2595-2602 (2596, 2599 f.); F. Gräfin Nesselrode Ehe und Familie, FS Kirchhof, 2013, 609-619, Rn. 6. - Restriktiv hinsichtlich der ,bewahrenden“ Tendenz der Institutsgarantie $M$. Zuleeg Verfassungsgarantie und sozialer Wandel - das Beispiel von Ehe und Familie, NVwZ 1986, 800-807 (801). - Gegenläufig der Hinweis von D. CoesterWaltjen in: I. v. Münch (Begr.)/P. Kunig (Hrsg.) Grundgesetz-Kommentar, Bd. 1, 6. Aufl. 2012, Art. 6 Rn. 3 aE: „die Lösung von festen Strukturen in Ehe und Familie weicht den Schutzschild des Abwehrrechts auf".

33 BVerfGE 29, 166 (176); 31, 58 (69); 62, 323 (330); 105, 313 (343: ,personelle Exklusivität“); Robbers (Fn. 14), Rn. 42; Stern (Fn. 3), 389.

${ }^{34}$ Subsumtion unter „Ehe“: Burgi (Fn. 11), Rn. 19; Coester-Waltjen (Fn. 32), Rn. 8, 35; Robbers (Fn. 14), Rn. 42; Zuleeg (Fn. 32), 802; jedenfalls für polygame Verbindungen, die „nach ihrer Ausgestaltung und Führung einer echten Lebensgemeinschaft entsprechen“, Stern (Fn. 3), 389; offengelassen in BVerfGE 76, 1 (41 f.). Subsumtion unter „Familie“ über die Gemeinschaft mit Kindern: BVerwGE 71, 228 (231); Uhle (Fn. 9), Rn. 3. - Entsprechend verpflichtet Art. 6 Abs. 1 GG dazu, eine nach ausländischem Recht wirksam vor einem Geistlichen, nach deutschem Recht formunwirksam geschlossene, „hinkende“ Ehe anzuerkennen, obwohl nach deutschem Recht die Mitwirkung eines Standesbeamten ,als Ordnungselement wesentliche Bedeutung“ hat; BVerfGE 62, 323 (329-333).

${ }^{35}$ Siehe oben Fn. 23. 
dieser den Schutz und die Förderung von Ehe und Familie voranstellen. ${ }^{36}$ Soweit diese Wirkungsdimension des Art. 6 Abs. 1 GG nicht mit denen als subjektives Abwehrrecht, als objektive Schutzpflicht, ${ }^{37}$ als besonderes Diskriminierungsverbot ${ }^{38}$ und als Institutsgarantie verschwimmen soll, ${ }^{39}$ bedarf sie einer Übersetzung des für sich genommen nichtssagenden, ${ }^{40}$ schillernden, für beliebige Inbesitznahme anfälligen „Wertes“ in normative Merkmale dessen, was die wertentscheidende Grundsatznorm besonders geschützt und gefördert haben will. Diese Merkmale können wiederum anspruchsvoller sein als die Merkmale des abwehrrechtlichen Schutzbereiches und die der garantierten Institute. Sie umschreiben dann Ehe und Familie als ein verfassungsrechtliches Leitbild, ein Modell, eine Normalität, deren Verwirklichung die staatliche Ordnung den Menschen ermöglichen und erleichtern soll.

Spätestens hier scheiden sich die Geister in ihrer Meinung über Art. 6 Abs. 1 GG. Hier löst sich aus dem Wertenebel die - je nach Vorverständnis - Ikone oder Schreckensgestalt von „Mutter, Vater, Kind“. Die Protokolle des Deutschen Bundestages notieren an entsprechender Stelle jeweils den Zwischenruf: „Quatsch!“41 Die rechtswissenschaftliche Literatur scheint etwas aufgeschlossener für den Gedanken zu sein, daß in der Wertentscheidung des Art. 6 Abs. 1 GG für Ehe und Familie so etwas wie

36 Aufgeschlüsselt unter anderem in ein „Abbildungsgebot“ von $M$. Schüffner Eheschutz und Lebenspartnerschaft. Eine verfassungsrechtliche Untersuchung des Lebenspartnerschaftsrechts im Lichte des Art. 6 GG, 2007, 317-325; im Anschluß an M. Burgi Schützt das Grundgesetz die Ehe vor der Konkurrenz anderer Lebensgemeinschaften?, Der Staat 39 (2000), 487-508 (501-508).

37 BVerfGE 6, 55 (76); Nesselrode (Fn. 3), 149-151.

38 BVerfGE 6, 55 (76); 18, 97 (105); 28, 324 (346 f.); 82, 60 (78, 80); ebenso, allerdings unter dem Maßstab des Art. 3 Abs. 1 GG ,in Verbindung mit“ Art. 6 Abs. 1 GG: BVerfGE 18, 257 (269); 67, 186 (195 f.); 75, 382 (393); 87, 234 (255 f.); Coester-Waltjen (Fn. 32), Rn. 37 f.; Robbers (Fn. 14), Rn. 9, 50; Steiner (Fn. 9), Rn. 17.

${ }^{39}$ Ipsen (Fn. 26), Rn. 7: keine höhere Schutzintensität, aber Anerkennung eines „Wertes“.

40 Ablehnend daher H. Goerlich Wertordnung und Grundgesetz. Kritik einer Argumentationsfigur des Bundesverfassungsgerichts, 1973, 113-116.

${ }^{41}$ Deutscher Bundestag, 14. Wahlperiode, Stenographischer Bericht der 115. Sitzung am 7.7.2000, Erste Beratung des Entwurfs eines Gesetzes zur Beendigung der Diskriminierung gleichgeschlechtlicher Gemeinschaften: Lebenspartnerschaften (Lebenspartnerschaftsgesetz - LPartG), 10962 (A): „Sabine Jünger [PDS]: Quatsch!“ 17. Wahlperiode, Stenographischer Bericht der 228. Sitzung am 14.3.2013, Erste Beratung des Entwurfs für ein „Gesetz zur Einführung des Rechts auf Eheschließung für Personen gleichen Geschlechts“, 28489 (D): „Britta Haßelmann [BÜNDNIS 90/DIE GRÜNEN]: Ist doch Quatsch, Herr Geis!“ 
ein Leitbild verfassungsrechtlich wirksam werden soll, ${ }^{42}$ wenngleich ohne eine Leitbildgarantie zum kanonisierten grundrechtsdogmatischen Inventar zu zählen.

Das Bundesverfassungsgericht ist, während es sich fortwährend zur Bedeutung des Art. 6 Abs. 1 GG als wertentscheidende Grundsatznorm bekennt, zurückhaltend damit, sie zu einer Leitbildgarantie von Ehe und Familie zu konkretisieren. Erst recht sind sie übersteigende Aussagen wie die von 1969, „daß nach den in Art. 6 Abs. 1 GG verfassungsrechtlich garantierten Wertvorstellungen die Ehe die einzige legitime Form umfassender Lebensgemeinschaft zwischen Mann und Frau ist und die gesunde körperliche und seelische Entwicklung des Kindes grundsätzlich das Geborgensein in der nur in der Ehe verwirklichten vollständigen Familiengemeinschaft mit Vater und Mutter voraussetzt", ${ }^{43}$ sporadisch geblieben. Ansätze zur Orientierung an einem Leitbild läßt es immerhin dort erkennen, wo es einzelnen Merkmalen der Ehe eine über die Bestimmung des abwehrrechtlichen Schutzbereichs hinausgehende Wertung zuerkennt, etwa die Mehrehe als „der Vorstellung des Grundgesetzes von Ehe und Familie fremd" bezeichnet ${ }^{44}$ oder wie in der Entscheidung von 2002

${ }^{42}$ In unterschiedlicher Akzentuierung: v. Campenhausen Verfassungsgarantie und sozialer Wandel (Fn. 2), 15, 22; Classen (Fn. 9), 1087, 1089; Gärditz (Fn. 9), 931, 935, 937; Di Fabio (Fn. 28); Gröschner (Fn. 24), Rn. 13, 44, 68, 75, 97; Häberle (Fn. 16), 5-9, 24; M. Jestaedt in: Bonner Kommentar (Fn. 24), Art. 6 Abs. 2 und 3 (Stand: 74.-75. Lieferung, 1995), Rn. 53, 66, 256; B. Klein Das neue Eheverbot der bestehenden Eingetragenen Lebenspartnerschaft gemäß $§ 1306$ BGB am Maßstab des Art. 6 Abs. 1 GG. Unter besonderer Berücksichtigung der Stellung der Ehe und der Eingetragenen Lebenspartnerschaft im Gefüge des Grundgesetzes, 2008, 106 f.; Lecheler Schutz von Ehe und Familie (Fn. 27), Rn. 42-47; Nesselrode (Fn. 3), 63, 100 f., 104, 123, 172-177; Rijsbergen (Fn. 11), 133 f., 225 f.; Robbers (Fn. 14), Rn. 17, 163, 165; M. Ruffert Vorrang der Verfassung und Eigenständigkeit des Privatrechts. Eine verfassungsrechtliche Untersuchung zur Privatrechtswirkung des Grundgesetzes, 2001, 404, 414; V. Schmid Die Familie in Artikel 6 des Grundgesetzes, 1989; Schüffner (Fn. 36), 369 f.; C. Seiler Grundzüge eines öffentlichen Familienrechts, 2008, 36 f.; Stern (Fn. 3), 333, 402; Steiner (Fn. 9), Rn. 7, 38; Uhle (Fn. 9), Rn. 14, 17 f.

43 BVerfGE 25, 167 (196). Im Anschluß daran noch 1987: „Die Ehe [...] ist alleinige Grundlage einer vollständigen Familiengemeinschaft und als solche Voraussetzung für die bestmögliche körperliche, geistige und seelische Entwicklung von Kindern“; BVerfGE 76, 1 (52). Weitere Nachweise bei Mager (Fn. 31), $208 \mathrm{f}$.

${ }_{44}$ BVerfGE 76, 1 (41 f.). In derselben Entscheidung erstreckt es die Institutsgarantie bemerkenswerterweise über ,die den Kern des Ehe- und Familienrechts bildenden Vorschriften“ hinaus auf ,bestimmende Merkmale des Bildes von Ehe und Familie, das der Verfassung zugrunde liegt“ (49). Diese Formulierung ist noch einmal aufgegriffen worden in BVerfGE 80, 81 (92). Von einem „Leitbild des Grundgesetzes von der Ehe und ihrer Bedeutung“ spricht ferner BVerfGE 53, 224 (250), im Hinblick darauf, „daß zu ihrem Wesen die gelebte Verwirklichung der ehelichen Gemeinschaft gehört". 
über das Lebenspartnerschaftsgesetz die „personelle Exklusivität“ ein „Wesensmerkmal“ der Ehe nennt, dessen Schutz ein Alternativverhältnis zwischen Ehe und Lebenspartnerschaft gebiete. ${ }^{45}$

\section{Intentionen einer Leitbildgarantie}

Die grundrechtsdogmatische Konstruktion einer Leitbildgarantie entnimmt der verfassungsrechtlichen Wertentscheidung eine differenzierte Bewertung des Freiheitsgebrauchs jenseits der Anerkennung des privaten Freiheitsinteresses. Maßstab der differenzierten Bewertung ist die Ratio ${ }^{46}$ der Verfassungsnorm, soweit sie den privaten Freiheitsgebrauch in ein besonderes öffentliches Interesse einbezieht.

So umfaßt der freiheitsrechtliche Schutz des Art. 6 Abs. 1 GG die negative $^{47}$ wie die positive ${ }^{48}$ Eheschließungsfreiheit, doch die darüber hinausgehende Wertentscheidung verbindet nur mit dem Gebrauch der positiven Eheschließungsfreiheit das besondere öffentliche Interesse an den gesellschaftlichen Wirkungen der Ehe: Die Entscheidung für ein Single-Leben genießt individualrechtlichen Schutz, aber kein öffentliches Interesse. Der freiheitsrechtliche Schutz des Art. 6 Abs. 1 GG und das öffentliche Interesse an Ehe und Familie umfassen kinderlose ${ }^{49}$ wie kinderreiche Ehen, die Pflege und Erziehung von Kindern durch Alleinerziehende $^{50}$ wie durch Paare, durch unverheiratete ${ }^{51}$ wie durch verheiratete

45 BVerfGE 105, 313 (343).

46 BVerfGE 36, 146 (163), zu den Anforderungen an die Begründung eines Eheverbots: Es muß sich „aus dem Bild der heutigen verweltlichten Ehe“ begründen, wozu nicht eine „uralte kultische Regel“ genügt, sondern „,sachliche, verstandesmäßig faßbare Gründe" nötig sind. - S. Huster Die ethische Neutralität des Staates. Eine liberale Interpretation der Verfassung, 2002, 500-505, verfeinert diese Forderung in eine Unterscheidung zwischen „ethisch-substantiellen“ und „politisch-funktionalen Begründungsansätzen“".

47 Robbers (Fn. 14), Rn. 57; Uhle (Fn. 9), Rn. 22; hingegen dem Art. 2 Abs. 1 GG zugerechnet von BVerfGE 56, 363 (384); Gröschner (Fn. 24), Rn. 53. Ipsen (Fn. 26), Rn. 62, wendet ein, daß die Ehelosigkeit nicht Gegenstand der Institutsgarantie sein kann; das ist richtig, begründet aber nicht die Auslagerung der negativen Freiheitsdimension aus Art. 6 Abs. 1 GG, sondern die hier unternommene Differenzierung der Schutzbereiche von Freiheitsrecht und Institutsgarantie innerhalb des Art. 6 Abs. 1 GG.

48 Robbers (Fn. 14), Rn. 51; Stern (Fn. 3), 413 f., jeweils mit weiteren Nachweisen.

$49 \operatorname{Ipsen}$ (Fn. 26), Rn. $16 \mathrm{f}$.

50 BVerfGE 18, 97 (105 f.); Robbers (Fn. 14), Rn. 77, 90.

${ }_{51}$ BVerfG, U. vom 19.2.2013 - 1 BvL 1/11 - [Sukzessivadoption], Abs. 64, 99; implizit bereits BVerfGE 10, 59 (66); ferner BVerfGE 79, 256 (267); 106, 166 (176); 108, 82 (112); Stern (Fn. 3), 400. - Ebenso für den Tatbestand des Art. 8 EMRK: EGMR, U. (K) vom 26.5.1994 - 16969/90 - Keegan gegen Irland, Abs. 44 f. - Anders zum 
Paare, die Wahrnehmung von Elternverantwortung gegenüber leiblichen wie gegenüber adoptierten Kindern; ${ }^{52}$ doch das öffentliche Interesse ist gegenüber diesen Möglichkeiten der Freiheitsausübung nicht neutral: Das öffentliche Interesse richtet sich jeweils darauf, daß Paare Verantwortung füreinander übernehmen, daß sie Verantwortung für Kinder übernehmen, daß sie Kinder zur Welt bringen, daß Kinder in möglichst kindeswohlgemäßen, möglichst stabilen, möglichst rechtlich gesicherten Verhältnissen aufwachsen können.

Die Wertentscheidung der Verfassung begründet eine Präferenz für Bedingungen, in denen die gesellschaftspolitische Ratio der Verfassungsnorm gut und besser verwirklicht wird. Sie bewertet sie als ,gut so!“ und ist für Steigerungen zu einem ,besser so!“ offen. Die je für sich eigenständigen Wertentscheidungen zugunsten der Ehe und zugunsten der Familie summieren sich zugunsten der auf Familie gerichteten Ehe und der auf Ehe gegründeten Familie. ${ }^{53}$

Eine auf die Auslegung des Art. 6 Abs. 1 GG als wertentscheidende Grundsatznorm gegründete Leitbildgarantie ist ein Mittel der Zukunftsgestaltung durch öffentliches Recht. Sie wirkt über den Gesetzgeber, dessen Ermessen an eine Intention gebunden wird und der in dieser Intention Sachgründe für differenzierte Rechtsgestaltungen vorgegeben bekommt. Über eine Staatszielbestimmung geht die wertentscheidende Grundsatznorm insofern hinaus, als sie nicht allein die Intention vorgibt, sondern sie an die Institute von Ehe und Familie und deren leitbildprägende Merkmale bindet. ${ }^{54} \mathrm{Um}$ der Funktionen von Ehe und Familie in ihrer Gesamtheit willen ${ }^{55}$ schützt sie Ehe und Familie als Form. ${ }^{56}$ Mit dieser

Begriff der Familie nach Art. 6 Abs. 1 GG noch v. Campenhausen Verfassungsgarantie und sozialer Wandel (Fn. 2), 21-25.

52 Allgemein: Robbers (Fn. 14), Rn. 19, 90: „Nicht nur leitbildkonforme Familien“; ebenso Stern (Fn. 3), 399; anderer Ansicht, soweit der Familienbegriff grundsätzlich an „zumindest prinzipiell ehefähige Partnerschaften“ gebunden sein soll, Uhle (Fn. 9), Rn. 18; deutlich enger noch Lecheler Schutz von Ehe und Familie (Fn. 27), Rn. 42-47.

${ }_{53}$ Nesselrode (Fn. 3), 164-169, 172-177.

${ }^{54}$ In diesem Sinne für die Ehe als Optimum für die Gründung einer Familie und das Aufwachsen von Kindern: Robbers (Fn. 14), Rn. 17 f. Dabei geht es durchaus „nicht um die Zementierung bloßer Formen“, sondern ,um die Bewahrung des verfassungsrechtlichen Kerngehaltes"; siehe wiederum Robbers (Fn. 14), Rn. 48.

${ }_{55}$ Robbers (Fn. 14), Rn. 31; Steiger Verfassungsgarantie und sozialer Wandel (Fn. 2), 77. Ebenso Burgi (Fn. 11), Rn. 38, verbunden mit einer Abgrenzung von einer „Funktionalisierung des Grundrechtsschutzes auf der [...] Tatbestandsebene“ (Rn. 17). - Eine Gegenposition ist die vollständige funktionale Entkoppelung von Ehe und Familie, die die Ehe ausschließlich in ihrer Funktion als „Beistands- und Verantwortungsgemeinschaft, durch die sie den Staat entlastet", geschützt sieht, die Familie hingegen ausschließlich in ihrer „reproduktiven Funktion“, in der „Eltern mit der Geburt sowie 
Anbindung des Funktionsschutzes an die Form begegnet sie gesellschaftspolitischen Gegenmodellen und entsprechenden Dynamiken gesellschaftlicher Praxis, welche die Tauglichkeit des Leitbilds in Frage stellen und andere Modelle als ebenso zweckmäßig verfechten mögen, als eine auf keine weitere Rechtfertigung angewiesene verfassungsrechtliche Dezision.

Als ein Mittel zur Zukunftsgestaltung wirkt eine Leitbildgarantie auch über die öffentliche Affirmation des öffentlichen Interesses an Ehe und Familie. Daß das Eherecht die bürgerliche Ehe als öffentliches Institut ausformt und die Eheschließung als Staatsakt vor dem Standesbeamten inszeniert, ${ }^{57}$ erklärt sich als Kommunikation des öffentlichen Interesses an der Ehe. Gegenüber religiösen Auffassungen vom „Wesen“ der Ehe beschränkt sich die staatliche Ordnung um ihrer religiösen und weltanschaulichen Neutralität willen auf ein „Bild der ,verweltlichten“ bürgerlichrechtlichen Ehe" ${ }^{\text {"58 }}$. Das öffentliche Interesse an der Ehe deckt eben nicht den zivilreligiösen Übereifer leitbildseliger Standesbeamter, die die Nupturienten von Staats wegen über die Liebe belehren und ähnliches. Unbeschadet dessen macht ein verfassungsrechtliches Leitbild von Ehe und Familie den Grundrechtsträgern ein (implizites) Identifikationsangebot ${ }^{59}$ für ihre allfälligen religiösen Selbstverständnisse von ihrer Ehe ${ }^{60}$ und ihren Familienverhältnissen. Seine Funktion ist aber die Affirmation des säkularen öffentlichen Interesses. ${ }^{61}$

der Pflege und Erziehung von Kindern reproduktive und den Staat entlastende Aufgaben erfüllen": Brosius-Gersdorf (Fn. 17), Rn. 43.

56 W. Pauly Sperrwirkungen des verfassungsrechtlichen Ehebegriffs, NJW 1997, 1955-1957 (1955): „Das vom Verfassungsgeber normierte Rechtsinstitut ,Ehe“ transzendiert die konkrete Funktionalität der je einzelnen Ehe, ohne dadurch seine Finalität und Grundstruktur zu verlieren."

57 Zur Geschichte der Zivilehe Stern (Fn. 3), 342-344.

${ }^{58}$ BVerfGE 31, 58 (83); 53, 224 (245).

${ }_{59}$ Mit Identifikationsangeboten integriert der Staat religiöse und weltanschauliche Selbstverständnisse, ohne selbst das Verbot religiöser oder weltanschaulicher Identifikation zu übertreten; M. Germann in: Epping/Hillgruber (Fn. 9), Art. 4, Rn. 82.

${ }^{60}$ Wobei die jüngeren Entwicklungen den Abstand zu kirchlichen Verständnissen vergrößern; siehe H. M. Heinig Neuere Entwicklungen im Eherecht an der Schnittfläche von staatlicher und kirchlicher Rechtsordnung, ZevKR 55 (2010), 20-45 (23-27). - Zum ambivalenten Rückzug der staatlichen Aufmerksamkeit von den „religiösen Feierlichkeiten einer Eheschließung “ in § 67 PStG in der alten Fassung der Bekanntmachung vom 8.8.1957 (BGBl. I 1125), mit Wirkung zum 1.1.2009 aufgehoben durch Gesetz vom 19.2.2007 (BGBl. I 122), siehe H. Schüller Die verblüffende Aufhebung des Voraustrauungsverbots und ihre Auswirkungen, NJW 2008, 2745-2749.

${ }^{61}$ Damit ist nicht gesagt, daß diese Affirmation notwendig an die standesamtliche Form gebunden ist; zur Diskussion über eine mögliche Öffnung zur fakultativen Zivilehe siehe einerseits - contra - Gröschner (Fn. 24), Rn. 41; Stern (Fn. 3), 387 f. mwN; 
Die Schwierigkeiten einer Leitbildgarantie liegen auf der Hand. Sie zieht die allgemeinen Bedenken dagegen auf sich, die Grundrechtsnormen des Grundgesetzes über den Freiheitsschutz hinaus mit einer „Werteordnung" aufzuladen. ${ }^{62}$ Dem im Grundgesetz angelegten liberalen Staatsverständnis macht sie sich dahin verdächtig, Freiheit zur „dienenden Freiheit" umzufunktionieren, die private Lebens- und Zukunftsgestaltung für die gesellschaftliche Zukunftsgestaltung in den Dienst zu nehmen und ihr unterzuordnen. ${ }^{63}$ Sie scheint diskriminierenden Affekten Deckung zu geben. Sie ist anfällig für Rollenstereotypen, die sie jenseits der strukturbildenden, freiheitsverträglichen und damit rollenneutralen Merkmale von Ehe und Familie als Leitbild für ein partikulares, paternalistisches, rollenverhaftetes Leitbild für Ehe ${ }^{64}$ und Familie in Anspruch zu nehmen trachten können. Sie scheint sich dazu anzubieten, mit ihrem antidynamischen Moment die dynamischen Momente des Grundrechts zu hemmen. Das sind einsichtige Gründe dafür, mit der Auslegung des Art. 6 Abs. 1 GG im Sinne einer Leitbildgarantie zurückhaltend zu sein.

In dem Maß aber, in dem das Gebot zum Schützen und Fördern von Ehe und Familie von leitbildprägenden Merkmalen abstrahiert wird, wird die grundrechtsdogmatisch kanonisierte Wirkung des Art. 6 Abs. 1 GG als wertentscheidende Grundsatznorm zum Passepartout. Das hat Folgen.

andererseits - pro - Heinig (Fn. 60), 41-45; W. Waldstein Zum Problem der obligatorischen Zivilehe, FS Link, 2003, 529-543; für einen bloß einfachgesetzlichen Status der obligatorischen Zivilehe überzeugend Pirson (Fn. 24), Rn. 18, 98; Robbers (Fn. 14), Rn. 39.

${ }^{62}$ E. -W. Böckenförde Grundrechte als Grundsatznormen, Der Staat 29 (1990), 1-31; auch in: ders. Staat, Verfassung, Demokratie. Studien zur Verfassungstheorie und zum Verfassungsrecht, 2. Aufl. 1992, 159-199 (185-199); Goerlich (Fn. 40); Steiger Verfassungsgarantie und sozialer Wandel (Fn. 2), 66 mwN. Vor einem umso größeren „Änderungsbedarf im Verständnis der Norm [...], je stärker bestimmte Leitbilder bei ihrer Interpretation berücksichtigt werden“, und einer Tendenz zur Moralisierung des Rechts warnt Classen (Fn. 9), 1093. - Siehe auch den Hinweis auf die Nähe der Auslegung des Art. 6 GG als „Wertentscheidung“ zur Staatslehre Rudolf Smends und anderer bei Stern (Fn. 3), $427 \mathrm{f}$.

${ }_{63}^{63}$ Das ist die Sorge von Zuleeg (Fn. 32).

${ }^{64}$ Hiergegen treffend Steiger Verfassungsgarantie und sozialer Wandel (Fn. 2), 59. Einen Überblick über die Lösung des bürgerlichen Eherechts vom Leitbild der „Hausfrauenehe" nach 1949 gibt Stern (Fn. 3), 356 f. - Zur Ehegestaltungsfreiheit in der Aufgabenverteilung zwischen den Ehegatten zuletzt BVerfG, B. vom 7.5.2013 - 2 BvR 909/06, 1981/06, 288/07 - [Lebenspartner-Splitting], Abs. 82; ferner BVerfGE 87, 234 (258 f.); Robbers (Fn. 14), Rn. 75 mwN; Steiner (Fn. 9), Rn. 11-16. 


\section{Wirksamkeit der Dynamik: Grundrechtsdogmatik von Ehe und Familie unter Spannung}

\section{Dynamik im Schutzbereich von Familien- und Elternrecht}

Der verfassungsrechtliche Begriff der „Familie“ ist in seiner Definition als "Gemeinschaft von Eltern und Kindern"65 von vornherein offen für eine dynamische Veränderung seiner Reichweite. ${ }^{66}$ Mit dem Merkmal „Gemeinschaft" verweist er auf die soziale Wirklichkeit, in der Kinder mit Eltern leben, Pflege und Erziehung erfahren und selbständig werden. ${ }^{67}$ Mit dem Merkmal „Eltern“ verweist er auf eine Beziehung, die in ihrer Kasuistik meist mit dem Elternrecht nach Art. 6 Abs. 2 S. 1 GG übereinstimmt, sich in ihren grundrechtsdogmatischen Bestimmungskriterien jedoch davon unterscheidet. In ihnen dominiert die soziale Beziehung zum Kind. ${ }^{68}$ Die Entscheidung des Bundesverfassungsgerichts vom 19. Februar 2013 zur Sukzessivadoption hat das - im Vorbeigehen, aber emphatisch - für die „sozial-familiäre Gemeinschaft“ eines Kindes mit dem eingetragenen Lebenspartner seines Vaters oder seiner Mutter nur bestätigt. ${ }^{69}$

65 Siehe oben Fn. 18.

66 Stern (Fn. 3), 394 f. Die grundrechtsdogmatische Kontur des Begriffs versteckt sich bisher hinter einer Kasuistik von Familientypen.

67 Von der „Lebens- und Erziehungsgemeinschaft“ über die „Hausgemeinschaft“ bis zur „Begegnungsgemeinschaft“: BVerfGE 80, 81 (90 f.); Robbers (Fn. 14), Rn. 82; Stern (Fn. 3), 395. Dieser Ansatz läßt Raum für eine ,Vermutung zugunsten der ehelichen Familie in Art. 6 Abs. 1 GG“, entwickelt bei Schmid (Fn. 42), 390-395.

68 Auf Abstammung und rechtliche Elternstellung kommt es nicht an. Das setzte schon die notorische, vom Bundesverfassungsgericht bereits 1964 ohne Nachweise als „,allgemein anerkannt“ bezeichnete Aufzählung der Stief- und der Pflegefamilie unter die von Art. 6 Abs. 1 GG geschützten Familientypen voraus; siehe BVerfGE 18, 97 (105 f.). Für die Beziehung zwischen dem Kind und dem mit der Mutter verheirateten Stiefvater siehe BVerfGE 79, 256 (267); für die Pflegefamilie siehe BVerfGE 68, 176 (187); 79, 51 (59). - Auch für die Subsumtion der Beziehung zwischen einem Kind und seinem nichtehelichen Vater unter „Familie“ kommt es auf die tatsächlichen Beziehungen an; siehe BVerfGE 108, 82 (107, 112, 116); Nesselrode (Fn. 3), 262-264; Steiner (Fn. 9), Rn. 43; anders: die leibliche Verwandtschaft allein genügt nach Robbers (Fn. 14), Rn. 90; Abstammung und Unterhaltspflicht genügen nach Burgi (Fn. 11), Rn. 21.

${ }^{69}$ BVerfG, U. vom 19.2.2013 - 1 BvL 1/11 - [Sukzessivadoption], Ls. 3, Abs. 60-65 mwN; im Ergebnis zustimmend Classen (Fn. 9), 1091; P. Reimer/M. Jestaedt Anmerkung, JZ 2013, 468-472 (470); siehe auch A. Sickert Die lebenspartnerschaftliche Familie. Das Lebenspartnerschaftsgesetz und Art. 6 Abs. 1 GG, 2005; anders noch Gärditz (Fn. 9), 932. - Die Orientierung des Familienbegriffs an den sozialen Beziehungen zum Kind unterstützt die Forderung aus der Rechtswissenschaft, die Familie nicht auf die Kleinfamilie mit Eltern und Kindern zu beschränken, sondern auch Großeltern und andere nahe Verwandte einzuschließen, sofern eben die tatsächliche Beziehung zwischen dem Kind und diesen weiteren Personen der sozialen Elternrolle entspricht; siehe Rob- 
Die dynamische Öffnung des Familienbegriffs für die tatsächliche Vielfalt sozialer Nähebeziehungen ist in seinen Merkmalen seit jeher angelegt. Dadurch ist er zugleich aufnahmefähig für Wertungen, mit denen das europäische und internationale Recht mit seinen hauptsächlich familienbezogenen Bestimmungen in das Verfassungsrecht hineinwirkt (was hier nur erwähnt, nicht ausgeführt werden kann). ${ }^{70}$ In seiner Anwendungsflexibilität bringt der Familienbegriff das dynamische Moment der Grundrechtsdogmatik zum Tragen, ohne seine eigene dogmatische Gestalt zu ändern.

Das Elternrecht nach Art. 6 Abs. 2 S. 1 GG bestimmt sich dagegen primär nach der einfachgesetzlichen Zuordnung, die ihrerseits die leibliche Elternschaft rechtlich anzuerkennen oder an eine soziale Beziehung anzuknüpfen hat.

Leibliche Eltern haben kein verfassungsunmittelbares Elternrecht, sind aber in einem dem Elternrecht vorausliegenden verfassungsrechtlichen Grundstatus der Elternschaft in den persönlichen Schutzbereich des Art. 6 Abs. 2 S. 1 GG einbezogen. ${ }^{71}$ Dieser schützt ihren Zugang zum Eltern-

bers (Fn. 14), Rn. 86-89 mwN; Steiger Verfassungsgarantie und sozialer Wandel (Fn. 2), 79 f.; Tettinger (Fn. 3), 136 f.; offengelassen in BVerfGE 39, 316 (326). Eine folgerichtige Orientierung an den sozialen Beziehungen ist weitergehend darauf angelegt, die dabei noch mitgeführten, durch den Zweck des Familienschutzes nicht begründeten Begrenzungen zu überwinden: auf Verwandte - siehe zum Beispiel Stern (Fn. 3), 398 f. - oder auf „personenstandsrechtlich verbundene Paare“ - siehe Classen (Fn. 9), 1091; gegenüber dieser Beschränkung muß folgerichtig die (tatbestandliche) „Entkoppelung" der Familie von der Ehe auch bei eingetragenen Lebenspartnerschaften ihre Entsprechung finden; im Ergebnis dem entsprechend Stern (Fn. 3), 402 f. (403: ,gleichgeschlechtliche Gemeinschaften mit Kindern“). Zur „Entkoppelung“ der Familie von der Ehe siehe nur Gröschner (Fn. 24), Rn. 69 f.

${ }^{70} \mathrm{Zu}$ den Vorgaben aus dem Recht der Europäischen Union: Nesselrode (Fn. 3), 226-230. Zu den Vorgaben aus der Europäischen Menschenrechtskonvention: I. Fahrenhorst Familienrecht und Europäische Menschenrechtskonvention. Das Ehe- und Familienrecht der Bundesrepublik Deutschland und seine Vereinbarkeit mit der Europäischen Konvention zum Schutz der Menschenrechte und Grundfreiheiten, 1994; Nesselrode (Fn. 3), 213-221. Zu den Vorgaben aus dem weiteren Völkerrecht: M. Palm-Risse Der völkerrechtliche Schutz von Ehe und Familie, 1990; relativierend BVerfG, U. vom 19.2.2013 - 1 BvL 1/11 - [Sukzessivadoption], Abs. 101. Zu faktischen Wirkungen der internationalen und ausländischen Rechtsentwicklung auf die gesellschaftlichen Normen ebd., Abs. 56.

${ }^{71}$ BVerfGE 108, 82 (99, 101). - BVerfGE 84, 168 (179), hatte noch offengelassen, ob die verfassungsrechtliche Elternstellung des nichtehelichen Vaters von der weiteren Voraussetzung abhängig ist, daß ,er mit dem Kind und der Mutter zusammenlebt und damit die Voraussetzungen für die Wahrnehmung seiner elterlichen Verantwortung erfüllt". Jedenfalls unter dieser Voraussetzung könne ihm die Elternstellung nicht abgesprochen werden. - Die Unterscheidung zwischen Elternschaft und Elternrecht deckt 
recht in unterschiedlichem Maß: Die Mutter, die das Kind geboren hat, hat einen unbedingten verfassungsrechtlichen Anspruch auf rechtliche Anerkennung als Mutter. Die verfassungsrechtliche Stellung des Vaters, von dem das Kind genetisch abstammt, muß im Regelfall auch sein Elternrecht nach sich ziehen; ${ }^{72}$ das steht aber unter dem Vorbehalt der Konkurrenz zu einem anderen Vaterschaftsprätendenten, worüber der Gesetzgeber gegebenenfalls nach dem Kindeswohl ${ }^{73}$ und damit nach den sozialen Beziehungen des Kindes ${ }^{74} \mathrm{zu}$ entscheiden hat. Das gleiche muß für die genetische Mutter gelten, wenn sie - rechtswidrig, aber möglich von der biologischen Mutter („Leihmutter") verschieden ist. ${ }^{75}$ Dieser verfassungsrechtliche Grundstatus der leiblichen Elternschaft ist nicht identisch mit dem Elternrecht, sondern nur eine Vorstufe ${ }^{76}$ davon. Eine soziale Beziehung zum Kind allein begründet keine verfassungsrechtliche Elternschaft in diesem Sinn, ${ }^{77}$ also auch keinen Schutz des Interesses an der Übernahme des Elternrechts. ${ }^{78}$ Erst die bürgerlich-rechtliche Zuordnung versieht diese soziale Beziehung mit dem Elternrecht.

Im personellen Schutzbereich des Art. 6 Abs. $2 \mathrm{~S} .1 \mathrm{GG}$ sind demnach für ein Kind bis zu fünf Menschen: die genetische Mutter, die biologische

sich insofern nicht mit der zwischen persönlichem und sachlichem Schutzbereich - so aber Burgi (Fn. 11), Rn. 78; Jestaedt (Fn. 42), Rn. 73 -, als auch die einfachgesetzliche Übertragung des Elternrechts auf andere als die leiblichen Eltern den Zugang zum persönlichen Schutzbereich vermittelt.

72 BVerfGE 79, 256 (267); 108, 82 (100, 104); siehe auch Gärditz (Fn. 9), 931; Robbers (Fn. 14), Rn. 166, 183. - Eine eheliche Verbundenheit der Eltern spielt hierbei keine Rolle mehr; dazu kritisch H. D. Horn Die Einheit von Ehe und Familie - Ende einer normativen Idealität. - Anmerkung zum Beschluß des BVerfG vom 7. Mai 1991 -, DÖV 1991, 830-834.

73 BVerfGE 92, 158 (178 f.); Robbers (Fn. 14), Rn. 169 f.

${ }^{74}$ Hier ist die gesetzliche Vermutung einzuordnen, daß das Kind vom Ehemann der Mutter abstammt; verfassungsrechtlich gefordert nach BVerfGE 79, 256 (267). Näher Nesselrode (Fn. 3), 263-265.

75 Jestaedt (Fn. 42), Rn. 79; Robbers (Fn. 14), Rn. 175. Unentschieden geblieben im Fall einer unzulässigen Verfassungsbeschwerde gegen die Weigerung der Personenstandsbehörde, ein durch eine Leihmutter in Kalifornien geborenes Kind als Kind der genetischen Eltern ins Personenstandsregister einzutragen: BVerfG, B. (K) vom 22.8. 2012 - 1 BvR 573/12 -.

${ }^{76}$ Spiegelbildlich fallen nach einer Übertragung des Elternrechts durch Adoption die leiblichen Eltern in diesen Grundstatus zurück; siehe BVerfGE 24, 119 (137 f.); Robbers (Fn. 14), Rn. 176.

77 Jestaedt (Fn. 42), Rn. 59 f.

${ }^{78}$ BVerfG, U. vom 19.2.2013 - 1 BvL 1/11 - [Sukzessivadoption], Ls. 2, Abs. 57, 59; anderer Ansicht $C$. Grehl Das Adoptionsrecht gleichgeschlechtlicher Paare unter verfassungsrechtlichen Gesichtspunkten, 2008, 148-155, die wohl so etwas wie ein allgemeines Freiheitsrecht zur Adoption unterstellt. 
Mutter und der genetische Vater im Grundstatus der Elternschaft, sowie im Status des Elternrechts das bürgerlich-rechtlich anerkannte Elternpaar als Mutter und Vater, beziehungsweise nach Adoption durch zwei eingetragene Lebenspartner als Mütterpaar oder Väterpaar. ${ }^{79}$ Das Elternrecht selbst ist nach gegenwärtiger Rechtslage auf ein Elternpaar als Mutter und Vater ${ }^{80}$ oder als Mütterpaar oder Väterpaar beschränkt. ${ }^{81}$ Die Grundrechtsdogmatik könnte künftige Entwicklungen der Fortpflanzungsmedizin dahin aufnehmen, daß die genetisch begründete Elternschaft für ein geklontes Kind ${ }^{82}$ in einer Person zusammenfällt oder sich auf zwei Männer oder zwei Frauen als Erbgutspender verteilt. - Die Grundrechtsdogmatik zu Art. 6 Abs. 2 S. 1 GG ist aber auch dynamisch genug, um mit der Situation zurechtzukommen, daß ein Kind leiblich und rechtlich genau eine Mutter und einen Vater hat.

Alle teleologischen Kriterien für die dynamische Bestimmung des Schutzbereichs von Familien- und Elternrecht bündeln sich im Kindeswohl. In der Maßgeblichkeit des Kindeswohls sind auch alle öffentlichen Interessen an den kulturellen und sozialen Leistungen der Familie aufgefangen. Die offene Flanke in der Maßgeblichkeit des Kindeswohls ist das ihr vorausliegende Urteil darüber, welche Familien- und Elternbeziehungen dem Kindeswohl am besten dienen. Die vom Bundesverfassungsgericht dem Art. 6 Abs. 2 S. 1 GG unterstellte Dezision, daß das Elternrecht primär den leiblichen Eltern und stets nicht mehr als einem Elternpaar ${ }^{83}$

79 BVerfG, U. vom 19.2.2013 - 1 BvL 1/11 - [Sukzessivadoption], Ls. 2, Abs. 48, 99; in dieselbe Richtung deutete bereits die Zurückweisung einer konkreten Normenkontrolle gegen $\S 9$ Abs. 7 S. 2 LPartG durch BVerfG, B. (K) vom 10.8.2009 - 1 BvL 15/09 -, Abs. 15 (abgesehen von formalen Gründen). - Nicht durchgesetzt hat sich damit das von Gärditz (Fn. 9), 931, überzeugend dargelegte Verständnis, daß ein in Art. 6 Abs. 2 S. 1 GG gesetztes „verfassungsrechtliches Leitbild familienrechtlicher Konstruktion“ das Elternrecht an die Dualität von Mutter und Vater bindet; so auch noch Burgi (Fn. 11), Rn. 85; Jestaedt (Fn. 42), Rn. 67; zögernd Coester-Waltjen (Fn. 32), Rn. 76. Die verschiedenen Wege gleichgeschlechtlicher Paare zur leiblichen und rechtlichen Elternschaft sind eingehend beschrieben und diskutiert bei $M$. Dittberner Lebenspartnerschaft und Kindschaftsrecht. Die rechtliche Situation gleichgeschlechtlicher Paare unter besonderer Berücksichtigung kindschaftsrechtlicher Regelungen, 2004, 33-42, 106-109, 141 f., 170-173, 182-205. - Seit der Unanwendbarkeit des $\S 8$ Abs. 1 Nr. 3 Transsexuellengesetz gemäß BVerfG, B. vom 11.1.2011 - 1 BvR 3295/07 -, E 128, 109137 , ist es außerdem möglich, daß sich eine transsexuelle Person unter Beibehaltung ihrer Fortpflanzungsfähigkeit personenstandsrechtlich einem anderen Geschlecht zuordnen läßt, so daß eine Frau Vater und ein Mann Mutter werden kann.

80 BVerfGE 108, 82 (101, 103); anderer Ansicht Brosius-Gersdorf (Fn. 17), Rn. 150; W. Höfling Elternrecht (§ 155), in: HStR, 3. Aufl., Bd. VII (Fn. 26), 477-520, Rn. 75.

81 BVerfG, U. vom 19.2.2013 - 1 BvL 1/11 - [Sukzessivadoption], Abs. 52.

82 Robbers (Fn. 14), Rn. 181.

83 Siehe eben Fn. 72, 80 und 81. 
zuzuordnen ist, verschließt sich dem dynamischen Wettstreit der Kindeswohlexpertisen.$^{84}$ Gerade dadurch - aber auch nur insoweit - beugt sie der Gefahr vor, daß das Kindeswohl als Projektionsfläche für die Interessen von Erwachsenen in Beschlag genommen wird.

\section{Dynamik in den Maßstäben der Familiengerechtigkeit}

Der Schutz von Ehe und Familie steht naturgemäß unter dem Druck gesellschaftspolitischer, volkswirtschaftlicher, fiskalischer und anderer Interessen daran, den Freiheitsgebrauch in Ehe und Familie einzuschränken oder in bestimmte Bahnen zu lenken, die Institute von Ehe und Familie sich gefügig zu machen, die Wertentscheidung für Ehe und Familie aufzuwiegen. Die normative Wirkung des Art. 6 Abs. 1 GG bemißt sich daran, wie weit seine spezifischen Maßstäbe als Abwehrrecht, als Institutsgarantie und als wertentscheidende Grundsatznorm die Reichweite der in und mit dem Ehe- und Familienschutz konkurrierenden Interessen determinieren; wie weit sich also die „Familiengerechtigkeit" ${ }^{65}$ im Familienrecht, Steuerrecht, Sozialrecht, Sozialversicherungsrecht, Ausländer-

84 Anders aber hinsichtlich der Dualität von Mutter- und Vaterrolle BVerfG, U. vom 19.2.2013 - 1 BvL 1/11 - [Sukzessivadoption], Abs. 79 f. Überzeugender Gärditz (Fn. 9), 931 f., 936 f., der die Rechtfertigungslast nicht aufseiten des (eingriffslosen) Ausschlusses von Adoptionen, sondern aufseiten der Verfügung über den Status des Kindes sieht.

85 Umfassend M. Pechstein Familiengerechtigkeit als Gestaltungsgebot für die staatliche Ordnung. Zur Abgrenzung von Eingriff und Leistung bei Maßnahmen des sog. Familienlastenausgleichs, 1994; Seiler (Fn. 42); ders. Familiengerechtigkeit, in: W. Kluth (Hrsg.) Facetten der Gerechtigkeit, 2010, 40-67. Fragen der Familiengerechtigkeit bildeten einen Schwerpunkt im Staatsrechtslehrervortrag von v. Campenhausen Verfassungsgarantie und sozialer Wandel (Fn. 2), 29-50; siehe außerdem etwa T. Aubel Der verfassungsrechtliche Mutterschutz. Ein Beitrag zur Dogmatik der Leistungsgrundrechte am Beispiel des Art. 6 Abs. 4 GG, 2003; Brosius-Gersdorf Demografischer Wandel und Familienförderung (Fn. 26); G. Kirchhof Der besondere Schutz der Familie in Art. 6 Abs. 1 des Grundgesetzes. Abwehrrecht, Einrichtungsgarantie, Benachteiligungsverbot, staatliche Schutz- und Förderpflicht, AöR 129 (2004), 542-583 (572-581); $P$. Kirchhof Ehe und Familie im staatlichen und kirchlichen Steuerrecht, in: Essener Gespräche 21 (Fn. 27), 117-153; A. Leisner-Egensperger Besteuerung von Ehe und Familie, FS Kirchhof (Fn. 32), 1903-1911; C. Maurer Verfassungsrechtliche Anforderungen an die Besteuerung von Ehegatten und Familien. Eine Prüfung der Familienförderungsgesetzgebung und ihrer Konsequenzen, 2004; Nesselrode (Fn. 3), 62-94, 235-268; dies. (Fn. 32), Rn. 12-19; Steiner (Fn. 9), Rn. 47-58; Tettinger (Fn. 3), 143145, 150-152; M. Tünnemann Der verfassungsrechtliche Schutz der Familie und die Förderung der Kindererziehung im Rahmen des staatlichen Kinderleistungsausgleichs, 2002; M. Wangen Der Familienlastenausgleich im Spannungsfeld von sozialstaatlicher Sicherheit und rechtsstaatlicher Freiheit. Familienlastenausgleich oder familiengerechte Ausgestaltung der Alterssicherung und der Einkommensbesteuerung, 2003. 
recht, Arbeits- und Dienstrecht et cetera gerade in spezifischen Grundrechtsfolgen des Art. 6 Abs. 1 GG darstellt.

Dabei hängt die Leistungsfähigkeit der abwehrrechtlichen Dimension des Ehe- und Familienschutzes an ihrer Spezialisierung auf staatliche Eingriffe. Die Reichweite der Institutsgarantie beschränkt sich auf die Gestaltung des bürgerlichen Ehe- und Familienrechts selbst. ${ }^{86}$ Alle hingegen weder von Abwehrrecht und Institutsgarantie noch von entsprechend eng zugeschnittenen Schutz- und Leistungspflichttatbeständen erfaßten Aspekte der „Familiengerechtigkeit“ fallen in die Netze der Gleichheitsrechtsdogmatik. In ihr schaffen die allgemeinen und besonderen Gleichheitsregeln des Art. 3 GG ein mehrdimensionales Gelände aus gesetzgeberischen Ermessensräumen und richterlichen Kontrollmaßstäben. Staatliche Steuerung durch Wohltat statt durch Eingriff läßt die Maßstäbe der Abwehrrechtsdogmatik rosten und versetzt die dynamischen Maßstäbe der Gleichheitsrechtsdogmatik in Schwung.

Das ist nichts neues und nichts für Art. $6 \mathrm{GG}$ besonderes. Aktuellen Anschauungsstoff bietet immerhin das Bundeselterngeld- und Elternzeitgesetz mit „Partnermonaten“ und Betreuungsgeld. ${ }^{87}$

86 BVerfG, U. vom 19.2.2013 - 1 BvL 1/11 - [Sukzessivadoption], Abs. 97; B. vom 19.6.2012 - 2 BvR 1397/09 - [Familienzuschlag], Abs. 67 = E 131, 239 (260 f.). Anders noch BVerfGE 76, 1 (49); 80, 81 (92); siehe oben in Fn. 44.

$87 \S 4$ Abs. 1-3, §§ 4a-4d Gesetz zum Elterngeld und zur Elternzeit (Bundeselterngeld- und Elternzeitgesetz - BEEG) vom 5.12.2006 (BGBl. I 2748), zuletzt geändert am 15.2.2013 (BGBl. I 254). Beide Regelungen knüpfen an eine bestimmte Entscheidung über die Kinderbetreuung die Zuerkennung einer staatlichen Leistung. Eine entsprechende Belastung griffe in das Ehe- und Familiengestaltungsrecht aus Art. 6 Abs. 1 GG ein; das Vorenthalten der staatlichen Leistung hingegen ist, abwehrrechtsdogmatisch betrachtet, eingriffslos; siehe R. Müller-Terpitz Vätermonate und Kindergartenpflicht wie viel Staat verträgt die Familie?, JZ 2006, 991-997 (994); C. Seiler Das Elterngeld im Lichte des Grundgesetzes, NVwZ 2007, 129-134 (132 f.); anders F. Brosius-Gersdorf Das Elterngeld als Einkommensersatzleistung des Staates - Progressive Staffelung bei der Familienförderung und demografischer Wandel in Deutschland, NJW 2007, $177-$ 182 (179); dies. Vätermonate - Staatliche Familienförderung zwischen Neutralitätspflicht und Durchsetzung der Gleichberechtigung der Geschlechter -, VSSR 2008, 299-326 (302-316); J. Wieland Verfassungsfragen des Betreuungsgeldes. Rechtsgutachten für die Fraktion der SPD im Deutschen Bundestag, 2012, abrufbar unter <http:// www.spdfraktion.de/sites/default/files/gutachten_wieland_verfassungsfragen_des_ betreuungsgeldes_august_2012-1.pdf > , 6. - Gleichheitsrechtsdogmatisch läßt sich das Betreuungsgeld wie eine allgemeine Familienförderleistung betrachten, die für eine etwas weniger subventionierte und etwas mehr kostendeckende Gebühr öffentlich geförderter Kinderbetreuung oder eben nach freier Wahl für anderen Familienaufwand ausgegeben werden könnte; gegen F. Brosius-Gersdorf Die Rolle des Staates in der Kinderbetreuung: Betreuungsgeld oder Förderung der Kinderbetreuung in Tageseinrichtungen und Tagespflege?, RdJB 2011, 440-450; dies. Das neue Betreuungsgeldgesetz - Familienförderung wider das Grundgesetz, NJW 2013, 2316-2321 (2319 f.); Wieland a.a. O., 8, 
3. Dynamik im systematischen Verhältnis des Ehe- und Familienschutzes zum allgemeinen Gleichbehandlungsgebot

Aus der weiterreichenden Wirkung des Gleichheitsrechts rührt die zur Zeit mächtigste Dynamik in der grundrechtsdogmatischen Aufstellung von Ehe und Familie her: die Unterwerfung des besonderen Schutzes von Ehe und Familie unter die Maßstäbe des allgemeinen Gleichbehandlungsgebots.

Im systematischen Verhältnis des Art. 6 Abs. 1 GG zu Art. 3 Abs. 1 GG kommt es darauf an, ob der besondere Schutz von Ehe und Familie eine fördernde Ungleichbehandlung als verfassungsunmittelbarer Differenzierungsgrund ${ }^{88} \mathrm{zu}$ rechtfertigen vermag. ${ }^{89}$ Diese Wirkung hängt davon

10; im Ergebnis für Verfassungsmäßigkeit unter Hinweis auf den „gesetzgeberischen Gestaltungsspielraum“ Uhle (Fn. 9), Rn. 35. - Die „Partnermonate“ lassen sich gleichheitsrechtsdogmatisch als unmittelbare Diskriminierung einzeln oder beiderseits erwerbstätiger Eltern erkennen, welche sich nicht für zwei Monate in der Kinderbetreuung abwechseln möchten. Für eine Rechtfertigung über das Gleichstellungsprogramm aus Art. 3 Abs. 2 S. 2 GG (das insofern als Leitbild einer bestimmten Verteilung von Familienaufgaben gerade diejenige Rechtfertigungskraft erhält, die in anderen Gleichheitsprüfungen dem Schutz von Ehe und Familie versagt bleiben soll) Brosius-Gersdorf Vätermonate, a.a.O., 325 f.; dem implizit zuneigend BVerfG, B. (K) vom 19.8.2011 1 BvL 15/11 -, Abs. 15-22 (Abweisung einer konkreten Normenkontrolle mangels Auseinandersetzung der Begründung mit einer Rechtfertigung des Eingriffs in Art. 6 Abs. 1 GG über Art. 3 Abs. 2 GG).

88 BVerfG, B. vom 4.10.1993 - 1 BvR 640/93 -, NJW 1993, 3058 f. (3058); von Coelln (Fn. 11), Rn. 50; Ipsen (Fn. 26), Rn. 58; M. Sachs Rechtsförmliche Lebenspartnerschaften für Menschen gleichen Geschlechts - Verfassungsgebot oder Verfassungsverstoß?, JR 2001, 45-50 (46 f.); Schüffner (Fn. 36), 412-414; Seiler (Fn. 42), 46; Uhle (Fn. 9), Rn. 36.2 mwN; siehe auch B. Pieroth/T. Kingreen Funktionen des Ehegrundrechts am Beispiel des Lebenspartnerschaftsgesetzes, KritV 85 (2002), 219-241 (236, 241: „Differenzierungsermächtigung“); ebenso C. Freytag Lebenspartnerschaftsgesetz, Eheschutzgebot und Differenzierungsverbot - Eine verfassungsrechtliche Untersuchung unter Berücksichtigung der neuesten Entscheidungen des Bundesverfassungsgerichts in dieser Sache -, DÖV 2002, 445-455 (453).

${ }^{89}$ Die Entwicklung der Gleichheitsrechtsdogmatik zu einem Instrument, das gesteigerte Anforderungen an eine Ungleichbehandlung nach ihren Wirkungen und Zwecken differenziert, hat die Kontrolle am Maßstab des Gleichheitssatzes dynamisiert; siehe zu der seit BVerfGE 55, 72 (88), etablierten, immer noch so genannten „Neuen Formel“ und ihrer seit BVerfGE 88, 87 (96 f.), weiter elaborierten Fassung nur $U$. Kischel in: Epping/Hillgruber (Fn. 9), Art. 3, Rn. 28 f. Dieser Maßstab wird gegen Art. 6 Abs. 1 GG in Stellung gebracht von BVerfG, B. vom 7.7.2009 - 1 BvR 1164/07 - [Hinterbliebenenversorgung], Abs. 85-87 = E 124, 199 (219 f.); B. vom 21.7.2010 - 1 BvR 611/071, 2464/07 - [Erbschafts- und Schenkungssteuer], Abs. $80=$ E 126, 400 (416); B. vom 19.6.2012 - 2 BvR 1397/09 - [Familienzuschlag], Abs. 54-57 = E 131, 239 (255 f.); B. vom 18.7.2012 - 1 BvL 16/11 - [Grunderwerbsteuerbefreiung], Abs. 39 f. = E 132, 179 (188 f.: Rn. 30 f.); U. vom 19.2.2013 - 1 BvL 1/11 - [Sukzessivadoption], Abs. 72; B. vom 7.5.2013 - 2 BvR 909/06, 1981/06, 288/07 - [Lebenspartner-Splitting], Abs. 74-77. 
ab, wie die Funktionen von Ehe und Familie zu ihrer Form ins Verhältnis gesetzt gesehen werden: Gibt Art. 6 Abs. 1 GG dem Gesetzgeber mit Ehe und Familie nicht nur ihre Funktionen, sondern auch ihre Form zu schützen und zu fördern auf, dann wirken Schutz und Förderung der Form von Ehe und Familie als ein verfassungsrechtlich vorgegebener, in der Verfassungsanwendung nicht weiter rechtfertigungsbedürftiger Zweck. ${ }^{90}$ Sieht man in Art. 6 Abs. 1 GG dagegen mit der Form von Ehe und Familie nur ihre einzelnen Funktionen geschützt, dann steht die Rechtfertigung einer Begünstigung von Ehe ${ }^{91}$ und Familie unter der Bedingung ihrer weiteren Rechtfertigung durch eine ihrer Funktionen: Dann nimmt die Gleichheitsprüfung Durchgriff hinter die Form auf die einzelne Funktion von Ehe und Familie. In diesem Durchgriff sind Ehe und Familie von funktionalen Äquivalenten nicht unterscheidbar. Dabei bestimmt sich die funktionale Äquivalenz nicht nach dem Gesamtpotential von Ehe und Familie, sondern nur nach der Teilfunktion, in welcher der rechtfertigende Grund für die Ungleichbehandlung gesucht wird. ${ }^{92}$

90 So etwa Gärditz (Fn. 9), 933.

91 Die Begünstigung der Ehe zieht dann als solche schon den Vorwurf einer mittelbaren Diskriminierung wegen der sexuellen Orientierung auf sich: BVerfG, B. vom 7.7.2009 - 1 BvR 1164/07 - [Hinterbliebenenversorgung], Abs. 89-93 = E 124, 199 (221 f.); B. vom 19.6.2012 - 2 BvR 1397/09 - [Familienzuschlag], Ls. 1, Abs. 62 f. = E 131, 239 (258 f.); B. vom 18.7.2012 - 1 BvL 16/11 - [Grunderwerbsteuerbefreiung], Abs. 43 f. = E 132, 179 (190: Rn. 34 f.); U. vom 19.2.2013 - 1 BvL 1/11 - [Sukzessivadoption], Abs. 104; B. vom 7.5.2013 - 2 BvR 909/06, 1981/06, 288/07 - [LebenspartnerSplitting], Abs. 78 f., 103. BVerfG, B. vom 18.7.2012 - 1 BvL 16/11 - [Grunderwerbsteuerbefreiung], Abs. 44 = E 132, 179 (190: Rn. 35), spricht sogar von „Anknüpfung an die sexuelle Orientierung".

92 Wie die Leistung für das Aufwachsen von Kindern in ,,behüteten“ Verhältnissen: BVerfG, B. vom 19.6.2012 - 2 BvR 1397/09 - [Familienzuschlag], Abs. $76=$ E 131, 239 (264). Ebenso für die verbindliche Gestaltung der Lebenspartnerschaft wie der Ehe ,als umfassende institutionalisierte Verantwortungsgemeinschaft" und „Gemeinschaft des Erwerbs und Verbrauchs“ sowie für die Eignung dazu, „Voraussetzung für die Begründung von Elternschaft zu sein“, BVerfG, B. vom 7.5.2013 - 2 BvR 909/06, 1981/06, 288/07 - [Lebenspartner-Splitting], Abs. 91, 94 f., 102. Zu den Rückwirkungen einer solchen Gleichstellung auf das übrige Familienrecht, wo in Sorgerechts- und Umgangsrechtsstreitigkeiten der Bezug zum andersgeschlechtlichen Elternteil als ein Kindeswohlargument gilt, GadelThiele (Fn. 9), 147. - Vom Gesetzeszweck her entsprechend im Hinblick auf vermögensrechtliche Regelungsbedürfnisse BVerfG, B. vom 18.7.2012 - 1 BvL 16/11 - [Grunderwerbsteuerbefreiung], Abs. 46, 51, 52 = E 132, 179 (190 f., 192 f.: Rn. 37, 42, 43); im Hinblick auf den Ausgleich von Mehrbedarf BVerfG, B. vom 19.6.2012 - 2 BvR 1397/09 - [Familienzuschlag], Abs. 72-75 = E 131, 239 (262-264). BVerfG, U. vom 19.2.2013 - 1 BvL 1/11 - [Sukzessivadoption], Abs. 44, deutet mit dem Unbehagen daran, daß ein Kind nach Einzeladoption ,abweichend vom in Art. 6 Abs. 2 Satz 1 GG unterstellten Fall, nicht mehrere ,Eltern', sondern lediglich einen Elternteil" hat, ein Leitbild des möglichst von zwei Menschen adoptierten Kindes an, 
Diesen Durchgriff hinter die Form auf die Teilfunktionen der Ehe faßt das Bundesverfassungsgericht ${ }^{93}$ in die paradoxe ${ }^{94}$ Formel, der Gesetzgeber dürfe die Ehe begünstigen, aber nicht andere Lebensformen benachteiligen: Danach ,rechtfertigt der bloße Verweis auf das Schutzgebot der Ehe eine solche Differenzierung nicht“; vielmehr ,bedarf es jenseits der bloßen Berufung auf Art. 6 Abs. 1 GG eines hinreichend gewichtigen Sachgrundes, der gemessen am jeweiligen Regelungsgegenstand und -ziel die Benachteiligung anderer Lebensformen rechtfertigt. "95

für dessen Interessen an der Adoption (Abs. 82-90) es auf die Verbindung seiner Adoptiveltern in Ehe oder eingetragener Lebenspartnerschaft nicht mehr ankommt. Gegenläufig wirkt der Vorbehalt für eine verfassungsmäßige generelle Einschränkung der Adoption (Abs. 73, 106). - Das Funktionsargument wendet sich gegen die Kommensurabilität von gleichgeschlechtlichen Partnerschaften mit der Ehe in dem Einwand, daß sich die Ehe durch ihre Finalität als potentielle Vorstufe einer aus ihr hervorgehenden Familie von der gleichgeschlechtlichen Partnerschaft wesentlich unterscheidet; so zum Beispiel von Coelln (Fn. 11), Rn. 50; Ipsen (Fn. 26), Rn. 21 f.; mit einer gründlichen Durchführung nach sämtlichen Rechtsfolgen Schüffner (Fn. 36), 371 f., 453-732; ebenso mit der überspitzten Reduktion dahin, daß die Ehe ,nicht wegen der mit ihr verbundenen gegenseitigen Verantwortungsübernahme der Ehepartner“, ,sondern wegen der aus ihr potentiell hervorgehenden Familie" geschützt sei, Uhle (Fn. 9), Rn. 4, 36.3.

${ }_{93}$ BVerfG, B. vom 7.7.2009 - 1 BvR 1164/07 - [Hinterbliebenenversorgung], Abs. 102, $105=$ E 124, 199 (225 f.); im Anschluß daran BVerfG, B. vom 21.7.2010 - 1 BvR 611/071, 2464/07 - [Erbschafts- und Schenkungssteuer], Abs. 91 = E 126, 400 (420); B. vom 19.6.2012 - 2 BvR 1397/09 - [Familienzuschlag], Abs. 66 f. = E 131, 239 (259-261); B. vom 18.7.2012 - 1 BvL 16/11 - [Grunderwerbsteuerbefreiung], Abs. 48 = E 132, 179 (191 f.: Rn. 39); U. vom 19.2.2013 - 1 BvL 1/11 - [Sukzessivadoption], Abs. 98; B. vom 7.5.2013 - 2 BvR 909/06, 1981/06, 288/07 - [Lebenspartner-Splitting], Abs. 83 f. - Anders hingegen noch BVerfG, B. (K) vom 20.9.2007 - 2 BvR 855/06 -, Abs. 15-23; B. (K) vom 6.5.2008 - 2 BvR 1830/06 -, Abs. 9, 13, 17.

${ }_{94}$ Nur scheinbar ist die Paradoxie aufgelöst durch eine Unterscheidung der Lebensformen danach, ob sie "nach dem geregelten Lebenssachverhalt und den mit der Normierung verfolgten Zielen der Ehe vergleichbar sind" (so daß das Recht zum Privilegieren gegenüber „nicht vergleichbaren“ Lebensformen unberührt bliebe); siehe BVerfG, B. vom 7.7.2009 - 1 BvR 1164/07 - [Hinterbliebenenversorgung], Abs. 105 = E 124, 199 (226). Die Rechtfertigung einer Ungleichbehandlung „nicht vergleichbarer“ Lebensformen ergibt sich schon aus dem allgemeinen Gleichheitssatz; auf Art. 6 Abs. 1 GG kommt es dafür nicht an. „Wegen des verfassungsrechtlichen Schutzes der Ehe“, wie es der Vordersatz ausdrücklich formuliert - BVerfG, B. vom 7.7.2009 - 1 BvR 1164/07 [Hinterbliebenenversorgung], Abs. $102=$ E 124, 199 (225) - dem Gesetzgeber ihre Privilegierung zuzugestehen, ergäbe nur ohne Durchgriff auf funktionale Äquivalenzen einen Sinn; doch auf genau diesen stellt der im Text gleich zitierte Nachsatz ab. Die als Ausgangspunkt mitzitierte Entscheidung BVerfGE 105, 313 (348) [Lebenspartnerschaftsgesetz], läßt diese Paradoxie noch nicht erkennen, da sie nur im Vordersatz mit jener Formel übereinstimmt.

${ }_{95}$ BVerfG, B. vom 7.7.2009 - 1 BvR 1164/07 - [Hinterbliebenenversorgung], Abs. $105=$ E 124, 199 (226); kritisch Hillgruber (Fn. 9); dagegen C. D. Classen Der 
Im Ergebnis dementiert der Durchgriff auf die Funktionen von Ehe und Familie eine eigenständige Wirkung des Schutzes von Ehe und Familie in Art. 6 Abs. 1 GG. ${ }^{96}$ Die grundrechtsdogmatische Stellung des Art. 6 Abs. 1 GG in seinem systematischen Verhältnis zu Art. 3 Abs. 1 GG ist dahin entschieden, daß die ,wertentscheidende Grundsatznorm“ des Schutzes von Ehe und Familie dem Gleichheitssatz nichts hinzuzufügen hat.

besondere Schutz der Ehe - aufgehoben durch das BVerfG?, JZ 2010, 411 f.; kritisch auch Gärditz (Fn. 9), 933 f. - Anders noch BVerfGE 105, 313 (343) [Lebenspartnerschaftsgesetz], wo es eine Asymmetrie der wechselseitigen Exklusivität von Ehe und eingetragener Lebenspartnerschaft zulasten der zweitgenannten als ,angesichts der Gewährleistung des Art. 6 Abs. 1 GG noch hinnehmbar" bewertet (bei erkennbarer Sympathie für die symmetrische Lösung durch ein Ehehindernis, wie es der Gesetzgeber später in $\$ 1306$ BGB nachgetragen hat).

${ }^{96}$ Nebenher ist aus der Absage an ein Abstandsgebot ein Abstandsverbot geworden. Zur Auslegung des „,besonderen Schutzes“ als Abstandsgebot siehe Scholz/Uhle (Fn. 9), 397 f.; ebenso Ipsen (Fn. 26), Rn. 55-57; G. Krings Die „eingetragene Lebenspartnerschaft" für gleichgeschlechtliche Paare. Der Gesetzgeber zwischen Schutzabstandsgebot und Gleichheitssatz, ZRP 2000, 409-415; D. C. Umbach in: ders./T. Clemens (Hrsg.) Grundgesetz. Mitarbeiterkommentar und Handbuch, 2002, Art. 6 Rn. 57b, 62 f., 66-68; ähnlich Burgi (Fn. 36), 501-508; ders. (Fn. 11), Rn. 47 (,Abbildungsgebot“, bezogen auf die Wertentscheidung zugunsten der Ehe); Pauly (Fn. 56), 1956 („Öffnungs-, Abbildungs- und Bezeichnungsverbot", bezogen auf die Übertragung der Strukturmerkmale des Instituts auf andere Lebensgemeinschaften); G. Robbers Eingetragene Lebenspartnerschaften. Verfassungsrechtliche Überlegungen, JZ 2001, 779-786 (783 f.); Tettinger (Fn. 3), 140 (,Differenzierungsgebot“); zurückgewiesen von BVerfGE 105, 313 (348350) [Lebenspartnerschaftsgesetz]; hiergegen noch G. Kirchhof (Fn. 85), 562 f.; Nesselrode (Fn. 3), 157 f., 198; Steiner (Fn. 9), Rn. 38; Uhle (Fn. 9), Rn. 36, 38; dem Bundesverfassungsgericht beipflichtend Classen (Fn. 9), 1089; Coester-Waltjen (Fn. 32), Rn. 16, 50; Gröschner (Fn. 24), Rn. 49; ebenso Freytag (Fn. 88), 448-451; Pieroth/Kingreen (Fn. 88), 233-241; J. Wasmuth Zur Verfassungsmäßigkeit der eingetragenen Lebenspartnerschaft, Der Staat 41 (2002), 47-71 (56-59, 65). Aus der Kritik am Abstandsverbot siehe von Coelln (Fn. 11), Rn. 18, 49 f.; GadelThiele (Fn. 9), 149-151; G. Krings Vom Differenzierungsgebot zum Differenzierungsverbot - Hinterbliebenenversorgung eingetragener Lebenspartnerschaften, NVwZ 2011, 26 f.; Uhle (Fn. 9), Rn. 36.2-36.3. - Der EGMR hat am Maßstab des Art. 14 in Verbindung mit Art. 8 EMRK Ungleichbehandlungen zwischen der Ehe, die nach Art. 12 EMRK zulässig den Verbindungen von Frau und Mann vorbehalten bleiben dürfe, und einer für gleichgeschlechtliche Paare eröffneten anderen Form rechtlicher Anerkennung ausdrücklich dem Beurteilungsspielraum der Konventionsstaaten überlassen: EGMR, U. vom 24.6. 2010 - 30141/04 - Schalk und Kopf gegen Österreich -, Abs. 54-64 (zu Art. 12 EMRK), 101, 108 f. (zu Art. 14 EMRK). 


\section{Dynamik im Begriff der Ehe}

In der Folge ist der Verfassungsbegriff „Ehe“ ein Anschauungsstück für eine Dynamik, welche die Grundrechtsdogmatik vom einfachen Gesetzesrecht her unter Spannung setzt. Betroffen ist das Strukturmerkmal der Verschiedengeschlechtlichkeit, das durch die einfachgesetzliche Gleichstellung gleichgeschlechtlicher Verbindungen mit der Ehe in Frage gestellt ist.

Dieser Befund mag irritieren, weil die Definition des Begriffs „Ehe“ äußerlich nicht verändert worden ist; im Gegenteil haben sowohl der Gesetzgeber als auch das Bundesverfassungsgericht die eingetragene Lebenspartnerschaft als ein ,aliud“ zur Ehe konstruiert und gerade damit die Vereinbarkeit mit Art. 6 Abs. 1 GG begründet. ${ }^{97}$ So gilt der verfassungsrechtliche Begriff der „Ehe“ als unverändert auf die Verbindung einer Frau mit einem Mann beschränkt. Eine grundrechtsdogmatische Erweiterung auf gleichgeschlechtliche Verbindungen ${ }^{98}$ lehnt das Bundesverfassungsgericht in fast einhelliger Übereinstimmung mit der Rechtswissenschaft $a b .{ }^{99}$

97 BVerfGE 105, 313 (351); ebenso noch Gröschner (Fn. 24), Rn. 47, 50; Robbers Eingetragene Lebenspartnerschaften (Fn. 96), 783 f.; Sickert (Fn. 69), 178, 185 f.; in zweiter Linie damit argumentierend auch $V$. Beck Die verfassungsrechtliche Begründung der Eingetragenen Lebenspartnerschaft, NJW 2001, 1894-1901 (1898, 1900).

98 AG Frankfurt a. M., B. vom 21.12.1992 - 40 UR III E 166/92 -, NJW 1993, 940 f.; K. Möller Der Ehebegriff des Grundgesetzes und die gleichgeschlechtliche Ehe, DÖV 2005, 64-71; wohl unter dem Vorbehalt einfachgesetzlicher Anerkennung S. Ott Nichteheliche Lebensgemeinschaften und Grundgesetz, Vorgänge 140 (1997), 52-59 (54-56); ders. Die Begriffe „Ehe und Familie“ in Art. 6 I GG, NJW 1998, 117-119 (118); ähnlich Brosius-Gersdorf (Fn. 17), Rn. 83; weitere Nachweise bei Stern (Fn. 3), 374 f., Fn. 167.

99 BVerfG, B. vom 4.10.1993 - 1 BvR 640/93 -, NJW 1993, 3058 f. (3058), mit Verweis auf BVerfGE 49, 286 (300); bestätigt in BVerfGE 105, 313 (345) [Lebenspartnerschaftsgesetz]; BVerfG, B. vom 19.6.2012 - 2 BvR 1397/09 - [Familienzuschlag], Abs. 65 = E 131, 239 (259); B. vom 7.5.2013 - 2 BvR 909/06, 1981/06, 288/07 - [LebenspartnerSplitting], Abs. 81; siehe auch BVerwG, NVwZ 1997, 189 (190). Aus der Literatur: besonders gründlich Schüffner (Fn. 36), 127-202; außerdem etwa Classen (Fn. 9), 1087; von Coelln (Fn. 11), Rn. 6; Coester-Waltjen (Fn. 32), Rn. 9; Gröschner (Fn. 24), Rn. 44; Ipsen (Fn. 26), Rn. 9; Mager (Fn. 31), 452; Nesselrode (Fn. 3), 115 f.; Robbers (Fn. 14), Rn. 45; Sachs (Fn. 88), 45; Stern (Fn. 3), 373 f. mwN; Uhle (Fn. 9), Rn. 4; Umbach (Fn. 96), Rn. 57, 58-62. Siehe auch Friauf (Fn. 32), 2601: „Die konstitutiven Elemente des Verfassungsrechtsbegriffs ,Ehe“ [einschließlich der Geschlechtsverschiedenheit der Partner] sind, da normativ vorgegeben, gegenüber gesellschaftlichem Wertewandel ,resistent"." - Die Relativierung in BVerfGE 121, 175 (189-204), wonach eine bestehende Ehe auch nach Geschlechtsumwandlung eines Ehegatten bestehen bleiben können muß, erweitert nicht das Institut der Ehe (193, 195 f., 201, 202 f.), sondern paßt den abwehrrechtlichen Schutzbereich einer Ausnahmekonstellation an; Uhle (Fn. 9), Rn. 5. 
Doch ungeachtet dieser begrifflichen Unterscheidung der Ehe von der eingetragenen Lebenspartnerschaft bestehen in den Rechtsfolgen beider Institute unter der Herrschaft des Gleichbehandlungsgebots keine signifikanten Unterschiede mehr. ${ }^{100}$ Reste der Unterscheidung sind brüchig wie die auf Ehepaare beschränkte Möglichkeit der gemeinschaftlichen Adoption ( $§ 1741$ Abs. 2 BGB), deren Wirkung eingetragene Lebenspartner vorerst nur durch Sukzessivadoption herstellen können; ${ }^{101}$ oder sie sind

Sie wird aber auch als ein Anzeichen dafür gelesen, daß das „Ehekonstitutivum der Verschiedengeschlechtlichkeit“ „verblasst“; so etwa Heinig (Fn. 60), 27; schärfer Benedict (Fn. 9), 485.

100 Ausdrücklich hervorgehoben in BVerfG, B. vom 19.6.2012 - 2 BvR 1397/09 [Familienzuschlag], Abs. 69 f. = E 131, 239 (261); B. vom 18.7.2012 - 1 BvL 16/11 [Grunderwerbsteuerbefreiung], Abs. 18 = E 132, 179 (183: Rn. 9); B. vom 7.5.2013 2 BvR 909/06, 1981/06, 288/07 - [Lebenspartner-Splitting], Abs. 90 f. Es ist beim Bundesverfassungsgericht denn auch schon davon die Rede, daß Ehe und eingetragene Lebenspartnerschaft „im Wesentlichen gleichartig“ seien: B. vom 19.6.2012 - 2 BvR 1397/09 - [Familienzuschlag], Abs. 67 = E 131, 239 (261); B. vom 7.5.2013 - 2 BvR 909/06, 1981/06, 288/07 - [Lebenspartner-Splitting], Abs. 85. Das spiegelt sich in einer der Ehe parallelen Definition der eingetragenen Lebenspartnerschaft als ,familienrechtliches Institut" und der Zusammenfassung unter einem gemeinsamen Oberbegriff „einer auf Dauer angelegten, rechtlich verfestigten Partnerschaft": B. vom 18.7.2012 1 BvL 16/11 - [Grunderwerbsteuerbefreiung], Abs. 18, 44 = E 132, 179 (183, 190: Rn. 9, 35). - Weit zurück liegen die 2001 noch aus begründeter „Angst vor Art. 6 Abs. 1 GG“ unternommenen „Verrenkungen [...], die der Gesetzgeber macht, um die gleichgeschlechtliche Lebenspartnerschaft auf Abstand zur bürgerlich-rechtlichen Ehe zu halten“; D. Kaiser Das Lebenspartnerschaftsgesetz. Zur Gleichstellung homosexueller Partnerschaften aus familienrechtlicher Sicht, JZ 2001, 617-625 (625). - Die Entwicklung zusammenfassend Steiner (Fn. 9), Rn. 33-39; Uhle (Fn. 9), Rn. 36.2-36.4. - Damit sind die Voraussetzungen für eine entsprechende Verfassungsänderung überspielt worden; siehe Hillgruber (Fn. 9); Robbers (Fn. 14), Rn. 47. - Vor einem „strategischen“ Überspielen der Institutsgarantie durch „Aushöhlungsprozesse“ warnte bereits E. Schmidt-Jortzig in: VVDStRL 45 (1987), 129; entwarnend dagegen mit Hinweis auf die vermeintliche Unfähigkeit des Gesetzgebers zu „langfristiger Konzeption“ H. Steiger ebd., 144 (jeweils in der Aussprache). Zur entsprechenden Methode des Bundesverfassungsgerichts Rixen (Fn. 11), 871.

${ }^{101}$ Die Verfassungsmäßigkeit dieser letzten Beschränkung wird andeutungsvoll offengelassen durch BVerfG, U. vom 19.2.2013 - 1 BvL 1/11 - [Sukzessivadoption], Abs. 93; verneint von Brosius-Gersdorf (Fn. 17), Rn. 84, 120; Classen (Fn. 9), 1091 mwN; Grehl (Fn. 78), 148-174, 176-180; bejaht von Gärditz (Fn. 9). - Brüchig ist auch die Rechtfertigung dafür, daß $\S 27$ a Abs. 1 Nr. 3 SGB V die Ehe bei der sozialrechtlichen Finanzierung einer künstlichen Befruchtung bevorzugt; die Gründe für die Rechtfertigung des Ausschlusses nichtehelicher Lebensgemeinschaften gemäß BVerfG, U. vom 28.2.2007 - 1 BvL 5/03 -, E 117, 316 (327-329), sind nicht auf den Ausschluß eingetragener Lebenspartnerschaften übertragbar. Dessen Haltbarkeit gegenüber der Rechtsprechung zur Gleichstellung eingetragener Lebenspartnerschaften dürfte nur noch davon abhängen, ob sich ihnen gegenüber der Ausschluß heterologer Inseminationen gemäß $§ 27 \mathrm{a}$ Abs. 1 Nr. 4 SGB V rechtfertigen läßt. 
der gesetzesredaktionellen Aufräumarbeit überlassen wie $\S 12$ Abs. 1 S. 1 des Sprengstoffgesetzes ${ }^{102}$, der die Rechtsnachfolge in die Erlaubnis zum Umgang mit explosionsgefährlichen Stoffen dem hinterbliebenen Lebenspartner vorzuenthalten scheint. Auch der verfassungsrechtliche Schutz eingetragener Lebenspartner über Art. 2 Abs. 1 und Art. 3 Abs. 1 GG bleibt auf dem erreichten Stand der Auslegung dieser Vorschriften im Ergebnis in nichts hinter der formal verschlossenen Berufung auf den Eheschutz aus Art. 6 Abs. 1 GG zurück.

Ehe und eingetragene Lebenspartnerschaft sind also zwei in den wesentlichen Voraussetzungen und Rechtsfolgen restlos gleichgestaltete Institute geworden, die sich allein in ihrem Namen unterscheiden - abgesehen von der exakt komplementären Voraussetzung der Verschiedengeschlechtlichkeit einerseits, der Gleichgeschlechtlichkeit andererseits. Das verfassungsrechtliche Begriffsmerkmal der Verschiedengeschlechtlichkeit der Ehe, so obstinat es von allen Seiten beschworen wird, hat rechtlich jede Unterscheidungskraft verloren, es ist hinfällig. ${ }^{103}$ Damit hat der Begriff der „Ehe“ selbst als grundrechtsdogmatisches Element des Art. 6 Abs. $1 \mathrm{GG}$ eine dynamische Umgestaltung erfahren.

All das ist folgerichtig für ein Verständnis der wertentscheidenden Grundsatznorm, welches sich davor hütet, die ihrer Ratio entsprechenden Strukturmerkmale von Ehe und Familie zu einem über Programmsätze hinausgehenden, verfassungsrechtlich potenten, aber auch sorgfältig in freiheitskompatiblen Bahnen zu haltenden Leitbild (s. o. II. 4.) zu entwickeln.

102 Gesetz über explosionsgefährliche Stoffe (Sprengstoffgesetz - SprengG) in der Fassung der Bekanntmachung vom 10.9.2002 (BGBl. I 3518), zuletzt geändert am 7.8.2013 (BGBl. I 3154). - Siehe dazu die Antwort der Bundesregierung auf eine Große Anfrage zur „Verfassungsmäßigkeit der bestehenden Ungleichbehandlung eingetragener Lebenspartnerschaften gegenüber Ehen“, BT-Drs. 17/8248, 9 (sub 14.). Ähnliches gilt für die meisten dort aufgeführten Vorschriften, soweit sie nicht inzwischen bereits geändert sind.

${ }^{103}$ Vorläufig prominenteste Spitze dieser Dynamik, wenn auch vom Wahlkampf gezeichnet: Gesetzentwurf der Fraktionen SPD und BÜNDNIS 90/DIE GRÜNEN: Entwurf eines Gesetzes zur Einführung des Rechts auf Eheschließung für Personen gleichen Geschlechts, 12.3.2013, BT-Drs. 17/12677; übereinstimmend: Gesetzentwurf des Bundesrates: Entwurf eines Gesetzes zur Einführung des Rechts auf Eheschließung für Personen gleichen Geschlechts, 22.3.2013, BR-Drs. 196/13. - Für die Vereinbarkeit einer einfachgesetzlichen Erstreckung des Instituts der Ehe auf gleichgeschlechtliche Verbindungen mit Art. 6 Abs. 1 GG Brosius-Gersdorf (Fn. 17), Rn. 21, 81; Classen (Fn. 9), 1090; Ott Nichteheliche Lebensgemeinschaften (Fn. 98), 54-56; ders. Ehe und Familie (Fn. 98), 118; wohl auch Rixen (Fn. 11), 872 f.; dagegen Mager (Fn. 31), 453; Ruffert (Fn. 42), 400; Scholz/Uhle (Fn. 9), 397; Schüffner (Fn. 36), 125-127; Uhle (Fn. 9), Rn. 5. 


\section{Zukunft der Dynamik: Grundrechtsdogmatik von Ehe und Familie in der Karawane des Verfassungswandels}

Soweit die dynamischen Entwicklungen der Grundrechtsdogmatik von Ehe und Familie daher rühren, daß sie hinter ein verfassungsrechtliches Leitbild auf die Teilfunktionen von Ehe und Familie durchgreifen, müssen sie alle grundrechtsdogmatischen Merkmale von Ehe und Familie erfassen, welche nicht in einer bestimmten Funktion aufgehen.

Für die Merkmale der Ehe im Sinne des Art. 6 Abs. 1 GG betrifft das nach der Verschiedengeschlechtlichkeit etwa die Beschränkung auf die Einehe $^{104}$ und den Ausschluß von Verwandten, insbesondere Geschwistern, von Ehe und Lebenspartnerschaft. ${ }^{105}$ Für das Elternrecht gibt es keinen funktionalen Grund dafür, an die Möglichkeit der biologischen Abstammung anzuknüpfen, wie es der Ausschluß eingetragener Lebenspartner von einer Elternschaftsfiktion entsprechend der Vaterschaftsvermutung des $\S 1592$ Nr. 1 BGB $^{106}$ und der Ausschluß von Frauen von

104 Welcher sachliche, funktionale Grund sollte nämlich den Ausschluß von Mehrehen rechtfertigen? Die Antwort liegt nur scheinbar auf der Hand, wenn sie sich nicht auf Vorurteile über die Möglichkeiten einer funktionalen Äquivalenz von dauerhaften, verantwortungs- und hingebungsvollen Lebensgemeinschaften zwischen mehr als zwei Menschen mit einer solchen zwischen zwei Menschen verschiedenen oder gleichen Geschlechts stützen soll. Vgl. damit das Argument bei Robbers (Fn. 14), Rn. 42: „abendländische Rechtstradition“. Folgerichtig für die Freiheit des Gesetzgebers, die Beschränkung auf die Einehe aufzuheben, Brosius-Gersdorf(Fn. 17), Rn. 50, 63, 79.

105 Wo ist nämlich das funktionale Defizit, das eine zu gleicher Verbindlichkeit wie in der Ehe gesteigerte Lebensgemeinschaft zwischen erwachsenen Verwandten von gleichen Rechten fernhält? Selbst wenn man das strafrechtliche Inzestverbot als gerechtfertigt unterstellt, obwohl BVerfGE 120, 224 (243-249), es dafür bei allem Bemühen um funktionale Gründe dem Gesetzgeber zugesteht, auch die ,gesellschaftliche Tabuisierung des Inzests“ als beachtliche Gestalt ,einer kulturhistorisch begründeten, nach wie vor wirkkräftigen gesellschaftlichen Überzeugung“ (248) in Anspruch zu nehmen, fehlt es jedenfalls an einer funktionalen Begründung dafür, warum Ehe und Lebenspartnerschaft auf Sexualgemeinschaft fixiert sein sollen.

106 Für Lebenspartnerschaften zweier Männer stellt sich die Frage nur deshalb nicht, weil nach gegenwärtigem Stand der Technik keiner von ihnen selbst ein Kind zur Welt bringen kann; es ist aber selbst insoweit mit Ausnahmen zu rechnen, seit eine Änderung der personenstandsrechtlichen Geschlechtszuordnung nicht mehr die Aufgabe der Fortpflanzungsfähigkeit voraussetzt; siehe oben in Fn. 79. In Lebenspartnerschaften zweier Frauen ist die Geburt von Kindern unter so oder so zu bewerkstelligender Beteiligung eines genetischen Vaters selbstverständlich möglich. Dem Bundesverfassungsgericht zufolge muß der Gesetzgeber für die Elternschaft regelmäßig an die biologische Abstammung anknüpfen; siehe oben Fn. 72. Der Ausschluß der eingetragenen Lebenspartnerin von der Vermutung des $\S 1592$ Nr. 1 BGB sei deshalb ,keine Ungleichbehandlung": BVerfG, B. vom 2.7.2010 - 1 BvR 666/10 -, Abs. 30 (allerdings ging es 
einem einvernehmlichen Erwerb des Elternrechts durch Erklärung entsprechend der Vaterschaftsanerkennung in $\S 1592 \mathrm{Nr} .2$ BGB $^{107}$ wie selbstverständlich voraussetzen. Zumindest widerlegbar ist der funktionale Grund dafür, daß das Elternrecht nicht mehr als zwei Elternteilen - also mehr als einem Vater und einer Mutter oder, auf Geheiß des Bundesverfassungsgerichts, zwei Müttern oder zwei Vätern - zugeordnet werden können soll. ${ }^{108}$

Insbesondere die Unterordnung der Grundrechtsdogmatik von Ehe und Familie unter den Gleichheitssatz hat gesellschaftspolitische Wirkungen, die sich kraft verfassungsgerichtlicher Autorität von gesellschaftspolitischen Entscheidungen des Gesetzgebers unabhängig machen und so eine Eigendynamik entwickeln. Eine konsistente Grundrechtsdogmatik könnte ihr Rechnung tragen, indem sie sich aus den bisher noch gehaltenen rhetorischen Stellungen zurückzöge: Die Rede vom Charakter des Art. 6 Abs. 1 GG als wertentscheidende Grundsatznorm wäre aufzugeben. Der Weg wäre dann frei dafür, die eingetragene Lebenspartnerschaft und andere Lebensgemeinschaften in das Institut der Ehe zu integrieren, die Ehe für die Mehrehe zu öffnen, den Staat aus dem öffentlichen Institut der obligatorischen Zivilehe zurückzuziehen, die Ehe somit an die Gesellschaft, an die Pluralität ihrer Eheverständnisse und an ihre Dynamik zurückzugeben, hierzu vielleicht alle Schutzwirkungen des Art. 6 Abs. 1 GG nach dem Vorbild des Art. 8 EMRK ${ }^{109}$ im abwehrrechtlichen

hier nicht um die rechtlichen Folgen der Elternschaft, sondern nur um den Nachweis der Abstammung in der Geburtsurkunde, also eine sekundäre Rechtsfolge). Das entspricht den biologischen Gegebenheiten - aber ein funktionaler Grund dafür ist nicht ersichtlich. Bei einem in einer Ehe geborenen Kind gibt das Gesetz, wenn kein Beteiligter widerspricht, der sozialen Beziehung den Vorrang vor der biologischen. Unter gleichen Bedingungen müßte es das auch bei einem in einer eingetragenen Lebenspartnerschaft geborenen Kind tun, indem es die Vaterschaftsvermutung zu einer entsprechend bedingten Elternschaftsfiktion erweitert.

${ }_{107}$ Die Vaterschaftsanerkennung in $\S 1592$ Nr. 2 BGB ist bisher naturgemäß auf Männer beschränkt, läßt aber bei allseitigem Einvernehmen die biologischen Tatsachen dahinstehen und ermöglicht im Ergebnis eine gewillkürte Vaterschaft; siehe T. Rauscher in: J. von Staudingers Kommentar zum Bürgerlichen Gesetzbuch, Buch 4: Familienrecht, §§ 1589-1600d (Abstammung), Neubearb. 2011, § 1592, Rn. 51, 53; J. Gernhuberl D. Coester-Waltjen Familienrecht, 6. Aufl. 2010, § 52 Rn. 3, 42 f.; kritisch H. F. Gaul Die Neuregelung des Abstammungsrechts durch das Kindschaftsrechtsreformgesetz, FamRZ 1997, 1441-1466 (1449-1451, 1454-1456). Der entsprechenden Priorität folgt auch $\S 1600$ Abs. 5 BGB mit dem Ausschluß der Vaterschaftsanfechtung nach einvernehmlicher heterologer Insemination.

108 BVerfG, U. vom 19.2.2013 - 1 BvL 1/11 - [Sukzessivadoption], Abs. 52: „Vermeidung von Verantwortungsunklarheit und Kompetenzkonflikten“.

109 EGMR, U. vom 13.6.1979 - 6833/74 - Marckx gegen Belgien; Nesselrode (Fn. 3), $218-221$. 
Schutz der erweiterten Familie als Varietät privater, auf Dauer und Verantwortung gerichteter Nahbeziehungen zu vereinigen. Die Grundrechtsdogmatik von Ehe und Familie in Art. 6 Abs. 1 GG könnte in dieser Dynamik zu einem pointiert liberalen Konzept umschwenken - beziehungsweise sich zurücksinken lassen in die grundrechtsdogmatische Ursuppe von 1949, in der von einer wertentscheidenden Grundsatznorm mit juristischer Direktivkraft noch nicht die Rede war.

Das wäre eine in sich schlüssige Lesart des Art. 6 Abs. 1 GG. Sie bräche aber tief in die Prämissen des grundrechtsdogmatischen Diskurses über diese Norm ein. ${ }^{110}$ Wer sich dagegen nicht von der Überzeugung abkoppeln will, daß es der Verfassung beim besonderen Schutz von Ehe und Familie auch um Zukunftsgestaltung geht, wird einen neuen Anschluß an ihr Verständnis als wertentscheidende Grundsatznorm suchen müssen.

Hierzu kann ihre Auslegung im Sinne einer Leitbildgarantie beitragen, die den Durchgriff auf die Teilfunktionen von Ehe und Familie auffängt. Das gewährleistete Leitbild wird das Merkmal der Verschiedengeschlechtlichkeit, die einst als günstige Bedingung für das Zeugen von Kindern galt, ${ }^{111}$ nicht mehr umfassen können. Insoweit hat die rechtliche Gleichstellung gleichgeschlechtlicher Partnerschaften eine praktisch unumkehrbare neue Rechtslage geschaffen und dabei verfassungsrechtliche Unterscheidungen derogiert. Mit den Augen der Methode, von denen je nach Standpunkt eines oder zwei zugedrückt werden müssen, ist dieser Vorgang als Verfassungswandel zu notieren, der durch die Gesetzgebung und die sie bestätigende und forcierende Verfassungsrechtsprechung je nach Standpunkt entweder aufgenommen oder bewirkt worden ist. ${ }^{112}$ Andere Merkmale eines Leitbilds sind in der Rechtsprechung des Bundesverfassungsgerichts noch angelegt. So rechtfertigt es das Inzestverbot damit, daß die mit dem Inzest verbundenen „Rollenüberschneidungen [...] nicht dem Bild der Familie [entsprechen], das Art. 6 Abs. 1 GG zugrunde liegt". ${ }^{113}$ Die Beschreibungen von Ehe und Lebenspartnerschaft lassen erkennen, daß das Bundesverfassungsgericht sie auf eine Verbindung von genau zwei Menschen beschränkt sieht. ${ }^{114}$ Das Elternrecht als „,natürliches Recht" gemäß Art. 6 Abs. 2 S. 1 GG möchte es primär an den

110 Die Gegenthese vertritt Classen (Fn. 9), 1093.

111 Robbers (Fn. 14), Rn. 46; weitergehend noch Rn. 47: „Art. 6 Abs. 1 hat im Sinne der Bewahrung des Herkömmlichen auch die gelebte Sexualität zum Schutzinhalt, insoweit zeichnet die Norm auch ein verfassungsrechtlich umhegtes Bild der Sexualität".

112 Anderer Ansicht Uhle (Fn. 9), Rn. 37.

113 BVerfGE 120, 224 (245).

114 Siehe oben Fn. 45. 
Abstammungsverhältnissen ausgerichtet wissen, ${ }^{115}$ was der an die biologischen Möglichkeiten gebundenen Vaterschaftsvermutung einen Vorrang vor gewillkürter Elternschaft gibt. Auch die Beschränkung des Elternrechts auf ein Elternpaar ${ }^{116}$ hat die Qualität eines leitbildprägenden Merkmals. ${ }^{117}$

Die Rekonstruktion einer Leitbildgarantie effektiviert den Art. 6 GG als wertentscheidende Grundsatznorm. Sie gibt der dynamischen Intention der Grundrechtsdogmatik von Ehe und Familie einen Maßstab. Gegenüber dem allgemeinen Gleichheitssatz in Art. 3 Abs. 1 GG verwirklicht sie die verfassungsrechtliche Wertentscheidung als verfassungsunmittelbaren Sachgrund für die Rechtfertigung von Ungleichbehandlungen nach den leitbildprägenden Merkmalen, die den Durchgriff auf Teilfunktionen auffangen. Gegenüber der Dynamik gesellschaftlicher Anschauungen darüber, welche leitbildprägenden Merkmale für das öffentliche Interesse signifikant sind, stützt sie künftig die formellen Voraussetzungen einer Verfassungsänderung. ${ }^{118}$

Angesichts der Dynamik, die sich der grundrechtsdogmatischen Gestalt des Schutzes von Ehe und Familie vermittelt, mag jeder Versuch, auf dem jeweils gerade erreichten Status Quo des Verfassungswandels für die weitere Entwicklung die antidynamische Intention dieses Schutzes grundrechtsdogmatisch in Stellung zu bringen, einen unbeholfenen Eindruck machen, rückständig wirken im doppelten Sinn des Rückstands als, Verspätung' und ,Rest'. Aber ohne Bemühungen um Konsistenz und Konti-

115 Siehe oben Fn. 72 sowie BVerfGE 108, 82 (104): Art. 6 Abs. 2 S. 1 GG gebiete, „möglichst eine Übereinstimmung von leiblicher und rechtlicher Elternschaft zu erreichen".

116 Siehe oben Fn. 80 und 81. Nach BVerfGE 108, 82 (101), „lässt schon der Umstand, dass ein Kind nur von einem Elternpaar abstammen kann, darauf schließen“. Daraus begründet sich die „Vorstellung von elterlicher Verantwortung, die Art. 6 Abs. 2 Satz 1 GG zugrunde liegt" (102, Abs. 62).

117 Ein weiterer Anknüpfungspunkt ist die Bezeichnung der Familiengemeinschaft des Kindes mit seinen durch die Ehe verbundenen Eltern als „Regelfall“; siehe BVerfGE 31, 194 (205); 56, 363 (382); 61, 358 (372); 84, 168 (179); 92, 158 (176 f.). - Für eine Stärkung der verbleibenden Strukturmerkmale von Ehe und Familie gegen Art. 3 Abs. 1 und 3 GG wohl auch Rixen (Fn. 11), 873.

118 Gegenüber verfassungsexternen Antidiskriminierungsprogrammen aus dem Völker- und Europarecht füllt sie die dort vorbehaltenen Regelungsspielräume des staatlichen Rechts; siehe nur (bezogen auf den Zugang gleichgeschlechtlicher Paare zur Ehe) EGMR, U. vom 24.6.2010 - 30141/04 - Schalk und Kopf gegen Österreich -, Abs. 5464, 101, 108 f. Dem Vorbehalt, den BVerfG, U. vom 30.6.2009 - 2 BvE 2, 5/08, 2 BvR 1010, 1022, 1259/08, 182/09 - [Vertrag von Lissabon], Abs. 249, 252, $260=$ E 123, 267 $(358,359,363)$, gegenüber der europäischen Integration zugunsten bedeutsamer Entscheidungen über das Familienrecht aufrichtet, gibt sie eine Kontur. 
nuität der Grundrechtsdogmatik bliebe der künftige Verfassungswandel hinter den darin formulierten Rationalitätsanforderungen zurück.

Verfassungswandel - als Phänomen - ist eine Resultante aus divergenten Kräften: Politischer Veränderungsdruck, solange er für eine formelle Verfassungsänderung zu schwach ist, strapaziert die Verfassungsauslegung über die Grenzen des bestehenden Konsenses hinaus; der Gesetzgeber widersteht ihm oder gibt ihm nach; das Verfassungsgericht kassiert oder billigt seine Überschreitungen, wenn es sie nicht vorwegnimmt. Die Verfassungsrechtswissenschaft hat in diesem Kräftespiel die Aufgabe der Kritik, die das gegenüber dynamischen Ansprüchen auf Zukunftsgestaltung widerständige, dämpfende und bremsende Moment der Grundrechtsdogmatik zur Wirkung zu bringen hat. Alle Akteure in diesem Kräftespiel verhandeln dabei jeweils grundrechtsdogmatische Überzeugungen, die unter den Bedingungen der Sozialisation im jeweils gegenwärtigen Verfassungskonsens gebildet werden. Die Zeitdimension des Verfassungswandels bildet sich daher auch im Wechsel der Generationen ab.

In anderen Kräftespielen können die Rollen anders verteilt sein, so daß etwa gegenüber einem lethargischen Verharren der Praxis in verfassungswidrigen Gewohnheiten die verfassungsrechtswissenschaftliche Kritik auf Veränderung drängen muß. Geht es aber um politisch induzierten Verfassungswandel, ist es Aufgabe der Verfassungsrechtswissenschaft, gegenüber der Veränderungsdynamik den verfassungsrechtsmethodischen Preis der Veränderung hochzuhalten. Wo Veränderungsinteressen den Gesetzgeber und seine verfassungsgerichtliche Kontrolle zu neuen Ufern treiben, muß die Verfassungsrechtswissenschaft zu einer disziplinierten Gangart rufen. So zieht die Karawane des Verfassungswandels generationsweise weiter Richtung Zukunft. 
Leitsätze des 2. Referenten über:

\section{Dynamische Grundrechtsdogmatik von Ehe und Familie?}

I. Vom ,sozialen Wandel“ zur ,dynamischen Grundrechtsdogmatik“ von Ehe und Familie

(1) Das Grundgesetz organisiert die Dynamik gesellschaftlicher Anschauungen von Ehe und Familie in der Macht der parlamentarischen Mehrheit, durch Gesetzgebung die Zukunft zu gestalten. Darin ist die Verfassungsänderung eingeschlossen - unter den Bedingungen des Art. 79 GG.

(2) Verfassungswandel ist kein verfassungsrechtsdogmatisches Argument, sondern ein Phänomen der Sozialisation verfassungsrechtsdogmatischer Argumentation - und als solches auch im Ehe- und Familienverfassungsrecht wirksam.

(3) Grundrechtsdogmatik kann ,,dynamisch“ heißen, wenn sie die Reichweite und die Wirkungen des Grundrechts an dynamische Veränderungen seines Gegenstands anzupassen fähig ist.

(4) In einem gesteigerten Sinn kann sie „dynamisch“ heißen, wenn sie darüber ihre eigene Gestalt verändert.

II. Gegenstand der Dynamik: Grundrechtsdogmatik von Ehe und Familie

1. Die dynamische und die antidynamische Intention der Grundrechtsdogmatik

(5) Grundrechtsdogmatik dient der Rationalität der Grundrechtsauslegung und -anwendung.

(6) Um dieser Funktion willen muß sie sich ,dynamisch“ entwickeln können.

(7) Doch im Verhältnis zur Dynamik politischer Ansprüche auf Zukunftsgestaltung sperrt sie sich gegen ,dynamische“ Anpassung.

2. Elemente der Grundrechtsdogmatik von Ehe und Familie

(8) Gegenstand der Tatbestände und Rechtsfolgen, der Ratio und Systematik des Art. 6 Abs. 1 GG sind sowohl private als auch öffentliche Interessen. 
(9) Das öffentliche Interesse an den Leistungen von Ehe und Familie richtet die Ratio von Art. 6 GG auf Verfassungsvoraussetzungen und insofern auf Zukunftsgestaltung durch öffentliches Recht.

3. Der Schutzbereich von Institutsgarantie und Wertentscheidung: Ansätze einer Leitbildgarantie

(10) Die Merkmale, welche die in Art. 6 GG garantierten Institute und die Gegenstände der ihm abgelesenen Wertentscheidung kennzeichnen, können anspruchsvoller sein als die Merkmale des abwehrrechtlichen Schutzbereichs.

(11) Insofern profilieren sie Ehe und Familie als verfassungsrechtliches Leitbild.

\section{Intentionen einer Leitbildgarantie}

(12) Eine auf die Auslegung des Art. 6 Abs. 1 GG als wertentscheidende Grundsatznorm gegründete Leitbildgarantie ist ein Mittel der Zukunftsgestaltung durch öffentliches Recht.

(13) Sie schützt Ehe und Familie um der Gesamtheit ihrer Funktionen willen als Form.

(14) Sie wirkt auch über die öffentliche Affirmation des öffentlichen Interesses an Ehe und Familie.

(15) Sie zielt auf Ehe und Familie als Leitbild, nicht aber auf ein Leitbild für Ehe und Familie.

(16) In dem Maß, in dem das Gebot zum Schützen und Fördern von Ehe und Familie von leitbildprägenden Merkmalen abstrahiert wird, wird die grundrechtsdogmatisch kanonisierte Wirkung des Art. 6 Abs. 1 GG als wertentscheidende Grundsatznorm zum Passepartout.

III. Wirksamkeit der Dynamik: Grundrechtsdogmatik von Ehe und Familie unter Spannung

1. Dynamik im Schutzbereich von Familien- und Elternrecht

(17) Der Verfassungsbegriff der „Familie“ ist von vornherein offen für die dynamische Vielfalt sozialer Nähebeziehungen.

(18) Die im Verfassungsbegriff der „Eltern“ (noch) einem Leitbild des „Natürlichen“ folgenden und so von dynamischen Kindeswohl-Kalkülen unbedingten Dezisionen vermögen der Gefahr vorzubeugen, daß das teleologisch maßgebliche Kindeswohl als Projektionsfläche für die Interessen von Erwachsenen in Beschlag genommen wird. 
2. Dynamik in den Maßstäben der Familiengerechtigkeit

(19) Die normative Wirkung des Art. 6 Abs. 1 GG bemißt sich daran, wie weit sich die „Familiengerechtigkeit" gerade in spezifischen Grundrechtsfolgen des Art. 6 Abs. 1 GG darstellt.

(20) Staatliche Steuerung durch Wohltat statt durch Eingriff verlagert (auch) den Schutz von Ehe und Familie aus den Maßstäben der Abwehrrechtsdogmatik in die dynamischen Maßstäbe der Gleichheitsrechtsdogmatik.

3. Dynamik im systematischen Verhältnis des Ehe- und Familienschutzes zum allgemeinen Gleichbehandlungsgebot

(21) Der gleichheitsrechtsdogmatische Durchgriff hinter die Form auf die Einzelfunktionen von Ehe und Familie dementiert eine eigenständige Wirkung ihres Schutzes aus Art. 6 Abs. 1 GG als wertentscheidende Grundsatznorm.

\section{Dynamik im Begriff der Ehe}

(22) Die praktisch restlose Gleichstellung der eingetragenen Lebenspartnerschaft mit der Ehe hat der Verschiedengeschlechtlichkeit der Ehe jede rechtliche Unterscheidungskraft genommen und damit den Begriff der Ehe in der Gestalt, in der er über die herrschende Verfassungsauslegung jenseits formelhafter Beschwörung wirksam wird, ,,dynamisch“ umgestaltet.

IV. Zukunft der Dynamik: Grundrechtsdogmatik von Ehe und Familie in der Karawane des Verfassungswandels

(23) Der gleichheitsrechtsdogmatische Durchgriff auf die Einzelfunktionen von Ehe und Familie hat die Tendenz zu einer Eigendynamik, die weitere Strukturmerkmale in den Schutzbereichen des Art. 6 Abs. 1 und 2 GG in Frage stellt.

(24) Ein Rückzug des öffentlichen Interesses aus der Ratio des Ehe- und Familienschutzes und eine Aufgabe seiner Deutung als wertentscheidende Grundsatznorm wäre als liberales Konzept in sich schlüssig, bräche aber tief in die Prämissen des grundrechtsdogmatischen Diskurses über Art. 6 GG ein.

(25) Die Rekonstruktion einer Leitbildgarantie kann den Art. 6 GG als wertentscheidende Grundsatznorm effektivieren. Elemente davon sind auch in der Rechtsprechung des Bundesverfassungsgerichts noch angelegt (zum Beispiel im Prinzip der Einehe). 
(26) Im Kräftespiel des Verfassungswandels hat die Verfassungsrechtswissenschaft die Aufgabe der Kritik, die das gegenüber politischen Ansprüchen auf dynamische Zukunftsgestaltung widerständige, dämpfende und bremsende Moment der Grundrechtsdogmatik zur Wirkung zu bringen hat. 


\section{Aussprache und Schlussworte}

\section{Dynamische Grundrechtsdogmatik von Ehe und Familie?}

Ruffert: Liebe Kolleginnen und Kollegen, ich habe den Versuch unternommen, genauso wie am gestrigen Nachmittag, die Diskussion zu gliedern, zunächst einen Problemkomplex, der sich mit methodischen Fragen (Verfassungswandel, Verfassungsauslegung, Verfassungsänderung) befasst; sodann eine Gruppe von Fragenden, die sich mit den Begriffen von Ehe und Familie auseinandersetzen, und am Schluss einige Fragen zu Konsequenzen der Ergebnisse, zu den man aus den ersten beiden Frageblöcken kommt.

Steiger: Ganz herzlichen Dank für beide Referate. Ich habe den Eindruck, das hat sich in den beiden Referaten auf so unterschiedliche Weise gezeigt, es handelt sich wohl um den schwierigsten Grundrechtskomplex bzw. um den schwierigsten Komplex einer Norm aus dem Grundrechtsteil des Grundgesetzes, den wir im Augenblick in der gesellschaftlichen Diskussion, aber auch im Verfassungsrecht überhaupt haben. Denn hier geht es offenbar um einen grundlegenden Wandel in der Gesellschaft. Insofern stimme ich Ihnen, Frau Böhm, in der Darstellung dieses sozialen Wandels völlig zu. Dieser Wandel ist unbestreitbar und in den vergangenen 27 Jahren - wie Herr Germann deutlich gemacht hat - ein ganzes Stück weiter gegangen. Es ist vor allen Dingen nicht nur ein sozialer Wandel, sondern ein Wandel, der mit nachdrücklicher Beihilfe des Bundesverfassungsgerichts - vielleicht sogar mit starker Initiative des Bundesverfassungsgerichts - in die Verfassungsordnung und damit natürlich auch in die allgemeine Rechtsordnung eingegangen ist. Insofern sind die Schritte in diesen 27 Jahren wesentlich intensiver geworden. Hier stimme ich Ihnen völlig zu. Aber gerade deswegen, Frau Böhm, frage ich mich, und vielleicht bin ich da Herrn Germann näher als Ihnen, ob diese drei Pfeiler wirklich noch stabil sind. Was heißt stabil? Ich stimme Ihnen zu, dass das Freiheitsrecht die Wandlung im sozialen Kontext, also in der Gesellschaft, herbeigeführt hat. Gerade der Freiheitsaspekt der Gestaltung von Ehe und Familie des Einzelnen oder der Einzelnen hat sich seit 1986 noch stärker dynamisch ausgewirkt. Das ist völlig richtig. Infolgedessen ist es für mich eigentlich konsequent, dass auch der Gleichheitsgesichtspunkt entsprechend voran gegangen ist. Denn das muss ja austariert werden. 
Aber gilt das wirklich noch für die Stabilität der Institutsgarantie? Da habe ich große Zweifel. Vor allen Dingen frage ich mich: Ist es wirklich sicher, Herr Germann, dass die Monogamie in Zukunft noch draußen bleibt? Da bin ich sehr unsicher. Gibt es aber auch gerade und vor allen Dingen für die objektive Wertordnung noch Stabilität? Nun habe ich sowieso immer große Vorbehalte gegen diesen Begriff gehabt, und hier scheint es mir ganz deutlich zu werden. Was ist eigentlich mit einer Familie, wenn die Erziehung weitestgehend ausgelagert wird? Gestern Abend war von 95 Prozent die Rede, bei denen die Kinderbetreuung außerhalb der Familie erfolgt. Da frage ich mich doch sehr, ob diese beiden Pfeiler, Institutsgarantie und Wertordnung, noch wirklich stabil sind, oder ob sie sich nicht fundamental geändert haben. Das gilt dann aber auch, Herr Germann, für das Leitbild. Infolgedessen weiß ich nicht, ob Ihre Hoffnung, die sie am Schluss geäußert haben - dass die Verfassungswissenschaftler noch eine gewisse Bremse sein können - berechtigt ist. Nein, ich glaube, das kann nur kommen durch einen erneuten sozialen Wandel, wie wir ihn im Übrigen im 19. Jahrhundert auch gehabt haben, der dann zu dieser institutionellen Auffassung von Ehe und Familie geführt hat. $\mathrm{Ob}$ das wieder so kommt, weiß ich nicht. Aber ich glaube, die eigentlichen Entwicklungen liegen im sozialen Bereich. Danke schön.

Hillgruber: Ich bin auch dankbar für beide Referate, habe aber noch Nachfragen, Nachfragen, die sich selbstverständlich auf dynamische Verfassungsinterpretation, Auslegungsgrenzen und Verfassungsänderung beziehen. Dass hier Dynamik am Werke ist, gesellschaftlicher Wandel, aber auch von den verschiedensten Akteuren betriebener Verfassungswandel, dies lässt sich schlechterdings nicht bestreiten. Aber mir geht es um die verfassungsrechtliche Bewertung. Frau Böhm, Sie haben in Ihrem Referat gesagt, um ein Beispiel herauszugreifen, dass die Verschiedengeschlechtlichkeit als Merkmal der Ehe nicht im Wortlaut der Verfassung angelegt sei. Gleiches hat das Verfassungsgericht bezogen auf Vater und Mutter hinsichtlich des Elternrechts gesagt. Das ist natürlich richtig. Aber, meine Damen und Herren, das löst doch erst den Interpretationsbedarf aus und beantwortet doch noch nicht die Frage in dem Sinne, wie sie vom Bundesverfassungsgericht beim Elternbegriff entschieden worden ist. Wenn das Verfassungsgericht beim Begriff der Eltern die Formulierung wählt, gleichgeschlechtliche Eltern hätten außerhalb des Vorstellungshorizonts des Verfassungsgebers gelegen, dann ist auch das eine merkwürdig diffuse Formulierung. Sie erweckt den Eindruck, als ob hier sozusagen ein neues soziales Phänomen aufgetreten war. Aber gleichgeschlechtliche Gemeinschaften und selbst Kinder in gleichgeschlechtlichen Gemeinschaften hat es natürlich auch schon vor 1949 gegeben. Nein, es geht nicht um ein 
neues soziales Phänomen, auf das mit „ergänzender" Verfassungsinterpretation reagiert werden soll, sondern es geht um eine Neubewertung eines Phänomens. Damit sind wir beim entscheidenden Punkt - Stichwort Wertentscheidung. Ich denke, die vom Verfassunggeber getroffene Wertentscheidung muss man selbstverständlich nicht teilen. Man kann rechtspolitisch auf ihre Änderung hinwirken. Die Frage ist nur, ob man sie noch im Wege der Verfassungsinterpretation bewerkstelligen kann. Und da taucht dann diese schillernde Formel vom Verfassungswandel auf, der Sie, lieber Herr Germann, sich auch sehr intensiv angenommen haben. Ich habe dazu noch eine Nachfrage: Sie selber sagen am Ende: Die Karawane zieht weiter. Selbstverständlich zieht die Karawane weiter. Aber juristisch würde ich es doch gerne noch etwas genauer wissen. Wozu führt denn nun ein vom Verfassungsgericht dekretierter Verfassungswandel? Stellt dies nicht, um es deutlich zu formulieren, eine „kalte“ Verfassungsänderung außerhalb des, wie ich annehmen würde, doch eigentlich exklusiven Verfahrens des Art. 79 GG dar? Begründet dies neues Verfassungsrecht? Oder gilt für solchen verfassungsgerichtlich dekretierten Verfassungswandel letztlich dasselbe wie für alle Entscheidungen des Bundesverfassungsgerichts? Sie haben jene Wirkungen, die ihnen $\S 31$ BVerfGG zuschreibt. Ich glaube, das ist eine jedenfalls verfassungsrechtlich nicht ganz unwichtige Frage, auch wenn der Gesetzgeber im Augenblick natürlich überhaupt keine Anstrengungen unternimmt, hier möglicherweise eine Korrektur vorzunehmen. Aber pro futuro scheint mir das doch eine wichtige, klärungsbedürftige Frage. Vielen Dank.

Volkmann: Ich finde auch, dass sich die beiden Referate hervorragend ergänzt haben. Wir haben einen Bericht von Monika Böhm über die tatsächliche Entwicklung der Grundrechtsdogmatik - mit vorsichtiger Sympathie für diese Entwicklung -, während Herr Germann die Rolle des Bremsers übernommen hat. Das ist sehr verdienstvoll; da aber auch Herr Hillgruber im Saal ist und sich schon zu Wort gemeldet hat, hatte ich ohnehin keine Sorgen, dass diese Rolle heute vakant bleiben würde. Die Frage ist allerdings, ob die dogmatischen Instrumente, die Sie dazu benutzt haben, die ihnen zugedachte Last auch tragen. Sie haben mit zwei Figuren argumentiert, zum einen mit der Deutung von Art. 6 GG als wertentscheidender Grundsatznorm oder Wertentscheidung, zum anderen mit der Deutung als verfassungsrechtliches Leitbild. Über Wesen und Wirkung solcher Leitbilder habe ich selber mal versucht, mir Gedanken zu machen. Deshalb war ich nachgerade ein bisschen erschüttert zu sehen, was hier daraus geworden ist. Der Sinn beider Figuren, meine ich, ist grundlegend verkannt, wenn man sie benutzt, um das Verfassungsrecht von gesellschaftlicher Dynamik abzuschotten. Es geht ganz im Gegenteil 
bei diesen Figuren wesentlich darum, die Verfassung für gesellschaftliche Dynamik zu öffnen sowie sie zur Verarbeitung dieser Dynamik zu befähigen. Das lässt sich bereits bei der Deutung einer Norm als wertentscheidende Grundsatznorm ablesen. Das ist ja nichts, was von sich aus in der Verfassung enthalten ist. Es ist das Resultat einer nachträglichen $\mathrm{Zu}$ schreibung, über die deshalb in den 50er Jahren erbittert gestritten worden ist; Ernst Forsthoff hat das Ganze einmal als Umbildung des Verfassungsgesetzes bezeichnet. Diese Zuschreibung ist also in einer bestimmten gesellschaftlichen Situation von einer bestimmten Rechts- und Verfassungsgemeinschaft vorgenommen worden. Jede Rechts- und Verfassungsgemeinschaft wird aber das als Wert auszeichnen, was ihr selbst wichtig erscheint. Es ist dann notwendig, dass sich diese Auszeichnung auch für den Wandel dieser Bewertungen und damit auch für den Einfluss der Tageswertungen öffnet, wie das in der Kritik der Wertejudikatur bei Böckenförde und anderen immer noch sehr scharfsinnig nachzulesen ist. Dasselbe gilt auch für die Deutung von Verfassungsnormen als Leitbilder. Wenn wir von solchen Leitbildern ausgehen, dann fließen nach der Verabschiedung der historisch-genetischen Interpretationen als vorherrschender Methode der Verfassungsauslegung notwendig die je vorhandenen gesellschaftlichen Wertüberzeugungen in ihre Formulierung mit ein. Beide Instrumente - sowohl die Deutung als wertentscheidende Grundsatznorm als auch die Figur der Leitbilder - dienen also gerade dazu, Verfassungen für Veränderungen in den Stand zu setzen und zu flexibilisieren. Sie haben natürlich recht, wenn Sie nun gerade Ehe und Familie als einen besonders neuralgischen Punkt dieser Flexibilisierung ansehen. Denn wenn wir uns anschauen, was sich da eigentlich im Laufe der Zeit gewandelt hat, wie wir Ehe und Familie damals interpretiert haben und wie wir sie heute oder künftig interpretieren, dann können wir uns ja schon die Frage stellen: Wenn die Verfassung nicht einmal an diesem vermeintlich klaren Punkt hält und trägt - wo hält und trägt sie eigentlich dann noch?

Michael: Michael Germann hat zugespitzt, ob das Gesamtthema unserer Tagung „Zukunftsgestaltung durch öffentliches Recht" ein rechtliches Thema ist oder ob es das Thema des verfassungsändernden Gesetzgebers ist. Wenn die Verfassungsdogmatik primär die Funktion haben soll, einen Wandel zu begrenzen bzw. seine Grenzen aufzuzeigen, dann müssen wir die Frage, ob Zukunftsgestaltung oder an ihrer Gestaltung durch Interpretation mitzuwirken unsere Aufgabe ist, letztlich verneinen. Das hängt meines Erachtens von einem Verständnis des Verfassungsänderungsrechts, vor allen Dingen von Art. 79 Abs. 2 GG, ab. Ist Art. 79 Abs. 2 GG das Maß aller Dinge für die Änderung von Verfassungsinhalten, wenn gesellschaftlicher Wandel eine solche Änderung nahelegen mag? Ist es also dem 
verfassungsändernden Gesetzgeber vorbehalten, das zu tun, was andernfalls durch Interpretation und dann eben auch durch das Bundesverfassungsgericht durch einen Verfassungswandel - wie dann behauptet wird vorweg genommen wird. Meines Erachtens ist es gerade umgekehrt. Art. 79 Abs. 2 GG ist nur auf den Gesetzgeber bezogen. Die Änderung des Verfassungsgesetzes durch den Gesetzgeber soll nicht an bloße einfache Mehrheiten gekoppelt sein. Den Gesetzgeber an Zweidrittelmehrheiten zu binden, wenn er schon die Verfassung soll ändern können, ist plausibel. Aber wir müssen diese Norm, damit sie nicht zu einer Herrschaft der Toten über die Lebenden führt, relativieren. Und zwar nicht nur durch Art. 146 GG (der zu operationalisieren ist), sondern auch durch das viel näherliegende und bei uns sehr verbreitete Instrument des Verfassungswandels durch das Bundesverfassungsgericht. Hierzu lässt sich vor allem Art. 3 Abs. 1 GG instrumentalisieren. Ich meine, dieser ist deshalb ein legitimes Instrument, weil er doch wenigstens an gesetzgeberische Maßnahmen anknüpft, weil damit verhindert wird, dass das Bundesverfassungsgericht ganz ohne den Gesetzgeber einen Wandel vorantreibt. Es wäre z. B. zu weit gehend, eine gleichgeschlechtliche Lebenspartnerschaft als Ehe i. S. d. Art. 6 Abs. 1 GG zu begreifen, ohne dass die gesetzliche Anerkennung von nichtehelichen Lebenspartnerschaften überhaupt je geschehen wäre. Das scheint mir der Unterschied zu sein. Wenn der Gesetzgeber wie in Deutschland geschehen nichteheliche Lebensgemeinschaften grundsätzlich anerkannt hat, dann mag der Unterschied zwischen den über Art. 3 Abs. 1 GG oder Art. 6 Abs. 1 GG konstruierten Geboten einer Gleichbehandlung nicht mehr offenbar sein. Aber wenn wir uns zurückversetzen etwa in ein Land wie Polen, wo das nicht geschehen ist und diskutiert wo noch über die grundsätzliche Anerkennung eines rechtlichen Status gleichgeschlechtlicher Partnerschaften gestritten wird, käme es darauf an. Über den allgemeinen Gleichheitssatz könnte man in Polen nicht argumentieren. Über eine weite Auslegung des Ehebegriffs, die sich in Deutschland inzwischen aufdrängt (und die wegen der Legaldefinition der Ehe in der polnischen Verfassung explizit ausgeschlossen wäre), sollte ein Verfassungsgericht nicht dem Gesetzgeber völlig enteilen. Ich meine, das wäre sonst ein problematischer Verfassungswandel, anders als der schrittweise Wandel im Wechselspiel des Gesetzgebers und des Verfassungsgerichts, der über den Gleichheitssatz vermittelt wird. Danke.

Grimm: Die Vorentscheidung für Dynamik in der Grundrechtsinterpretation ist durch die methodologische Maxime des Bundesverfassungsgerichts gefallen, dem Ziel eines Grundrechts oder der Funktion eines Grundrechts - vielleicht können wir nach Herrn Germann auch noch hinzufügen: der Leitentscheidung eines Grundrechts - zu optimaler Wirk- 
samkeit unter den jeweils gegebenen Umständen zu verhelfen. „Unter den jeweils gegebenen Umständen": diese Anforderung lässt sich nur verwirklichen durch dynamische Grundrechtsinterpretation. Sie öffnet die Interpretation für sozialen Wandel. Nun kommt sozialer Wandel nach meiner Auffassung in zwei Grundformen vor. Er kommt erstens vor als Umständewandel. Das ist in der ganz überwiegenden Zahl der Fälle ein Wandel, der durch wissenschaftlich-technischen Fortschritt induziert wird und sich dann auf vielen Ebenen äußern mag. Er kommt zweitens vor als Wertewandel. Für die erste Form (Umständewandel) hat sich in der Verfassungsrechtsprechung ein gar nicht so häufig bemerktes, aber völlig stereotyp angewandtes Muster herausgebildet: Es wird die bisherige Interpretation des Grundrechts referiert; es wird dann gefragt, ob im Regelungsbereich des Grundrechts ein Wandel eingetreten ist; es wird weiter gefragt, ob sich dieser Wandel, falls man bei der ursprünglichen Interpretation bleibt, nachteilig auf das Ziel des Grundrechts auswirkt. Wenn die Antwort Ja ist, wird eine neue (oft erweiternde) Interpretation gesucht, die dem Ziel wieder zur Verwirklichung verhilft. Wir haben es also mit einer Interpretation zu tun, in der eine Konstante vorhanden ist, nämlich das Ziel oder die Funktion oder das Leitbild. Ein Beispiel dafür ist der Wandel im Bereich der Deutung von Familie in Art. 6 GG. Deswegen ist auch die ausweitende Deutung von Familie relativ umstandslos akzeptiert worden. Beim Wertewandel ist das anders. Der Unterschied zwischen dem Umständewandel und dem Wertewandel scheint mir darin zu liegen, dass der Wertewandel das Ziel oder das Leitbild oder die Funktion selber betrifft. Das bedeutet, dass hier das konstante Element im Wandel entfällt. Wenn auch das Ziel fungibel wird, tritt die Gefahr eines ,anything goes" durch Interpretation ein. Dann kommt es nur noch auf die Erfolgsaussichten der neuen Interpretation an. Das ist der Fall der Ehe. Dies wirft nach meiner Auffassung die von den Vorrednern schon mehrfach gestellte Frage auf, wo die Grenze zu ziehen ist zwischen dem, was der Verfassungsinterpret darf, und dem, was dem verfassungsändernden Gesetzgeber vorbehalten ist. Also konkret gesagt: Durfte das Bundesverfassungsgericht im Bereich der Familie dynamisch interpretieren, weil es da um Umständewandel geht? Darf es das auch im Bereich der Ehe, obwohl es da um Wertewandel geht? Ich selber habe keine abgeschlossene Antwort auf die Frage. Aber dass sie gerade bei diesem Thema gestellt werden muss, das scheint mir eindeutig zu sein.

Püttner: Ich möchte in die gleiche Kerbe hauen. Ich halte diese jetzt vorgeführte Auslegung von Art. 6 Abs. $1 \mathrm{GG}$ für glatt verfassungswidrig. Damit ist eben im Grunde die Verfassung geändert worden. Darauf stelle ich die Frage: Warum geht man denn nicht den klar vorgezeichneten Weg 
der Verfassungsänderung nach Art. 79 GG? Wenn sich die gesellschaftlichen Auffassungen wirklich so gewandelt haben sollen, dann muss es doch auch möglich sein, dem mit Hilfe eines verfassungsändernden Gesetzes Rechnung zu tragen. Die Änderung sollte nicht durch Auslegung erfolgen, die im Grunde genommen die Verfassung entwertet, weil sie sie dem Zeitgeist unterwirft. Denken Sie bitte daran, dass die Verfassung manchmal auch ungeliebte Minderheiten schützen will. Wenn diese Minderheiten ihr Recht geltend machen und ihnen dann gesagt wird: Ja, der Zeitgeist ist aber anders, wir müssen das jetzt anders interpretieren. Dann heißt das doch, dass man im Grunde genommen keinen Schutz mehr nach der Verfassung bekommt. Das sollte nicht sein. Deshalb plädiere ich leidenschaftlich dafür, dass in solchen Fällen der Weg der Verfassungsänderung über Art. 79 GG gegangen wird und nicht diese totale Auslegung uns beherrscht. Sie können auch nachlesen, wie es sich damit verhält. Die Vertreter der Freirechtslehre haben das alles schon vor gut 100 Jahren genauer dargelegt. Dort finden Sie das und können, glaube ich, erkennen, wie gefährlich der Weg einer solch weiten Auslegung ist.

Mager: In der Tat war die Herausforderung des Themas eine methodische: Wie verhalten sich Geschichte und Genese dieser Norm (Art. 6 GG) zu sozialem Wandel? Wie verhalten sich Rechtsinstitutsgarantie, Abwehrrecht und Leistungsdimension zueinander? Ganz besonders auch: Wie verhält sich Art. 6 GG eigentlich zu Art. 3 GG? Insofern haben Sie, Frau Böhm, am Ende die Frage aufgeworfen: Wo sind die Grenzen der dynamischen Grundrechtsauslegung? Das ist eigentlich auch meine Frage an Sie, weil ich insoweit von Ihnen nicht viel gehört habe, außer dass der soziale Wandel den Gesetzgeber beeinflusst und der einfache Gesetzgeber dann wieder die Verfassungsinterpretation beeinflusst. Da bleibt von der Rechtsinstitutsgarantie als Ausgestaltungsvorgabe für den einfachen Gesetzgeber eigentlich nichts mehr über. Ähnlich wie Herr Püttner fühle ich mich ein bisschen an die unbegrenzte Auslegung erinnert. Ich frage mich, wo das dem Recht eigene Kontrafaktische bleibt.

Herrn Germann hat eine starke Analyse und auch Differenzierung zwischen den einzelnen Gehalten von Art. $6 \mathrm{GG}$ vorgetragen. Anders als Herr Volkmann fand ich die Interpretation als Leitbild sehr gut, insbesondere auch die Betonung einer verfassungsrechtlichen Sicherung als Leitbild im Gegensatz zu einer verfassungsrechtlichen Garantie für ein Leitbild. Diese Unterscheidung dient gerade der Freiheitssicherung. Art. 6 GG schützt Ehe und Familie als Leitbild und schreibt sie nicht als Lebensform vor. Das scheint mir im Übrigen auch der allergrößte gesellschaftliche Wandel zu sein, dass eine Art kämpferische Alleinstellung von Ehe und Familie im alten bürgerlichen Sinne aufgegeben wurde. Insoweit 
besteht, denke ich, wirklich Konsens. Im Übrigen hat uns Frau Böhm ja gesagt, dass statistisch 70 Prozent der Kinder in Familien mit verheiratetem Paar leben. Das scheint mir doch empirisch gesehen durchaus nach wie vor als Leitbild zu taugen.

Was mich jetzt aber interessiert, nachdem ich sehr beeindruckt Ihren Analysen gelauscht habe, Herr Germann, warum Sie ausgerechnet die Gegengeschlechtlichkeit als Merkmal der Ehe aufgeben? Diese Frage stellt sich mir im Hinblick darauf, dass sie ja völlig zu Recht die natürliche Elternschaft als Leitbild des Art. 6 Abs. 2 GG hervorheben, die natürliche Elternschaft, die deshalb freiheitssichernd ist, weil sie verhindert, dass der Staat den allerersten Zugriff auf Zuschreibungen von Elternschaft bekommt oder dass Kinder gar zur Ware werden, die auf irgendeinem Markt erworben werden kann. Darin liegt ein großes Freiheitspotential. Gerade im Blick darauf, dass die Gegengeschlechtlichkeit notwendige nicht hinreichende, das ist uns allen klar - Voraussetzung für die Elternschaft ist, stellt sich mir deshalb die Frage, warum Sie ausgerechnet dieses Merkmal aufgeben? Vielen Dank.

Lege: Vieles ist vorweggenommen worden. Von mir daher nur zwei kurze Fragen an Frau Böhm. Sie haben in Ihrer These 8 formuliert: „Art. 6 Abs. 1 GG ist auf eine dynamische Auslegung hin angelegt, weil das Schutzgebot der Verfassung die Institutionen der Ehe und Familie nicht abstrakt umfasst (...).“ Bei diesem Weil-Satz gehe ich sehr mit Ihnen mit. Ehe und Familie sind sicherlich vom Verfassunggeber konkret gemeint, und zwar im Rahmen des damaligen Gesetzgebungshorizonts. Sie fahren dann aber fort: „(...) sondern in ihrer Ausgestaltung durch den Gesetzgeber." Ich glaube, das ist etwas überinterpretiert, wenn man Art. 6 GG mit einer anderen Verfassungsnorm, zugleich einer anderen Institutsgarantie, vergleicht, nämlich mit Art. 14 Abs. 1 GG. Dort heißt es ausdrücklich: „Inhalt und Schranken werden durch die Gesetze bestimmt.“ Das heißt es in Art. 6 GG nun gerade nicht. Deshalb darf man wohl schlussfolgern, dass mit Ehe und Familie etwas Konkreteres gemeint ist als im Eigentumsgrundrecht, nämlich das, was nach der Vorstellung des damaligen Verfassunggebers damit gemeint war - und nicht das, was außerhalb seines Horizontes lag. - Damit kommen wir zu Ihrer letzten These, auf die schon Frau Mager hingewiesen hat. Die letzte These sagt - ein wenig unentschieden, wie ich finde -: Was Ehe und Familie angeht, da ist das öffentliche Recht ,,sicher zukunftsfähig“. Mit anderen Worten: Wir müssen uns keine Sorgen machen. Dann aber heißt es weiter: „Über die Grenzen einer dynamischen Grundrechtsdogmatik (...) wird weiter gestritten werden müssen." In der Tat, und hier hatte ich die gleiche Assoziation wie Frau Mager: Bernd Rüthers hat ein berühmtes Buch über die unbegrenzte 
Auslegung geschrieben. Gut, es ging damals um die Auslegung des Zivilrechts in der Zeit des Nationalsozialismus. Und es bestehen heute sicherlich Unterschiede zur damaligen Zeit. Trotzdem muss man fragen: Wie weit sind "Grenzverschiebungen" hinzunehmen, und wo nicht mehr? Wenn man betrachtet, was Sie entwickelt haben, scheint die Lösung zu sein: Eine schleichende Entgrenzung geht, und die Nationalsozialisten waren lediglich brutaler. Dazu fällt mir allerdings ein weiteres Zitat aus der damaligen Zeit ein, ein Zitat von Carl Schmitt (der kurz auch einmal in Greifswald war): „Wir sind auf der Seite der kommenden Dinge“. Sehr schön fand ich bei Michael Germann die Beobachtung, dass es keinen Unterschied mehr gibt zwischen einem Begriff und seinem funktionalen Äquivalent. Besser kann man die Dinge nicht auf den Punkt bringen (und außerdem ist es ein kleiner Rückblick auf unsere Grundlagenveranstaltung am Mittwoch zur Soziologie der Verfassung). Vielen Dank.

Hufen: Ein kurzer Einwurf: Es ist jetzt zum dritten Mal das Buch von Herrn Rüthers über die unbegrenzte Auslegung erwähnt worden. Es war sogar von „totaler Auslegung“ die Rede. Da ist es nicht weit zu totalitärer Auslegung. Demgegenüber möchte ich doch feststellen: Das Buch von Herrn Rüthers handelt über die völlig entgrenzten Richter im Nationalsozialismus. Und das hat mit unserer Problematik historisch und methodisch überhaupt nichts zu tun. Danke.

Ruffert: Damit endet der methodische Themenkomplex. Wir kommen nun zu Fragen der Begriffe, Bilder im Bereich Ehe und Familie.

Brosius-Gersdorf: Liebe Frau Böhm, lieber Herr Germann, zunächst meinen ganz herzlichen Dank an beide Referenten. Sie haben das große Glück, dass Sie vom Vorstand ein ebenso spannendes wie explosives Thema zuerkannt bekommen haben. Wir haben das große Glück, dass wir zwei großartige Referenten und zwei sehr spannende Referate gehört haben. Gleichwohl meine ich, Herr Germann, dass Ihr Referat doch einige Fragen aufwirft. Dies betrifft vor allem die Thesen 10 folgende. Damit knüpfe ich auch an das an, was schon Herr Volkmann und Herr Grimm gesagt haben. Sie sprechen von Leitbildern im Bereich des Eheund Familiengrundrechts. Ich meine, wir sollten, statt von Leitbildern zu sprechen, uns zunächst einmal klar werden über den Gehalt des Verfassungsbegriffs der Ehe und das, was durch die Institutsgarantie des Ehegrundrechts wirklich verfassungsfest gesichert ist. Vorweg eine grundsätzliche Bemerkung zum Verhältnis der Institute Ehe und Familie. Das ist eine grundlegende Frage, die sich auswirkt auf die gesamte Grundrechtsdogmatik im Bereich der beiden Grundrechte. Ehe und Familie sind 
durch das Grundgesetz, Frau Böhm hat das hervorragend dargelegt, als rechtlich voneinander unabhängige, entkoppelte Institute gewährleistet. Die Familie folgt nicht mehr zwingend aus der Ehe, wie das noch in der Weimarer Reichsverfassung war. Sie können tatsächlich Hand in Hand gehen, aber das ist nicht zwingend erforderlich und, wie wir alle wissen, heute auch nicht mehr durchgehend der Fall. Woraus folgt das? Frau Böhm hat wesentliche Argumente genannt: die Fassung der Norm sowie das systematische Verhältnis zur Weimarer Reichsverfassung. Vor allem aber folgt diese rechtliche Entkoppelung aus den unterschiedlichen Schutzzwecken des Ehe- und des Familiengrundrechts. Das ist eine ganz wichtige Grundlegung. Das Ehegrundrecht schützt eheliche Gemeinschaften wegen ihrer partnerschaftlichen Beistands- und Verantwortungsleistungen. Das Familiengrundrecht knüpft an die Elternverantwortung an, die Menschen für Kinder wahrnehmen. Daraus leiten sich natürlich vielfältige Anforderungen an den staatlichen Umgang mit Ehen und Familien ab. Jetzt zum entscheidenden Punkt, an dem sich diese Entkoppelung der Institute Ehe und Familie unmittelbar auswirkt. Was sichert das Ehegrundrecht des Art. $6 \mathrm{GG}$ wirklich als verfassungsfesten Kern der Ehe? Der Begriff der Ehe ist damit angesprochen. Grundsätzlich - das ist nun wirklich keine neue grundrechtsdogmatische Entwicklung - ist Art. 6 GG natürlich gerade im Bereich des Ehegrundrechts (weniger im Bereich des Familiengrundrechts) ein sehr stark normgeprägtes Grundrecht. Das heißt, der Begriff der Ehe ist in weitem Maße der Ausgestaltung des Gesetzgebers überlassen. Einzige Schranke: die Institutsgarantie. Deshalb die Kernfrage: Welche Elemente der Ehe sind durch die Institutsgarantie gegenüber Zugriffen des Gesetzgebers wirklich verfassungsfest garantiert? Frau Böhm hat einige Elemente genannt, über die wir uns, glaube ich, alle schnell verständigen können. Aber hier ist die Kernfrage: Ist es wirklich auch die Verschiedengeschlechtlichkeit der Partner? Ich meine, die Antwort ist ein klares Nein. Denn durch die Institutsgarantie des Ehegrundrechts sind nur die Strukturmerkmale als verfassungsfest gesichert, die für die Verwirklichung der Funktion der Ehe als partnerschaftliche Beistands- und Verantwortungsgemeinschaft notwendig sind. Die Fortpflanzungsfähigkeit der Ehe - sei es tatsächlich, sei es potentiell - ist kein Merkmal der Ehe. Diese Offenheit der Verfassung für den Begriff der Ehe sowie die weitgehende Überantwortung der Ausgestaltung des Ehebegriffs an den Gesetzgeber sind ein ganz großes Verdienst des Grundgesetzes, das wir nicht unnötig klein reden sollten. Denn es erlaubt dem Gesetzgeber, die Veränderungen, die sich im Bereich der Ehe unübersehbar vollzogen haben, aufzunehmen. Daraus ergeben sich vielfältige Ableitungen, zum einen: Der Gesetzgeber darf das Institut der Ehe für gleichgeschlechtliche Paare öffnen. Zum anderen: Ehen und Lebenspartnerschaften sind im 
Kontext des Eherechts gleich zu behandeln. Letzteres ist heute weitgehend der Fall. Vielen Dank.

Huster: Ich fand es sehr auffällig, dass beide Referate im Grunde genommen die Entwicklung der Dogmatik des Art. 6 GG und insbesondere der Rechtsprechung doch sehr übereinstimmend beschrieben haben. Und zwar in dem Sinne, dass in dieser Rechtsprechung Art. 6 GG das, was Herr Germann sehr schön als Leitbildfunktion oder Leitbildgarantie beschrieben hat, in dem jedenfalls von ihm gemeinten Sinne doch weitgehend verloren hat. Die interessante Frage ist jetzt, und dazu möchte ich einige Überlegungen vortragen: Warum ist das eigentlich so gekommen? Warum hat man von dieser Leitbildfunktion in der Rechtsprechung Abstand genommen? Warum interessiert die eigentlich niemanden mehr? Jetzt kann man natürlich sagen, dass dies der Zeitgeist ist, dass dies gesellschaftliche Verfallserscheinungen sind, die jetzt eben beim Bundesverfassungsgericht angekommen sind. Aber ich glaube, dass es auch einige strukturelle Gründe dafür gibt, die mit der spezifischen Aufgabe von Verfassungsrecht und auch Verfassungsrechtsprechung $\mathrm{zu}$ tun haben. Der erste Grund scheint mir folgender zu sein: Herr Germann hat darauf hingewiesen, dass in seiner Konstruktion die Leitbildfunktion bzw. die Leitbildgarantie einen sozusagen überschießenden Gehalt gegenüber dem individuellen Grundrechtsschutz hat. Ich glaube, dass das das Verfassungsrecht in eine schwierige Situation bringt, weil man jetzt unterschiedliche und vielleicht sogar widerstrebende Gehalte in die gleiche Norm hineinliest. Ein ganz triviales Beispiel: Der Staat unterstützt die besonders Bedürftigen, zum Beispiel die alleinerziehende Mutter. Ist das nicht schon etwas, was er eigentlich gar nicht tun dürfte, wenn er das Leitbild der auf die Ehe gegründeten vollständigen Familie unterstützen soll? Solche Fragen stellen sich dann innerhalb der Interpretation des Art. 6 GG. Ich glaube, wir sollten es eher vermeiden, widerstrebende Postulate in diese Norm hineinzulesen. Noch wichtiger erscheint mir mein zweiter Punkt. Herr Germann hat sehr stark auf das öffentliche Interesse an der Form von Ehe und Familie abgestellt. Ich glaube, die Verfolgung von öffentlichen Interessen - selbst wenn man das mal so anerkennt - ist doch etwas, das wir typischerweise eher der Politik zuschreiben - nicht dem Verfassungsrecht und einem Verfassungsgericht. Dafür gibt es zwei Gründe. Erstens ist die Verfolgung von öffentlichen Interessen immer ganz stark empirie- und situationsabhängig. Und hier ist die Politik bei der Frage, wie man am besten Familien unterstützt, in einer besseren Ausgangsposition als ein Verfassungsgericht. Der zweite, noch grundsätzlichere Punkt ist, dass in einer pluralistischen Gesellschaft das Verfassungsrecht grundsätzlich in eine schwierige Situation gerät, wenn es sich sozusagen 
als Bremser oder als Widerstand gegen gesellschaftliche Entwicklungen versteht. Das Verfassungsrecht gerät dann in so eine Art WagenburgMentalität: Es beobachtet sehr kritisch die Entwicklung da draußen. Das ist doch eher etwas, was mit Erziehung, fast mit Bevormundung der Bevölkerung durch das Verfassungsrecht und durch das Verfassungsgericht zu tun hat. Dies kann tendenziell das Verfassungsrecht auch delegitimieren. Insoweit darf ich im Anschluss an das, was im letzten Bundestagswahlkampf passiert ist, vielleicht sagen: Die Leitbildfunktion des Art. 6 GG ist sozusagen der Veggieday des Verfassungsrechts. Danke.

Schuler-Harms: Meine Damen und Herren, ich kann nach dieser langen Diskussion quer einsteigen und mich sofort der Institutsgarantie zuwenden, die auch ich für einen sehr spannenden Punkt in diesem Thema zur Dynamik der Grundrechtsdogmatik halte. In der Tat ist es aus meiner Sicht der rechtliche Wandel - nicht allein und vielleicht zum wenigsten der soziale - den es noch näher zu betrachten gilt. Das Grundrecht der Ehe als Institutsgarantie hat in seiner Geschichte - das hat uns Frau Böhm sehr schön dargestellt - einen deutlichen Wandel erlebt. Vielleicht hätte man noch etwas deutlicher machen können, wie stark dieser Wandel auch rechtliche Züge trägt, angefangen von der Reform durch das Gleichberechtigungsgesetz von 1953 (Frau Böhm, Sie haben es angesprochen); in der Scheidungsreform von 1976, als die Unauflöslichkeit der Ehe als ein Merkmal des Wesens der Ehe im Grunde gefallen ist; in der Unterhaltsreform von 2008, in der diese Unauflöslichkeit auch im Hinblick auf die Scheidungsfolgen gefallen ist; und in der Kindschaftsrechtsreform von 1998, in der die nichteheliche Elternschaft in Bezug auf das Sorge- und Unterhaltsrecht bereits an die eheliche annähert wurde. Das sind eminente, bahnbrechende Entwicklungen mit Auswirkungen auf die Institutsgarantie, lange bevor wir über die Frage der Verschiedengeschlechtlichkeit als Merkmal der Ehe sprechen. Die Institutsgarantie muss diesen Wandel verarbeiten. Meine Frage an die Referenten ist: Welches sind eigentlich die Maßstäbe für die Veränderlichkeit einer Institutsgarantie? Wie soll dort ein Wandel verfassungsrechtsdogmatisch verarbeitet werden? Ich würde in der Frage der Verschiedengeschlechtlichkeit übrigens der von Frau Brosius-Gersdorf vertretenen Position eine andere entgegensetzen. Intuitiv würde ich Verschiedengeschlechtlichkeit zum Wesen der Ehe zählen und die Gleichstellung von gleichgeschlechtlicher Partnerschaft einerseits und Ehe als verschiedengeschlechtlicher Partnerschaft andererseits nur aus Art. 3 Abs. 1 ableiten. Meinen zweiten Punkt will ich kürzer machen. Ein dynamisches Element der Grundrechtsinterpretation in der Rechtsprechung des Bundesverfassungsgerichts zur Ehe sind Bilder. Das Bundesverfassungsgericht hat eine geraume Zeit mit Ehebildern gearbei- 
tet - mit dem Bild der Hausfrauenehe, der Versorgerehe, der Berufstätigenehe. Diese Bilder hat es schließlich aufgelöst. Welche Funktion hat diese Figur in der Rechtsprechung des Bundesverfassungsgerichts für die Dogmatik von Art. 6 GG nach Meinung der Referentin und des Referenten? Das würde mich interessieren. Letzter Punkt: Konsistenz. Konsistenz haben Sie angesprochen, Frau Böhm, und völlig zu Recht dargelegt, dass es sich vermutlich um ein sehr stark rechtspolitisch geprägtes Prinzip handelt, mit dem die Politik auf Wirksamkeit der Familienförderung abstellt und mit dem sie auch auf Ressourcenschonung abstellen kann. Dennoch gibt es Elemente der Konsistenz, die in der Grundrechtsdogmatik des Art. 6 GG Dynamik befördern können. Ein solches Element ist die wertentscheidende Grundsatznorm, die Fragen der Ausgestaltung in die Schutz- und Fördergarantie hinein transportieren muss. Denn in Bezug auf Ausgestaltung einerseits und auf Schutz und Förderung andererseits darf es nicht zu Widersprüchen kommen. Insofern auch hier noch einmal die Frage an die Referenten: Was wird eigentlich aus der Schutzverantwortung, die in Art. 6 GG festgeschrieben ist, wenn wir von einer so weitreichenden Veränderung der Institutsgarantie und auch der rechtlichen Ausgestaltung der Ehe ausgehen müssen? Danke.

Paulus: Zu zwei Punkten wollte ich kurz Stellung nehmen, die das Thema und auch unsere Diskussion sehr grundlegend bestimmen. Zunächst einmal zum Verhältnis von Art. 6 Abs. 1 GG und Art. 3 Abs. 1 GG. Das Bundesverfassungsgericht hat Art. 6 Abs. 1 GG in Bezug auf die Ehe überhaupt nicht neu interpretiert, sondern allenfalls in Bezug auf den Familienbegriff. Die Voraussetzungen, die Herr Grimm gerade dargestellt hat, sind bei dieser Reinterpretation relativ einfach zu erfüllen. Bei einer Reinterpretation der Ehe wäre das schwieriger, aber die hat das Bundesverfassungsgericht gerade nicht vorgenommen. Das Bundesverfassungsgericht hat auch Art. 6 Abs. 1 GG nicht funktional getrennt. Der besondere Schutz von Ehe und auch Familie rechtfertigt sich selbst - dies hat Herr Germann mit Recht gesagt - vollständig. Er muss sich nicht funktional und einzeln rechtfertigen. Das Bundesverfassungsgericht hat vielmehr Art. 3 Abs. $1 \mathrm{GG}$ angewendet und jeweils für die einzelnen Funktionen gefragt, ob dieser Schutz auszuweiten ist auf eine sehr kleine Gruppe. Frau Böhm hat dankenswerterweise darauf hingewiesen, dass es sich um 0.05 Prozent der Ehen handelt. Warum ist das wichtig? Die Kritik an dieser Ausweitung und die Beschwörung der Gefährdung von Art. 6 Abs. 1 GG wäre eindrucksvoller, wenn am Ende, einfach ausgedrückt, faktisch nicht mehr genug Geld da wäre, um die Ehe und Familie im klassischen Sinne zu schützen. Es könnte in der Tat zu teuer werden, wenn man den Schutz uferlos ausweitet. Aber es gibt eben keine uferlose Ausweitung, 
sondern eine auf eine kleine Minderheit begrenzte Ausweitung. Der Minderheitenschutz, da sind wir uns sicher alle einig, ist eine der vornehmsten Grundrechtsaufgaben des Bundesverfassungsgerichts. Das wäre im Übrigen deutlicher geworden, Herr Germann, wenn Sie aus dem 124. Band und auch aus der Entscheidung zur Sukzessivadoption vollständig zitiert hätten. Das darf ich jetzt nachholen. Der Satz heißt vollständig: „Geht die Privilegierung der Ehe mit einer Benachteiligung anderer Lebensformen einher", und jetzt kommt es, „obgleich diese nach dem geregelten Lebenssachverhalt und den mit der Normierung verfolgten Zielen der Ehe vergleichbar sind, rechtfertigt der bloße Verweis auf das Schutzgebot der Ehe" die Benachteiligung der Lebenspartnerschaft jedoch nicht. Das situiert sich in Art. 3 GG und nicht in Art. 6 GG. Deswegen stellt diese Argumentation auch keine Beeinträchtigung des besonderen Schutzes der staatlichen Ordnung aus Art. 6 Abs. 1 GG dar. Im Übrigen spricht dieser nicht von einem „Abstandsgebot“ sondern von besonderem Schutz. Das ist etwas anderes, und die Förderung wird von der Verfassungsrechtsprechung nicht beeinträchtigt, im Gegenteil. Nun zu einem zweiten Thema. Hier kann ich mich jetzt kurz halten, weil das eben schon angesprochen wurde. Die Rolle des Gesetzgebers. Da hätte ich gerne von beiden Referenten noch etwas mehr gehört, denn das betrifft im Wesentlichen, wie von Frau Brosius-Gersdorf angesprochen, unsere Zukunftsaufgabe. Es geht dabei nämlich nicht so sehr um einen vom Verfassungsgericht betriebenen Wandel, sondern erst mal um einen vom Gesetzgeber betriebenen Wandel. Das Verfassungsgericht hat auch nicht vor, sondern nach dem Gesetzgeber die Frage des Art. 3 Abs. 1 GG und der Ausweitung des Schutzes in bestimmten Einzelfunktionen auf die eingetragene Lebenspartnerschaft problematisiert - und dann dessen Vorgehen auch gebilligt. Es ist also der Gesetzgeber, der das erste Wort gesprochen hat. Jetzt komme ich zurück zu Art. 6 Abs. 1 GG. Da sind die spannenden Fragen, die sich in der Zukunft stellen könnten. Was machen wir bzw. wie ist die Verfassungslage, wenn der Gesetzgeber die Institutsgarantie der Ehe zum Beispiel neu interpretiert? Wo liegen die Schranken für den Gesetzgeber? Das sind, glaube ich, Herausforderungen, denen wir uns in der Zukunft stellen müssen. Deswegen hätte ich darüber gerne noch etwas von beiden Referenten gehört. Vielen Dank.

Lepsius: Auf der Seite des Gesetzgebers zu stehen, findet meine Zustimmung. Nur ist der Gesetzgeber natürlich auch politischem Wandel unterworfen und die bei Art. 3 GG anzusetzende Frage lautet dann: Wie verhält sich das Gericht gegenüber dem politischen Wandel in der Gesetzgebung? Wie verfährt es, wenn ein rot-grüner Gesetzgeber eine Entwicklung einführt, die ein schwarz-gelber Gesetzgeber nicht fortführen will? 
Hier kann man sich nicht einfach auf „den“ Gesetzgeber beziehen, wenn in der Zwischenzeit ein politischer Wechsel eingetreten ist. Sonst würde der politische Prozess im Grunde genommen vom Bundesverfassungsgericht instrumentalisiert werden. Das kann nicht im Sinne der prinzipiell begrüßenswerten Präeminenz des Gesetzgebers sein.

Gallwas: Herr Germann, ich möchte mich zunächst an Sie wenden. Sie haben in der Tat einen sehr interessanten Vortrag gehalten, einen Vortrag, der durchaus unter dem Motto „suaviter in modo, fortiter in re“ stehen könnte. Ein Beispiel für das „suaviter“: In Ihrem Leitsatz 21 steht ein Wort, bei dem ich mir nicht sicher bin, ob Ihnen nicht ein E statt einem O untergekommen ist. Sie schreiben, dass eine eigenständige Wirkung des Schutzes des Art. 6 Abs. 1 GG ,dementiert“" werde. Nach dem Gesamtinhalt Ihres Vortrags müsste es hier wohl „demontiert“ heißen. Damit bin ich bei meinem eigentlichen Anliegen. In Ihrem Leitsatz 4 schreiben Sie: In einem gesteigerten Sinn kann sie, gemeint ist die Grundrechtsdogmatik, »dynamisch« heißen, wenn sie ihre eigene Gestalt verändert. Dazu sind ein paar Worte zu sagen. Man muss verstehen, was Grundrechtsdogmatik für eine Funktion hat. Man darf aus meiner Sicht hierbei nicht außer Acht lassen, dass sie die Bindungswirkung, die in Art. 1 Abs. 3 GG festgelegt ist, konkretisiert. Es geht also nicht nur um einzelne dogmatische Aspekte oder Verhältnisse der Grundrechte, sondern in erster Linie um Ausformung und Stabilisierung dessen, was Art. 1 Abs. 3 GG gebietet. In dem Moment, in dem ich mit einer ,dynamischen Grundrechtsdogmatik" hantiere, demontiere ich diese zentrale Funktion aller Grundrechtsdogmatik. Das ist, nach meinem Dafürhalten, in Ihrem Leitsatz 4 $\mathrm{zu}$ vorsichtig angesprochen. Um dies noch zu verdeutlichen darf ich auf die These 13 von Frau Böhm hinweisen. Da heißt es: Über den „Hebel des Gleichheitssatzes“ sei man wiederholt ,zur Korrektur bzw. nachhaltigen Umgestaltung gewachsener Strukturen“ unter anderem im Sozialversicherungsrecht verpflichtet. Eben darum geht es auch bei der grundrechtsdogmatischen Frage des Verhältnisses zwischen Art. 6 Abs. 1 GG und Art. 3 Abs. 1 GG. Hier ist die Frage zu stellen, ob und inwieweit Art. 6 Abs. 1 GG sich für gleichheitsdogmatische Argumentationsfiguren öffnet - nämlich ob es nicht doch ein auf das Institut „Ehe“ bezogenes Differenzierungsgebot festlegt. Ich bin der Meinung, dass Art. 6 Abs. 1 GG sowohl ein solches Differenzierungsgebot, aber auch Differenzierungsverbote und Differenzierungsbefugnisse enthält. Vor diesem Hintergrund muss man, glaube ich, Ihre These von dem „Hebel des Gleichheitssatzes" doch ein wenig differenzierter sehen. 
Schmid, Viola: Nomen est Omen. In der „Zukunftsgestaltung“ (Titel der Tagung) gilt das Motto: „The best way to predict the future is to invent it." Deswegen befasse ich mich mit informationstechnologischem Wandel und richte meine Frage an Herrn Germann, der zum technologischem Wandel bei der Begründung der Familie, dem „Ob“, mit der PID (Präimplantationsdiagnostik) mir vielleicht einen Ansatzpunkt liefert. Ich will mich weitergehend - mit dem „Wie“ der Familie in der Informationsgesellschaft in meinem ergänzenden Beitrag befassen. Erlauben Sie mir, nach dem Motto „Wer keine Vergangenheit hat, hat keine Zukunft“ einen Rückblick auf römisches Familienstaatsrecht und hier das ius vitae ac necis. Ein römischer Sohn hat im Krieg einen militärischen Oberbefehl nicht befolgt und so eine Schlacht gewonnen. Der Vater und römische Würdenträger sah sich gezwungen, das Todesurteil über den Sohn selbst auszusprechen, weil der Sohn befehlswidrig gehandelt hatte. Zugestandenermaßen ist vor zwei Jahrtausenden ein völlig anderes Bild von familiärer Autorität auf der einen und familiärer Kompetenz auf der anderen Seite zu konstatieren. Die Autorität zur Verhängung der Todesstrafe gibt es in der BRD etwa außer im Wortlaut der hessischen Verfassung nicht. Der römische Fall spitzt aber nicht nur die Autoritätsfrage zu, sondern stellt auch die Kompetenzfrage. Sind die Eltern vom Recht bzw. vom Verfassungsrecht vorausgesetzt kompetenter als die Kinder? Diese Annahme steckt doch hinter der Autorität des ius vitae ac necis und der Notwendigkeit der emancipatio von der patria potestas! Ich meine, dass die von mir so genannte „Überlegenheits-Ratio“ und der technologische Wandel zu Beginn des dritten Jahrtausends hier für die Funktionalität der elterlichen Sorge eine neue Analyse verlangen. Uncharmant wie ich bin, deute ich an, dass ich glaube, dass in einer nicht unbeträchtlichen Anzahl von Fällen cum grano salis unsere Nachkommen, die sogenannten „Digital Natives“, technisch cyberkompetenter sind als wir, die „Digital Immigrants“. Konsequenterweise stellen sich für mich in einem proaktiven und reaktiven Szenario folgende Fragen. Proaktiv: Wie oft müssen etwa die Computer der Nachkommen kontrolliert werden? Welche Dokumentationspflichten gibt es für elterliche Belehrungen, damit Cybermobbing oder urheberrechtswidriger Download unterbleibt? Reaktiv: In wie weit haften Eltern für das Handeln ihrer Kinder auch im Cyberspace und in wie weit ist angesichts des technologischen Wandels hier eine verfassungsrechtliche Neuorientierung für die elterliche Sorge im Cyberspace notwendig? Die Frage der „Morpheus“-Entscheidung des BGH kennen Sie vielleicht: Mehrere Tausend Euro Haftung für das Verhalten eines, „13-jährigen ohne Verhaltensauffälligkeiten“? Schluss um, lassen Sie mich mit Ulpian fragen: „Impossibilium nulla obligatio est" für manche Eltern? Oder aber ein neues Verständnis von elterlicher Sorge im Cyberspace? Danke. 
Ruffert: In der letzten Fragendengruppe sind Beiträge zusammengeführt, die sich mit Konsequenzen, die sich aus unseren Erkenntnissen oder Fragestellungen ergeben können, in einzelnen Rechtsgebieten befassen. Wahrscheinlich zu Ihrer aller Bedauern ist das Sprengstoffrecht leider nicht dabei, auf das Herr Germann Bezug genommen hat.

Kirchhof, Gregor: Ich habe zunächst eine methodische Bemerkung und anschließend eine kleine Bemerkung zum Ehegatten-Splitting. Erst mal methodisch: Herr Grimm hat danach unterschieden, wie sich die Wirklichkeit ändert. Ich glaube, ich habe bei Herrn Germann noch eine Differenzierung festgestellt, wie dann diese Veränderungen im Recht aufgenommen werden. Wir müssen unterscheiden, ob eine Änderung in der Wirklichkeit auch zu einer Änderung der Grundrechtsdogmatik führt. Das gab es am Anfang der Bundesrepublik etwas vermehrt. Jetzt findet das weniger statt, weil sich die Grundrechtsdogmatik stark verdichtet hat. Aber gleichwohl haben wir hier eine Änderung - das hat auch Herr Gallwas betont - im Verhältnis von Art. 3 GG zu Art. 6 Abs. 1 GG. Hier haben Sie, Herr Germann, das fand ich sehr interessant, mögliche Folgen dargestellt und aufgezeigt, wohin diese Änderung führen kann. Zu Ihrer Analyse kann man Sie beglückwünschen - sie war sehr nachdenklich. Die Ergebnisse der Rechtsdeutung ändern sich zudem, wenn wir die bestehende Grundrechtsdogmatik anwenden und dann zu Ergebnissen gelangen, die wir vor 10 Jahren nicht geahnt hätten. Vor allem das erleben wir gerade bei Art. 6 GG. Und in der Tat - da gebe ich Herrn Paulus Recht hat sich insofern Art. 6 GG isoliert betrachtet grundrechtsdogmatisch nicht stark gewandelt. In beiden Fällen haben wir eine Grenze in der Frage, welche Änderungen dem verfassungsändernde Gesetzgeber vorbehalten sind. Hinzu tritt ein weiterer Gedanke. Welche Bindungen folgen daraus, dass der Gesetzgeber die Verfassung konkretisiert - aber auch das hat Herr Paulus bereits angesprochen. Den Auftrag der Verfassungskonkretisierung hat der Gesetzgeber in den letzten Jahren im Bereich des Art. 6 GG kaum erfüllt. Das ist die methodische Bemerkung. Zum Ehegatten-Splitting möchte ich kurz Folgendes sagen: Frau Böhm, bei Ihnen habe ich ein bekanntes Argument vermisst. Wenn wir Personengesellschaften - also Menschen, die sich aus rein wirtschaftlichen Gründen zusammentun - besteuern, bekommen sie eine Art Ehegatten-Splitting, weil wir das Einkommen selbstverständlich steuerlich teilen. Keiner würde daran denken, das als Vorteil oder als Begünstigung darzustellen. Wenn jetzt Menschen heiraten, dann bilden sie nicht nur eine Wirtschaftsgemeinschaft, sondern zudem - in den nüchternen Worten des Rechts eine Erwerbs-, Verbrauchs- und Verantwortungsgemeinschaft, die grundsätzlich auf Dauer angelegt ist. Ja, dann müssen doch diese Menschen 
erst recht diese Besteuerung bekommen. Deshalb kann das EhegattenSplitting nicht so einfach abgeschafft werden. Das war dann noch die Bemerkung zum Ehegatten-Splitting. Ich danke.

Gallwas: Direkt dazu: Wir dürfen hier nicht nur auf den Art. 6 Abs. 1 GG schauen. Vielmehr ist zu bedenken, dass - wenn sich andere Lebensformen entwickeln - das Grundgesetz, mindestens nach der Rechtsprechung des Bundesverfassungsgerichts, eine grundrechtliche Auffangfunktion bereitgestellt. Warum sollten Leute, die in anderer Weise lebenslang zusammenleben wollen, nicht durch Art. 2 Abs. 1 GG geschützt werden, nachdem wir heute das Sittengesetz anders interpretieren, als es das Bundesverfassungsgericht früher mit Rücksicht auf die Großkirchen getan hat. Das heißt, wenn wir aus Art. 6 Abs. 1 GG herausfallen, dann werden wir immerhin durch Art. 2 Abs. 1 GG aufgefangen. Und da Grundrechte nicht nur eine Abwehrfunktion, sondern auch eine Schutzfunktion haben, kann der Gesetzgeber - insoweit hat er einen erheblichen Gestaltungsspielraum - entsprechende Gleichstellungen herbeiführen. Dazu brauchen wir den Art. 6 Abs. 1 GG nicht.

Wallrabenstein: Ich möchte einen konstanten Punkt in der Dynamik oder dem Wandel des Schutzes von Ehe und Familie aufgreifen - ganz im Sinne von Herrn Grimm: Die partnerschaftliche - ich würde sagen - Fairness in einer Ehe ist nach der Rechtsprechung des Bundesverfassungsgerichts konstant über den Wandel hinweg zu schützen. Ich will aufzeigen, welche Folgerungen sich ergeben, wenn man dieses Gebot des Schutzes von Ehe und Familie auf die Rechtsordnung in anderen Bereichen überträgt - in diesem Fall auf die Sozialsysteme, insbesondere die Alterssicherung. Denn da wirkt es sich besonders aus. Und diese Auswirkungen nehmen im großen Maßstab eines Alterssicherungssystems ein viel größeres Ausmaß an als im kleinen Maßstab einer individuellen Paarbeziehung. Man könnte von einer „Hebelwirkung“ für Fairness in Ehe und Familie sprechen. Ich beobachte eine in den letzten 20 Jahren negative Entwicklung dessen, was Fairness - verstanden als Schutz von Partnern in einer Ehe - in ihrer Auswirkung auf das gesetzliche Rentenversicherungssystem bedeutet. Wenn man von den Vorgaben des Bundesverfassungsgerichts, die Witwerrente zu ändern, ausgeht und dann anschaut, was der Gesetzgeber daraus gemacht hat (die Einführung der Kindererziehungszeiten), dann ist mit diesem Wandel im einfachen Recht ein Verlust, glaube ich, an Wertschätzung oder fairer Behandlung von Frauen in der Alterssicherung einhergegangen. Das ist der Hebel, auf den ich hinweisen möchte. Die Berücksichtigung von Kindererziehungszeiten als Quasi-Ersatz für eine zurückgenommene Witwenrente nach altem Recht 
stellt in vielen Fällen Frauen weniger gut, als das alte Recht bei dem unterstellten alten Familienbild sich das vorgestellt hat - nämlich als Ehefrauen. Dieses Defizit ist etwas, was politisch heute als Defizit in der Alterssicherung von Frauen diskutiert wird und nicht hinreichend aufgefangen ist. Das gilt besonders in der nach unserm heutigen Rentensystem gedachten zweiten und dritten Säule der Alterssicherung, das ist die betriebliche Altersvorsorge und dann noch die private Altersvorsorge (die sogenannte Riesterrente). Bei der Riesterrente gewährt der Staat starke kompensatorische Zuschüsse, um dieses Defizit an fairer Behandlung aufzufangen. Aber nicht bei der betrieblichen Alterssicherung, die immer noch den „gap" in den Altersbezügen zwischen Männern und Frauen nicht auffängt und damit im großen Maßstab das alte Thema der Fairness nicht sinnvoll in die heutigen Bedingungen übersetzt. Darauf wollte ich hinweisen. Danke.

von Coelln: Als erste von zwei kurzen Bemerkungen zu Ihrem Beitrag, Frau Böhm, noch eine Anknüpfung an die Frage, ob die Einbeziehung auch gleichgeschlechtlicher Partnerschaften in den Ehebegriff nicht doch eines Verfassungsänderungsverfahrens nach Art. 79 GG bedürfte. Dies würde auch ich für vorzugswürdig halten. Vielleicht noch ein ergänzendes Argument: Sie haben ja selbst darauf hingewiesen, dass in einzelnen Landesverfassungen der Schutz auch bereits auf nichteheliche Partnerschaften etc. ausgeweitet worden sei. Ist das - unter Anwendung der ganz klassischen Methodenlehre - nicht eher Anlass für ein argumentum e contrario des Inhalts: Wenn es der Landesverfassungsgesetzgeber bereits gemacht hat, aber auf Bundesebene die verfassungsändernden Mehrheiten noch nicht zustande gekommen sind, dann ist der Begriff eben so zu verstehen, wie er bisher zu verstehen war. Wer ihn ändern will, soll sich die verfassungsändernden Mehrheiten suchen, deren Erreichen heute bei weitem nicht mehr ausgeschlossen scheint. Das ist doch der Weg, den das Grundgesetz vorgibt. Zum zweiten Punkt. Sie haben diverse Sozialleistungen mit dem Argument kritisiert, dass sie den Anreiz auf Frauen, berufstätig zu werden, reduzieren oder den Druck abbauen würden, berufstätig zu sein. Mit Verlaub, es ist sicherlich nicht Aufgabe des Staates, Anreize dafür zu schaffen, dass verheiratete Frauen oder Männer berufstätig sein sollen. Genauso wenig wie es Aufgabe des Staates ist, dafür zu sorgen, dass sie das nicht sein sollen. Das ist der Inhalt des Freiheitsgebots: Es ist Aufgabe des Staates, dafür zu sorgen, dass die Wahlfreiheit besteht, entweder berufstätig zu sein, auch in einer Ehe und womöglich mit Kindern, oder eben dies gerade nicht zu sein. Sie haben dann sogar das Argument herangezogen, dass es wegen der hohen Scheidungsraten riskant sei, zuhause $\mathrm{zu}$ bleiben, nicht berufstätig zu sein. Erst einmal ist die Inan- 
spruchnahme von Freiheit immer riskant. Aber ganz sicher kann es nicht Aufgabe des Staates sein, fürsorglich oder paternalistisch (wie man es ausdrücken will) die Frauen zur Berufstätigkeit zu zwingen, um sie schon mal auf die vermeintlich ohnehin anstehende Scheidung vorzubereiten.

Ruffert: Vielen Dank. Wir kommen nun zu den Schlussworten der Referenten. Das Wort hat zunächst Michael Germann.

Germann: Zu Beginn möchte ich ganz herzlich danken, dass ich hier die Gelegenheit bekommen habe, mich mit diesem interessanten Thema auseinanderzusetzen. Ich glaube, der Vorstand hat ein Thema ausgesucht, das uns hier auch gerade zur richtigen Zeit beschäftigt. Ich danke ebenso für die Diskussionsbeiträge, die mir viele Anregungen geben und Schwierigkeiten bereiten, angemessen darauf zu antworten.

Während der Vorbereitung des Referats war ich mehrmals nahe dran, den Knoten einfach durchzuhauen. Man möchte den Aporien, die sich da stellen, gerne entfliehen. Wie leicht und verlockend ist es, einfach zu sagen: Fangen wir doch von vorne an. Wir nehmen den Wortlaut, wie er ist, und interpretieren ihn als Freiheitsrecht; wir interpretieren ihn so, wie Art. 8 der Europäischen Menschenrechtskonvention, lassen den ganzen Überbau mit Grundsatznorm, Wertentscheidung, vielleicht auch die Institutsgarantie in einer irgendwie aufgefüllten Form, hinter uns und fangen noch einmal von vorne an. Wir könnten uns einfügen in die allgemeine Entwicklung, international, auch gesellschaftlich, und hätten diese Probleme nicht mehr. Die Schwierigkeit dabei ist, dass wir solche Bewegungen nur schwer in Einklang bringen können mit dem Vorrang der Verfassung in der Gestalt, die sie gewonnen hat. Methodisch ist es sicherlich ein Ausweg, hier in irgendeiner Weise mit dem Verfassungswandel zu operieren. Aber die Widerstände, die dabei zu überwinden sind, die holen uns spätestens bei Art. 1 Abs. 3 GG wieder ein. Der Gesetzgeber muss beteiligt sein, und wir verstehen den Gesetzgeber eben doch als einen, der an die Verfassung gebunden ist. Das Bundesverfassungsgericht kontrolliert den Gesetzgeber und hat die Aufgabe, genau diese Bindung zu verwirklichen. Hiermit eine Bewegung weg von der verfassungsdogmatischen Gestalt dieser Bindung in Einklang zu bringen, ist nicht so einfach. Auf der anderen Seite könnte man daraus den Schluss ziehen: Dann geht eben gar nichts im Sinne einer Bewegung. Dann bedarf es immer einer Verfassungsänderung, wenn sich an der gefundenen Gestalt der Verfassung in der Grundrechtsdogmatik etwas bewegen soll. Auch das lässt sich argumentativ durchhalten, wenn man alle Ideen des Verfassungswandels mit dem Hinweis auf Art. 79 GG zurückweist. Dann allerdings hat man es damit zu tun, dass alle anderen - insbesondere das Bundesverfassungs- 
gericht - weiterziehen. So klinkt man sich aus der Diskussion aus. Diese beiden Anforderungen an den Umgang mit dem Thema in Übereinstimmung zu bringen, ist das Problem, weswegen es, glaube ich, nicht ohne Schwierigkeiten und nicht ohne Widerspruch behandelt werden kann.

Ein methodischer und auch inhaltlicher Einwand, der von mehreren Diskussionsrednern hier aufgebracht worden ist, bezieht sich auf die Leistung oder Funktion jener Figur der wertentscheidenden Grundsatznorm. Diese Figur habe ich zum Glück nicht erfunden, sondern aufgegriffen aus dem fast unbestrittenen Standardrepertoire für die Auslegung des Art. 6 Abs. 1 GG. Herr Volkmann hat ein anderes Modell für den Umgang mit dieser Standardfigur vorgestellt, ein Modell, das auch aus dem Umgang mit der Institutsgarantie schon bekannt ist, nämlich zu sagen: Was hier als wertentscheidende Grundsatznorm vorgestellt wird, sei keine Bindung des Gesetzgebers, nicht etwas, was den Gesetzgeber in irgendeiner Weise beschränkt, sondern eine Formel, um dem Gesetzgeber Spielraum zu geben. Das kann man sicherlich so konstruieren, eine solche Figur kann man sich ausdenken. Ich will nur darauf hinweisen, dass das eine andere Figur wäre als diejenige, die in den Standards der Grundrechtsdogmatik als wertentscheidende Grundsatznorm verhandelt wird. Darin wird der Charakter als „Entscheidung“ durchaus ernst genommen. Diese Entscheidung hat Verfassungsrang und kann eben nicht durch Wandel - sozialer, gesellschaftlicher oder auch gesetzgeberischer Art - umgedreht und anders ausgefüllt werden. Als Verweis auf die Dynamik des sozialen Wandels oder des politischen Willens bekommt die wertentscheidende Grundsatznorm einen ganz anderen Charakter als den, den sie in der Bundesverfassungsgerichtsrechtsprechung bisher hatte. Sie bekommt dann den Charakter eines Passepartout. Dann ist sie eine Formel, in die man alles hineinfüllen kann, wofür man keine verfassungsändernden Mehrheiten zusammenbekommt. Das scheint mir mit dem Vorrang der Verfassung, dem diese Formel dienen soll, nicht gut in Übereinstimmung zu bringen zu sein.

Das beantwortet auch die Einwände etwa von Lothar Michael, der hier (gestern auch im Verhältnis zu Art. 79 Abs. 3 GG) gefragt hat: Soll das denn das Maß aller Dinge sein, was da an Bindungen des Gesetzgebers vorgestellt ist? Er hat so argumentiert, als ob die Verfassung nur den Gesetzgeber bände, aber nicht das Bundesverfassungsgericht - so wäre es fast zu verstehen gewesen. Das unterschätzt, meine ich, den Vorrang der Verfassung. Ähnliches sage ich zu der Idee von Herrn Huster, wonach die Definition von öffentlichen Interessen nicht Sache der Verfassung, sondern der Politik sei. Wenn man der Verfassung zugesteht, dass sie auch politische Entscheidungen enthalten kann, dann bekommen diese Entscheidungen Verfassungsrang und sind nur in einer qualifizierten Form Gegenstand der Politik. Dann sieht nämlich das Grundgesetz in Art. 79 
GG ein bestimmtes Verfahren sowie bestimmte Anforderungen vor, um eine Änderung dieser politischen Entscheidungen auch verfassungswirksam zu machen. Den Preis der Bindung an die Verfassung muss man eben zahlen. Ich bin jedenfalls nicht bereit, diesen Preis in der Verfassungsdogmatik zu zahlen. Wem das als „Bevormundung der Bevölkerung“ durch Verfassungsrecht erscheint, dem möchte ich sagen, dass das die ernstgenommene Bindung an die Verfassung ist. Die Bevölkerung ist nicht bevormundet, sondern aufgerufen, ihren politischen Willen entsprechend signifikant $\mathrm{zu}$ bilden und $\mathrm{zu}$ artikulieren. Hierbei ist es durchaus sinnvoll, dass eine Veränderung der Entscheidung mit Verfassungsrang qualifizierten Anforderungen an die Willensbildung unterliegt. Und diesen Weg gibt es. Ein Umweg darum ist immer problematisch. Herr Püttner hat gefragt, warum denn das verfassungspolitische Problem nicht einfach über Art. 79 Abs. 2 GG gelöst wird? Es war eine rhetorische Frage, auf die es eine einfache Antwort gibt: weil die Mehrheiten bis jetzt nicht zustande gekommen sind. Das sollte jeden demokratisch veranlagten Verfassungsrechtler nachdenklich machen.

Einige Einwände bezogen sich auf die Figur des Leitbilds. Mir ist durchaus bewusst (ich habe das auch zum Ausdruck gebracht), dass diese Figur und vor allem auch das Wort „Leitbild“ schwierig ist. Es ist belastet und missverständlich, und man muss sehr sorgfältig damit umgehen, wenn man damit etwas anfangen möchte. Die erste zu treffende Entscheidung ist: Leitbild für wen? Wer ist der Adressat dieses Leitbilds? Das ist eine wichtige Abgrenzung. Wenn es ein Leitbild für die Grundrechtssubjekte wäre, dann hätte diese Form des Leitbilds alle schädlichen Wirkungen, die mit der Ablösung von Leitbildern für Ehe und Familie überwunden worden sind. Wenn im Bundestag „Quatsch“ dazwischengerufen wird und dieser Zwischenruf anschließend etwas ausgeführt wird, dann ist deutlich zu spüren, dass viele die Wertentscheidung eines Leitbilds als eigene Bewertung erfahren und also zum Beispiel einwenden: „Ich bin nicht mit Vater und Mutter aufgewachsen, sondern von meiner alleinerziehenden Mutter großgezogen worden. Soll das weniger wert sein? Soll ich damit weniger wert sein?" Das wäre ein sehr dramatisches Missverständnis einer vernünftig begriffenen Leitbildfunktion. Die Frage müsste so zu wenden sein: Soll es dem Staat egal sein, ob Kinder mit Vater und Mutter oder allein mit der Mutter oder allein mit dem Vater aufwachsen? Soll es dem Staat egal sein? Er, der Staat, ist der Adressat eines Leitbilds. An ihn adressiert sich die Wertentscheidung, dass er bei allem, was er tun kann mit seinen beschränkten Mitteln, im Blick behalten soll, dass sich Kinder vielleicht Vater und Mutter wünschen können. Nur das ist die Funktion, nicht etwa eine Bewertung von Lebensformen, die diesem Leitbild ,nicht gerecht“" würden. Das ist eine wichtige Unterscheidung. 
Herr Paulus hat gesagt: Es hat sich doch gar nichts geändert. Auch andere Diskussionsredner haben die Rechtsprechung des Bundesverfassungsgerichts gegen die Diagnose einer Sinnänderung des Art. 6 GG verteidigt. Ich nehme es den Mitgliedern des Bundesverfassungsgerichts durchaus ab, dass sie Art. 6 GG unangetastet lassen wollten. Das kommt auch in der Gleichheitsformel, die Art. 6 GG mit Art. 3 GG konfrontiert, mit einem Nachsatz durchaus zum Ausdruck. Scheinbar ist die Paradoxie, auf die ich aufmerksam gemacht habe, aufgelöst durch eine Unterscheidung der Lebensformen danach, ob sie - und das ist jetzt der zweite Teil des Zitats, in der schriftlichen Fassung meines Referats in einer Fußnote nachzulesen - ,nach dem geregelten Lebenssachverhalt und den mit der Normierung verfolgten Zielen der Ehe vergleichbar sind", so dass das Recht zum Privilegieren, das das Bundesverfassungsgericht hervorhebt, gegenüber nicht „vergleichbaren“ Lebensformen unberührt bliebe. Die Rechtfertigung einer Ungleichbehandlung nicht „vergleichbarer“ Lebensformen ergibt sich aber schon aus Art. 3 GG. Dazu brauche ich Art. 6 GG nicht. Nachdem es im Vordersatz dieser paradoxen Formel heißt, dass eine Privilegierung „wegen des Schutzes der Ehe“ erlaubt sei, wird dieser Differenzierungsgrund „wegen des Schutzes der Ehe“ aufgehoben durch die nachfolgende Konditionierung über die Funktion. Das ist die Paradoxie. Wenn jetzt Herr Paulus sagt, dass es doch erst schwierig wird, wenn der Gesetzgeber auf die Idee kommt, die einfachgesetzliche Struktur der Ehe zu öffnen für gleichgeschlechtliche Partnerschaften, so muss ich sagen: Dann kann das Bundesverfassungsgericht vielleicht erleben, dass ihm diese Paradoxie wieder auf die Füße fällt. Das kann durchaus passieren.

Alles Weitere lasse ich jetzt leider unbeantwortet. Ich bedanke mich nochmals herzlich und denke, dass die Diskussion weitergehen wird.

Böhm: Vielen Dank an den Vorstand, dass er mich zu dem Thema eingeladen und mir damit die Möglichkeit gegeben hat, mich über den Zeitraum der letzten Monate und damit gerade in einem Zeitraum, in dem zum Thema unglaublich viel passiert ist, mit diesen aktuellen Fragen beschäftigen zu können. Vielen Dank auch an das Auditorium für die Nachfragen, für die Anregungen und natürlich auch für die Ergänzungen.

Als ich das Thema bekommen habe, habe ich darüber nachgedacht, wie ich es verstehen soll. „Dynamische Grundrechtsdogmatik von Ehe und Familie" und dann kommt auch noch ein Fragezeichen. Was ist eigentlich meine Aufgabe? Ich habe mich entschieden, es als meine Aufgabe anzusehen, nachzuzeichnen, wie sich die Dogmatik bei Ehe und Familie entwickelt hat. Es lag natürlich nahe, mit dem Zeitpunkt, in dem Art. 6 GG geschaffen wurde, anzufangen. Für mich war es eine Erlebnis- 
reise, dann festzustellen, wie vieles stabil geblieben ist und wie vieles sich geändert hat.

Ich knüpfe zunächst an Herrn Steiger an: Ich habe natürlich Ihren Beitrag auf der Münchener Tagung gelesen und auch die gesamte Diskussion, die in München geführt worden ist. Sie fragen jetzt, ob die Pfeiler der Grundrechtsdogmatik noch stabil sind. So ganz einfach fällt mir die Antwort nicht. Ich habe ehrlich gesagt das Gefühl, dass die Grundpfeiler stabil sind. Sie sind Veränderungen nicht entzogen, aber sie sind relativ stabil. Aber um sie herum hat sich vieles geändert. Die Frage ist, wie man das bewertet. Ist es gut, dass es diese Dynamik gibt? Oder ist es schlecht? Man ist dann ganz schnell bei der Frage, die hier auch aufgeworfen worden ist: Was ist eigentlich Aufgabe von Dogmatik? Verschiedentlich ist das Wort gefallen: Dogmatik bremst, bremst den Gesetzgeber und weist ihn in die Schranken. Ich überzeichne vielleicht ein bisschen, aber das sind Tendenzen, die angesprochen worden sind. Mein Verständnis von Dogmatik ist ein anderes. Dogmatik ist nicht Bremse, Dogmatik ist Hilfsmittel. Dogmatik ist Hilfsmittel, um Entscheidungen abzuleiten, Entwicklungen zu begleiten und bei neuen Sachverhalten angemessene Lösungen $\mathrm{zu}$ finden auf dem Hintergrund, den uns das Grundrecht in all seinen Auslegungsfacetten bietet. Das ist eine andere Blickrichtung: Dogmatik als Hilfe, um zu Ergebnissen zu kommen.

Ich will einräumen, dass ich das Ganze, und insofern auch meinen Vortrag, als Gratwanderung angesehen habe. Ich habe die Entwicklung nachgezeichnet und war immer wieder versucht, auch Entscheidungen zu treffen und alle möglichen Streitfragen zu lösen. Wie ist es jetzt mit der Ehe? Und wie soll es eigentlich im Steuerrecht gemacht werden? Ich habe es so empfunden, dass hinter diesen Fragen jeweils eine ganze Reihe von Einzelproblemen steckt und habe es als sachlich nicht angemessen angesehen, zu jedem Punkt auch eine Antwort zu geben. Ich will nachher bei einzelnen Fragen noch einmal darauf zurückkommen. Aber insofern war für mich die Aufgabenstellung eine andere. Natürlich wird zu Recht die Frage nach den Maßstäben der Veränderung gestellt. Insofern kann ich die Frage, wo denn eigentlich die Grenzen der Dogmatik liegen, gut verstehen. Ich glaube, Herr Grimm hat schon eine ganze Menge dazu gesagt, wo hier Grenzen zu setzen sind, welche Fragen man sich stellen muss, um es im Einzelfall zu beurteilen.

Es hat mich ein bisschen gewundert, dass eine Sache nicht weiter aufgegriffen worden ist: das ist der Blick nach außen, also der Rechtsvergleich und die Frage, was der Europäische Gerichtshof und der Europäische Gerichtshof für Menschenrechte für eine Rolle spielen. Ich glaube, das sind Bereiche, in denen es sich lohnt, immer wieder hinzuschauen. Nicht um das zu machen, was dort gemacht wird, sondern um miteinzu- 
beziehen, was dort passiert. Das hat in der Praxis, in der Dogmatik und in der Rechtsprechung Auswirkungen darauf, wie die Schutzgüter Ehe und Familie ausgelegt werden. Der Begriff der Familie ist sicherlich offener angelegt. Wir haben gesehen, wie weit die Entwicklung hier geht. Natürlich konzentriert sich jetzt die Diskussion auf die Frage, was eigentlich in Zukunft noch Ehe ist. Ich würde es gerne dem Nachdenken noch offen halten wollen, auch für mich selber. Ich war erstaunt, dass es beispielsweise in Spanien ein Gerichtsurteil gab, das eindeutig die gleichgeschlechtliche Ehe als verfassungsgemäß angesehen hat und welches sich im Übrigen ganz stark auch mit der deutschen Dogmatik auseinandergesetzt hat. Da hineinzuschauen ist sicherlich lohnenswert.

$\mathrm{Zu}$ den Schutzgütern bzw. zum Inhalt von Art. 6 GG: Ich verstehe es auch so, dass Art. 6 GG durch die Entwicklung nicht beschnitten worden ist, sondern dass er neue Facetten hinzugewonnen hat und dass der Schutz ausgeweitet worden ist über Art. 3 GG. Man muss dann ganz genau hinsehen, in welchen Fällen hier eigentlich die Weiterentwicklung stattgefunden hat. Es war kein Beschneiden des Schutzes der Ehe, sondern es war eine Ausweitung des Schutzes auf weitere Formen von Lebensgemeinschaften, und zwar - worauf hier zu Recht noch einmal hingewiesen wurde - von Lebensgemeinschaften, die durch gegenseitige Verantwortungsübernahme genauso verfasst sind wie die Ehe. Das finde ich an der Stelle noch einmal ganz wichtig zu betonen. Die Ausweitung ist aber nicht beliebig. Von daher bleibt Art. 2 GG als Auffanggrundrecht erhalten für alle weiteren Formen. Auch die nichteheliche Lebensgemeinschaft würde man unter diesen Schutzbereich fassen.

Es bleibt die Frage, was vom Differenzierungsgebot bleibt? Nicht mehr viel. Im Jahr 2006 erging eine Entscheidung zur Frage, ob die Kosten für eine künstliche Befruchtung durch die Krankenkasse zu übernehmen sind. Für die Ehe hat das Bundesverfassungsgericht dies bejaht, für alle anderen Formen nicht. Man kann sich hier für die Zukunft interessante Fragen vorstellen. Es sind dazu schon verschiedene Konstellationen angesprochen worden. Aber ansonsten kann ich nur sagen, dass sich offenbar das Differenzierungsgebot - soweit es als Abstandsgebot jemals bestanden hat - über das letzte Jahrzehnt hin aufgelöst hat.

$\mathrm{Zu}$ den Konsequenzen, auch was die steuerlichen Fragen angeht: Ich finde sie ausgesprochen spannend. Ich habe mich auch hier zurückgehalten und nur ein paar Maßstäbe aufgezeigt. Das Zitat, welches Sie, Herr Kirchhof, mir zugeschrieben haben, war vom Bundesfamilienministerium. Ich selber fand die Überlegung, das Ganze noch stärker an die Kinder anzuknüpfen, sehr bedenkenswert. Wenn es einfach um eine Ehe geht, dann reicht vielleicht wirklich die Abwehrkomponente. Aber wie weit berücksichtigt das Steuerrecht tatsächlich die Kinder? Das scheint mir 
doch der Punkt zu sein, über den wir nachdenken sollten. Ich habe als zweiten Teil aber auch gesagt: Wenn wir nur die Ehe betrachten und sehen, dass der Gesetzgeber den Ehegatten auch gegenseitige Verpflichtungen auferlegt, kann man auch die „Nur-Ehe“ ohne Kinder nicht alleine lassen und sollte sie beim Steuerrecht bedenken. Ich glaube, dieser Debatte - wie allen Debatten - würde es ganz gut tun, zu prüfen, wie groß die Auswirkungen verschiedener Modelle sind. Wenn man Berechnungen glauben darf, dann würde unter dem Strich der Unterschied nicht so groß sein. Das sollte man im Hinterkopf haben, wenn man bedenkt, welche Lösung präferiert wird.

Im Ergebnis bleibe ich dabei. Es gibt die dogmatischen Pfeiler, die sich nur wenig verändert haben. Darum herum war und ist Bewegung in der Dogmatik. Und ich bleibe bei meiner letzten These: Es gibt viele Einzelbereiche, die wir noch abzuarbeiten haben werden. Vielen Dank. 
